ALEXANDRE GALIANI GARMBIS

AVALIAÇÃO CRÍTICA DE ENGENHARIA EM DUTOS SUBMERSOS SUJEITOS A FLAMBAGEM LATERAL CONTROLADA 
ALEXANDRE GALIANI GARMBIS

\section{AVALIAÇÃO CRÍTICA DE ENGENHARIA EM DUTOS SUBMERSOS SUJEITOS A FLAMBAGEM LATERAL CONTROLADA}

Dissertação apresentada à Escola Politécnica da Universidade de São Paulo para obtenção do título de Mestre em

Engenharia

Área de concentração:

Engenharia Naval e Oceânica

Orientador: Prof. Titular

Cláudio Ruggieri 
Este exemplar foi revisado e alterado em relação à versão original, sob responsabilidade única do autor e com a anuência de seu orientador.

São Paulo, 17 de dezembro de 2012.

Assinatura do autor

Assinatura do orientador

FICHA CATALOGRÁFICA

Garmbis, Alexandre Galiani

Avaliação crítica de engenharia em dutos submersos sujei tos a flambagem lateral controlada / A.G. Garmbis. -- ed.rev. -São Paulo, 2012.

$100 \mathrm{p}$.

Dissertação (Mestrado) - Escola Politécnica da Universidade de São Paulo. Departamento de Engenharia Naval e Oceânica.

1. Integridade estrutural 2. Mecânica da fratura I. Universidade de São Paulo. Escola Politécnica. Departamento de Engenharia Naval e Oceânica II. t. 
Aos meus pais e mestres, e à minha esposa Ana... 


\section{AGRADECIMENTOS}

Ao meu orientador, o Professor Dr. Claudio Ruggieri, pelos valiosos conselhos, pelos diversos ensinamentos e discussões técnicas, por sua confiança inabalável e por sua paciência e atenção na reta final;

Aos meus colegas de trabalho e mestres Petrônio Zumpano Jr. e Genaro Zanon pelo apoio incondicional, pelo constante incentivo e por sua valiosa amizade;

Ao colega de trabalho Dr. Alexandre Santos Hassen pelo seu apoio nas análises de elementos finitos para simular o fenômeno da flambagem lateral controlada, e a todos os outros colegas que colaboraram direta ou indiretamente com a execução deste trabalho

Aos integrantes do NAMEF: Diego Burgos, Luís Parise, Marcelo Paredes, Rafael Savioli e Leonardo Mathias pelo apoio e companheirismo;

À Petróleo Brasileiro S.A. (Petrobras), companhia que me orgulho de fazer parte, pelo patrocínio e apoio institucional. 
"The only easy day was yesterday" U.S. Navy Seals 


\section{RESUMO}

Este trabalho busca avaliar o efeito da sobrepressão interna na avaliação crítica de engenharia (ECA) de dutos submersos sujeitos a flambagem lateral controlada, que essencialmente consiste na análise de carregamentos combinados associados a grandes deformações longitudinais. O objetivo principal é avaliar a viabilidade da adoção de corpos-de-prova SENT na avaliação da resistência à fratura em dutos sujeitos a esforços combinados utilizando procedimentos analíticos que incorporam do aumento das forças motrizes devido à sobrepressão interna. Este estudo apresenta uma revisão sobre os procedimentos de ECA utilizados em dutos submersos e sobre o efeito da pressão interna na capacidade de deformação de dutos. Os procedimentos adotados atualmente e procedimentos alternativos são discutidos e implementados em um problema prático envolvendo diferentes razões de diâmetros por espessuras, expoentes de encruamento, níveis de sobrepressão e deformação longitudinal. Alguns casos selecionados são comparados com soluções elasto-plásticas de $J$, e.g. EPRI. Os resultados apresentados fornecem uma boa compreensão sobre as vantagens e limitações de cada procedimento, incluindo a possibilidade de estender sua aplicação além do limite normativo de $0,4 \%$ de deformação longitudinal.

Palavras chave: ECA. Integridade estrutural. Mecânica da fratura. Dutos Submersos. 


\begin{abstract}
This work aims to evaluate the effect of internal overpressure on the engineering critical assessment (ECA) of submarine pipelines subjected to controlled lateral buckling, which essentially consists of the analysis of combined loading with large longitudinal strains at the buckle crown. The main goal is to evaluate the feasibility of using SENT specimens to characterize the fracture resistance in the assessments of pipelines subjected to combined loadings using analytical procedures that takes into account the increase of crack driving force due to internal overpressure. This study presents a revision about ECA procedures used in submarine pipelines and about the effect of biaxial stresses their tensile strain capacity. Both standard and alternative procedures are discussed and implemented in a practical problem involving different diameter to thickness ratios, hardening exponents, levels of internal pressure and longitudinal strain. Some selected cases are compared with full elastic-plastic $J$ solutions, e.g. EPRI. The results provide useful insights regarding the advantage and limitations of each procedure, including the possibilities to extend their applicability beyond the standard limit of $0,4 \%$ of longitudinal strain.
\end{abstract}

Keywords: ECA. Structural integrity. Fracture mechanics. Submarine pipelines. 


\section{LISTA DE FIGURAS}

Figura 1 - Teste em escala real de tubos contendo defeitos circunferenciais [8] .....19

Figura 2 - Principio fundamental da Mecânica da Fratura [9] ...............................21

Figura 3 - Modos de carregamento I, II e III (da esquerda para direita) [10] ............22

Figura 4 - Caracterização das tensões na ponta da trinca ......................................23

Figura 5 - Caminho de integração de $\mathrm{J}$ ao redor da ponta da trinca [8] ...................25

Figura 6 - Faixa de aplicação dos conceitos da mecânica da fratura [18] ................29

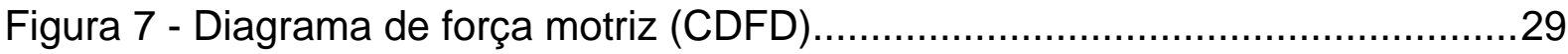

Figura 8 - Princípios básicos da metodologia EPRI [22] ……................................ 31

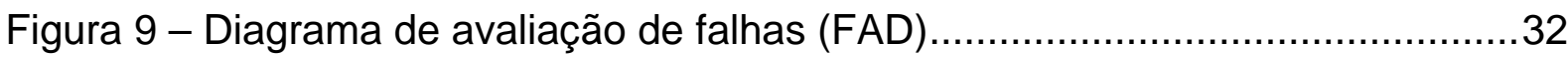

Figura 10 - Validação do FAD do PD6493 com resultados de testes em chapas de

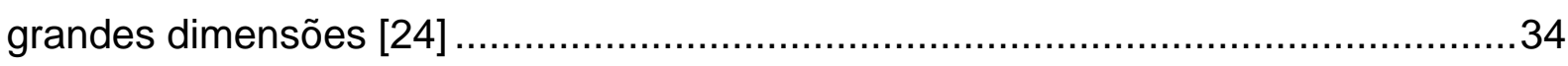

Figura 11 - Validação do FAD genérico com resultados de testes em chapas de grandes dimensões [24] ....

Figura 12 - Tipos de flambagem em dutos submersos: Flambagem Vertical e Lateral

Figura 13 - Modelo de elementos finitos da flambagem lateral [29] .39

Figura 14 - Resposta momento-curvatura e definição dos fatores de segurança. ....41

Figura 15 - Falha por fratura instável durante o lançamento de um duto. 44

Figura 16 - Ilustração de envelope crítico de defeito em função da altura crítica $\left(a_{c}\right)$ versus comprimento (2c) sob diferentes níveis de deformação longitudinal remota .45 Figura 17 - Fases analisadas no ECA .46

Figura 18 - Determinação das tensões primárias de membrana e flexão e aplicação da regra de Neuber [5]

Figura 19 - Esquema ilustrativo do efeito da geometria na tenacidade à fratura [40]

Figura 20 - Remoção do corpo de prova SENT e altura do entalhe no corpo de prova [7]. .53

Figura 21 - Resultados dos ensaios experimentais realizados por Østby et al. [8]...57 Figura 22 - Fotos dos corpos de prova após falha dos ensaios experimentais realizados por Østby et al. [8].

Figura 23 - Efeito da sobrepressão interna positiva na força motriz elasto-plástica 
Figura 24 - Redução da razão de biaxialidade em função do aumento da deformação [44].

Figura 25 - Relação da tensão normalizadora modificada $\left(\sigma_{0}\right)$ com a tensão circunferencial normalizada

Figura 26 - Comparação da equação 3.33 com resultados de análises de elementos finitos [46]. 62

Figura 27 - Efeito da tensão biaxial na curva de resistência a fratura de um material.

Figura 28 - Efeito da pressão interna na força motriz em função do momento aplicado: a) com extremidades abertas, b) com extremidades fechadas. 63

Figura 29 - Envelope crítico de defeitos para deformação longitudinal de 0,5\% e níveis de sobrepressão interna $(X)$ de 0, 25\% (P=14,8), 50\% (P=29,6) e 80\% $(P=47,3)$

Figura 30 - Efeito da correção da curva tensão-deformação (Ramberg-Osgood $\alpha 1$ n20) na curva FAD. 66

Figura 32 - Estrutura adotada para o estudo de caso. 67

Figura 33 - Curvas tensão-deformação de material Ramberg-Osgood 415 MPa e $\alpha=1$ 69

Figura 35 - Configuração geométrica do duto e posição do defeito avaliado [Crackwise]. 74

Figura 36 - Configuração do duto sujeito a flexão e posição do defeito avaliado [22] 75

Figura 37 - Configuração de duto sujeito a carregamentos combinados [23].... .76 


\section{LISTA DE GRÁFICOS}

Gráfico 1 - Altura crítica versus comprimento do defeito - D/t 10, $n 10, \varepsilon$ 0,5\%......79

Gráfico 2 - Altura crítica versus comprimento do defeito - D/t 10, $n 10, \varepsilon$ 1,0\%.......79

Gráfico 3 - Altura crítica versus comprimento do defeito - D/t 10 n 20 ع 0,5\%.........82

Gráfico 4 - Altura crítica versus comprimento do defeito - D/t 10 n 20 ع 1,0\%.........82

Gráfico 5 - Altura crítica versus comprimento do defeito - D/t $10 n 20$ ع 1,5\%.........83

Gráfico 6 - Altura crítica versus comprimento do defeito - D/t $15 n 10$ ع 0,5\%.........83

Gráfico 7 - Altura crítica versus comprimento do defeito - D/t $15 n 10$ ع 1,0\%.........84

Gráfico 8 - Altura crítica versus comprimento do defeito - D/t $15 n 20$ ع 0,5\%.........84

Gráfico 9 - Altura crítica versus comprimento do defeito - D/t $15 n 20$ ع 1,0\%.........85

Gráfico 10 - Altura crítica versus comprimento do defeito - D/t $15 n 20$ ع 1,5\%.......85

Gráfico 11 - Comparação da força motriz (CDFD) para os casos A, C e E ( $n=10)$...87

Gráfico 12 - Comparação da força motriz (CDFD) para os casos A, D e E ( $n=10)$...87

Gráfico 13 - Comparação da força motriz (CDFD) para os casos A, C e E $(n=20)$...88

Gráfico 14 - Comparação da força motriz (CDFD) para os casos A, D e E $(n=20)$..88 


\section{LISTA DE TABELAS}

Tabela 1 - Requisitos para resistência à fratura instável [5] .................................42

Tabela 2 - Valores de $h 1$ para cada nível de sobrepressão interna $(X) \ldots \ldots \ldots \ldots \ldots \ldots . . . .61$

Tabela 3 - Tensão de escoamento e ruptura dos materiais adotados na análise .....69

Tabela 4 - Módulo de elasticidade (E), Poisson ( $v$ ) e Coeficiente de Expansão

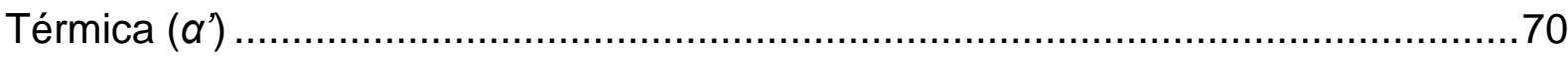

Tabela 5 - Diâmetros e Espessuras Consideradas ………...................................70

Tabela 6 - Limites de deformação longitudinal nominal ........................................71

Tabela 7 - Parâmetros adotados no cálculo da pressão de operação........................71

Tabela 8 - Pressão de operação em função do nível de sobrepressão interna........71

Tabela 9 -Tenacidade à fratura considerada na análise.........................................72

Tabela 10 - Principais diferenças nos procedimentos de ECA avaliados.................73

Tabela 11 - Tensão de escoamento corrigida pela equação $3.34 \ldots \ldots \ldots \ldots \ldots \ldots \ldots \ldots \ldots . . . . .74$

Tabela 12 - Dados comuns a todas as análises ................................................. 74

Tabela 13 - h1 para as configurações de defeitos analisadas (d/t 10) [23] ..............77

Tabela 14 - Altura crítica obtidas do Gráfico 2 para um defeito de comprimento $100 \mathrm{~mm}$. 


\section{LISTA DE ABREVIATURAS E SIGLAS}

$\begin{array}{ll}\text { API } & \text { American Petroleum Institute } \\ \text { ASTM } & \text { American Society for Testing and Materials } \\ \text { ATAP } & \text { Alta Temperatura e Alta Pressão } \\ \text { AUT } & \text { Automated Ultrassonic Testing } \\ \text { BSI } & \text { British Standard Institution } \\ \text { CDF } & \text { Crack Driving Force } \\ \text { CDFD } & \text { Crack Driving Force Diagram } \\ \text { CT } & \text { Compact Tension } \\ \text { CTOD } & \text { Crack Tip Opening Displacement, } \\ \text { DNV } & \text { Det Norske Veritas } \\ \text { ECA } & \text { Engineering Critical Assessment } \\ \text { EOL } & \text { End of Life } \\ \text { EPRI } & \text { Electrical Power Research Institute } \\ \text { FAD } & \text { Failure Assessment Diagram } \\ \text { HRR } & \text { Hutchinson, Rice e Rosengren } \\ \text { LDA } & \text { Lâmina d'água } \\ \text { MFEL } & \text { Mecânica da Fratura Elástica Linear } \\ \text { MFEP } & \text { Mecânica da Fratura Elasto-Plástica } \\ \text { SCF } & \text { Stress Concentration Factor } \\ \text { SENB } & \text { Single Edge Notched Bend } \\ \text { SENT } & \text { Single Edge Notched Tension } \\ \text { TWI } & \text { The Welding Institute } \\ \text { VAS } & \text { Virtual Anchor Spacing } \\ & \end{array}$




\section{LISTA DE SÍMBOLOS}

$2 c$

$a$

$A_{e}$

$A_{i}$

$b$

B

$d s$

$D_{e}$

e

E

$f_{i j}$

$f_{w}$

$F(a / t)$

$F_{a e}$

$F_{a}$

$g$

$h_{1}$

$I_{n}$

$J_{0,2,} J_{0,2 b l}$

$J_{e}$

$J_{p}$

$J_{\text {mat }}$

K

$K_{I}$

$K_{I C}$

$K_{\text {mat }}$

$K_{r}$

$L$

$L_{r}$

$L r_{\text {max }}$

$M$

Comprimento da trinca.

Altura da trinca.

Área do tubo em contato com a pressão externa.

Área do tubo em contato com a pressão interna .

Dimensão do ligamento remanescente.

Espessura do material.

Fração do comprimento do caminho de integração (figura 4).

Diâmetro externo do duto.

Algarismo neperiano (2,718282).

Módulo de elasticidade do material ou módulo de Young.

Função angular de $\theta$ e $n$

Fator de correção para componentes com geometria finita.

Fator de forma.

Força axial efetiva.

Força axial real.

Gravidade.

Parâmetro da metodologia EPRI.

Constante de integração.

Integral J da MFEP.

Tenacidade à fratura de iniciação.

Parcela Elástica da Integral J

Parcela Plástica da Integral J

Tenacidade à fratura.

Fator de intensidade de tensão da MFEL.

Fator de intensidade de tensão da MFEL no modo I.

Tenacidade à fratura no estado plano de deformação.

Tenacidade à fratura.

Razão de fratura.

Dimensão característica adimensional

Razão de carga ou Razão de colapso plástico.

Limite convencionado para a razão de carga.

Momento atuante. 


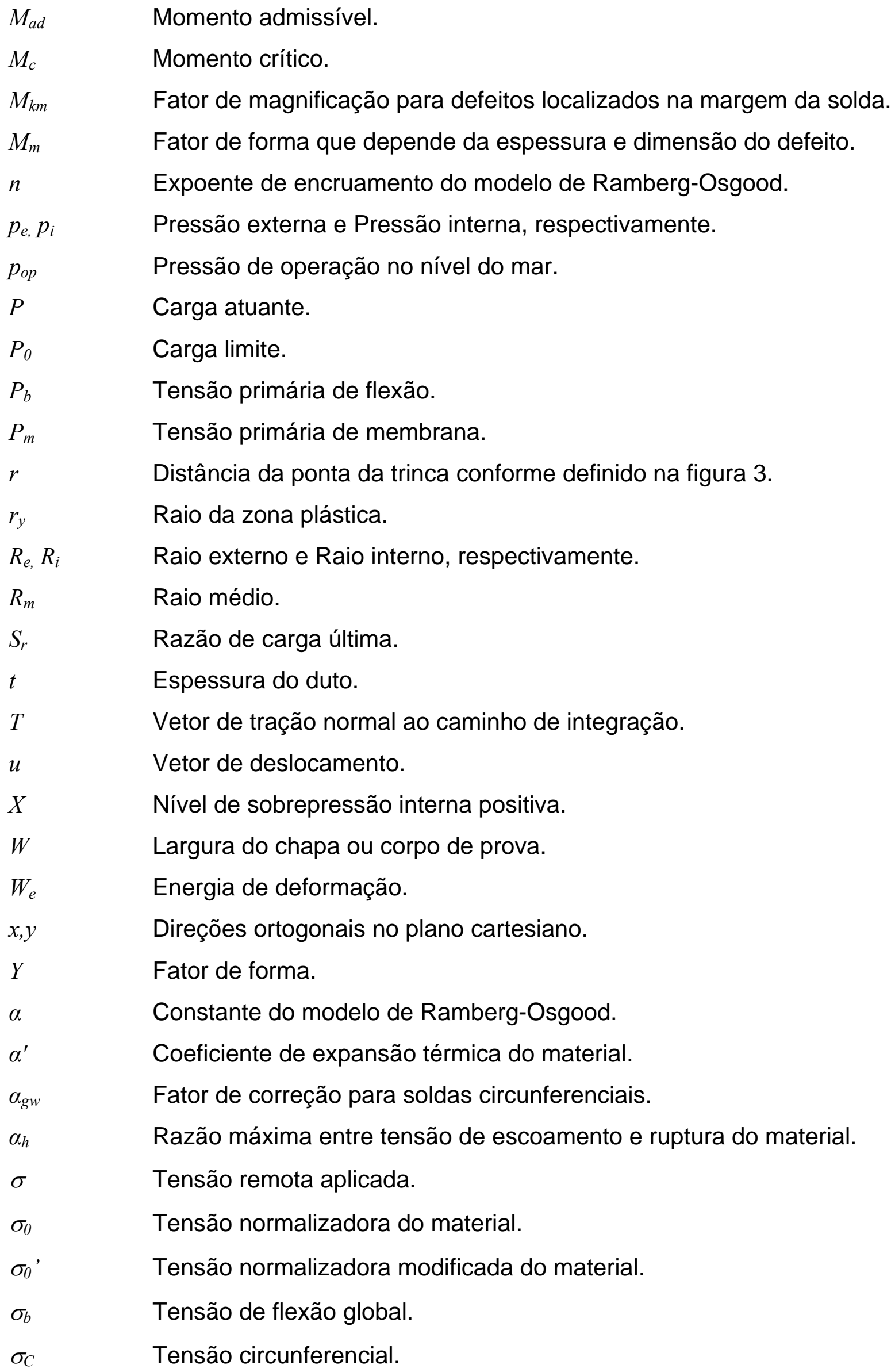




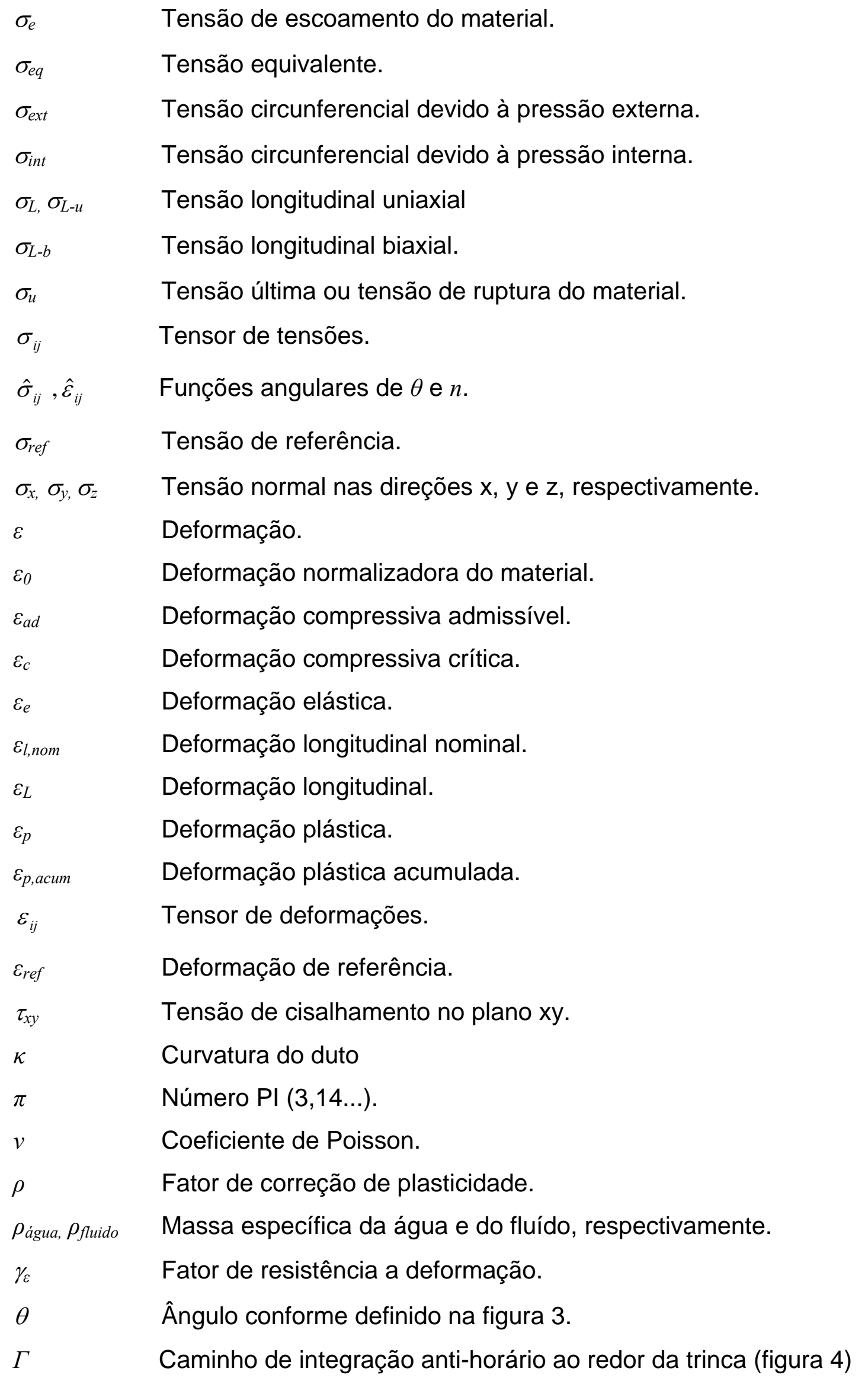




\section{SUMÁRIO}

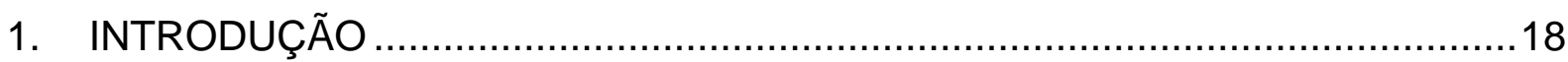

2. AVALIAÇÃO DE DEFEITOS UTILIZANDO OS PRINCÍPIOS DA MECÂNICA DA FRATURA .21

2.1 CONCEITOS FUNDAMENTAIS DA MECÂNICA DA FRATURA ...............21

2.1.1 Parâmetro Elástico-Linear: Fator de intensidade de tensão $(K)$..........22

2.1.2 Parâmetro Elasto-Plástico: Integral J.............................................25

2.2 METODOLOGIA PARA AVALIAÇÃO DE DEFEITOS EM ESTRUTURAS .28

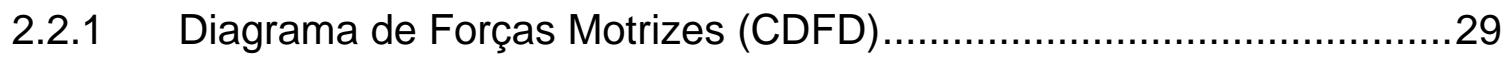

2.2.2 Diagrama de Avaliação de Falhas (FAD) .........................................

3. ECA EM DUTOS SUJEITOS A FLAMBAGEM LATERAL CONTROLADA .........37

3.1 FLAMBAGEM GLOBAL E FLAMBAGEM LATERAL CONTROLADA.........37

3.1.1 Avaliação da integridade sob carregamentos extremos .....................40

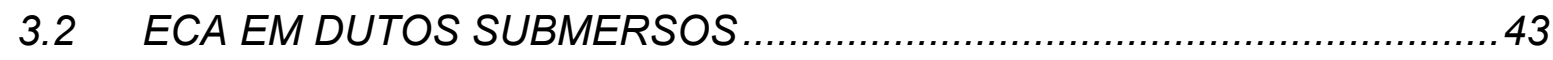

3.2.1 Histórico de desenvolvimento .......................................................

3.2.2 Metodologia de ECA conforme Apêndice A da DNV-OS-F101............44

3.2.3 Estimativa da tenacidade à fratura em dutos conforme RP-F108 ........51

3.3 ECA NO FINAL DE VIDA E O EFEITO DA PRESSÃO INTERNA ..............54

3.3.1 Efeito da pressão interna no comportamento à fratura do duto ............56

3.3.2 Procedimento padrão da OS-F101 e procedimentos alternativos.........64

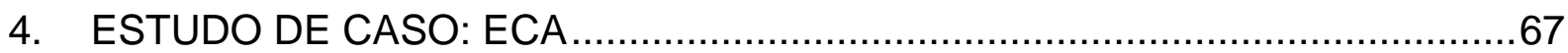

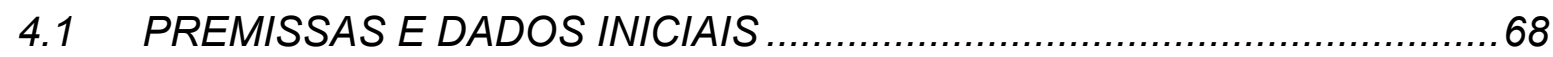

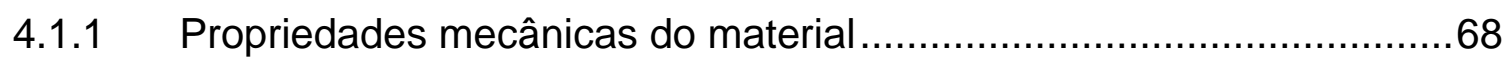

4.1.2 Diâmetro, espessura e nível de sobrepressão interna........................70

4.1.3 Tenacidade à fratura SENT e SENB ................................................... 72

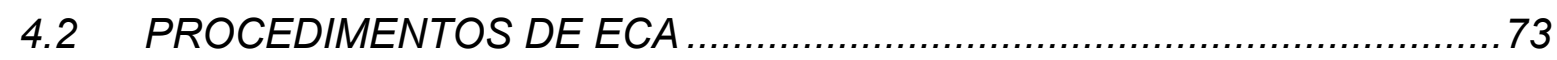

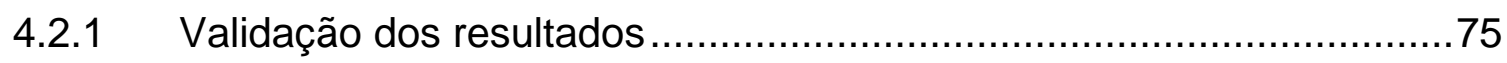

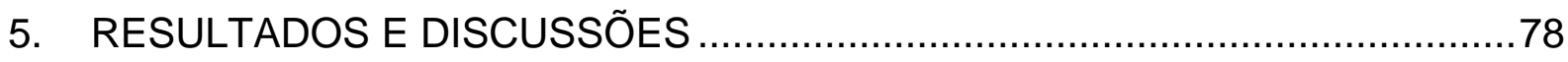

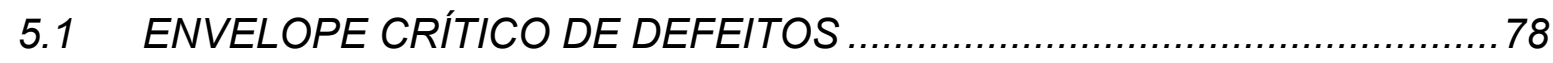

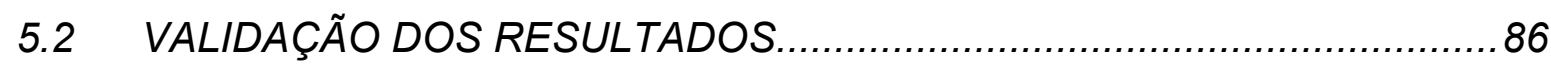

6. CONCLUSÃO E SUGESTÕES PARA TRABALHOS FUTUROS …...................89

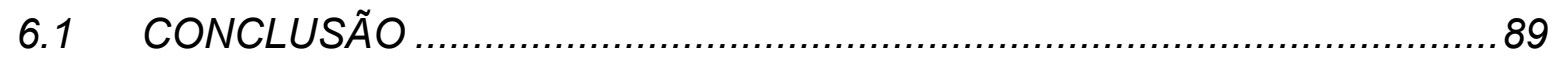

6.2 SUGESTÕES PARA TRABALHOS FUTUROS ..................................... 91

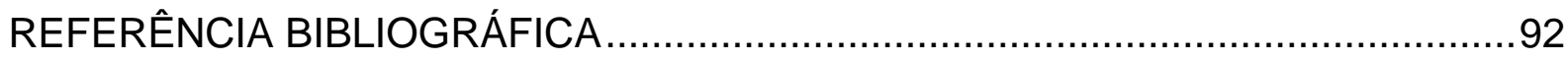

ANEXO A - ANÁLISE DE ELEMENTOS FINITOS …......................................... 


\section{INTRODUÇÃO}

A resistência à fratura de componentes pressurizados como dutos e vasos de pressão não é geralmente abordada de maneira explícita em seu projeto estrutural, mas este modo de falha é geralmente evitado por meio da correta seleção de materiais e com um rigoroso controle de qualidade durante sua fabricação, construção e montagem. Nesses casos, não existe uma relação direta entre as dimensões das descontinuidades aceitáveis e o carregamento sob o qual a estrutura está submetida.

Por outro lado, a "Avaliação Crítica de Engenharia", ou "Engineering Critical Assessment" (ECA) como é conhecido em inglês, é o termo utilizado para a avaliação da integridade de estruturas contendo defeitos tipo trinca ${ }^{1}$ pelos conceitos da mecânica da fratura. Uma análise ECA envolve conhecimentos multidisciplinares que podem tornar a análise muitas vezes complexa. Procedimentos e normas de avaliação de descontinuidades em estruturas metálicas e adequação ao uso [1-4] oferecem metodologias e orientações gerais, deixando sob a responsabilidade do engenheiro considerar as premissas corretas para modelar o problema de maneira consistente e segura. A falta de uniformidade nas premissas adotadas pode levar tanto a cenários conservadores, que inutilizem ou inviabilizem a operação de um equipamento, quanto inseguros, que possam levar a uma falha catastrófica.

Buscando uma maior uniformização nas análises de descontinuidades planares em soldas circunferenciais, a agência classificadora Det Norske Veritas (DNV) publicou um apêndice em sua norma de projeto para sistemas de dutos submersos [5], dedicado às análises ECA. O texto incorporou os resultados de um projeto de pesquisa sobre o controle da fratura em dutos sujeitos a grandes deformações plásticas [6,7], onde uma das principais contribuições foi a elaboração de uma abordagem ECA baseada na deformação aplicada, em contraste ao procedimento convencional baseado em tensões atuantes, e obtenção da tenacidade à fratura em corpos-de-prova com baixa triaxialidade, especificamente corpos-de-prova com entalhe lateral submetido a tração - SENT - com trinca rasa.

\footnotetext{
${ }^{1}$ Por defeitos tipo trinca incluem-se também descontinuidades planares geradas no processo de soldagem como, por exemplo, a falta de fusão e a falta de penetração.
} 
Esta abordagem introduzida pela DNV viabilizou a avaliação da resistência à fratura em dutos sujeitos a grandes deformações dentro do regime elasto-plástico do material. Entretanto, em casos onde existe a atuação simultânea de pressão interna e carregamentos longitudinais, a norma recomenda que sejam realizadas análises de elementos finitos para caracterizar as forças motrizes. A exceção aplica-se aos casos onde a deformação é menor que $0,4 \%$, onde a tenacidade à fratura deve ser caracterizada por meio de corpos-de-prova com maior triaxialidade, em específico, corpos-de-prova com entalhe lateral submetido a flexão em três pontos - SENB com trinca profunda.

O conservadorismo na análise de cenários com carregamentos combinados se deve aos resultados recentes de testes em escala real de tubos contendo defeitos circunferenciais (Figura 1) submetidos simultaneamente à pressão interna e flexão onde a capacidade de deformação foi significantemente reduzida em comparação com a imposição apenas da flexão. Acredita-se que a combinação da pressão interna com deformações longitudinais pode ser mais onerosa para o duto do que quando comparado com o mesmo nível de deformação longitudinal atuando sozinha devido a um aumento das forças motrizes da fratura enquanto a resistência à fratura do material não é afetada [5].

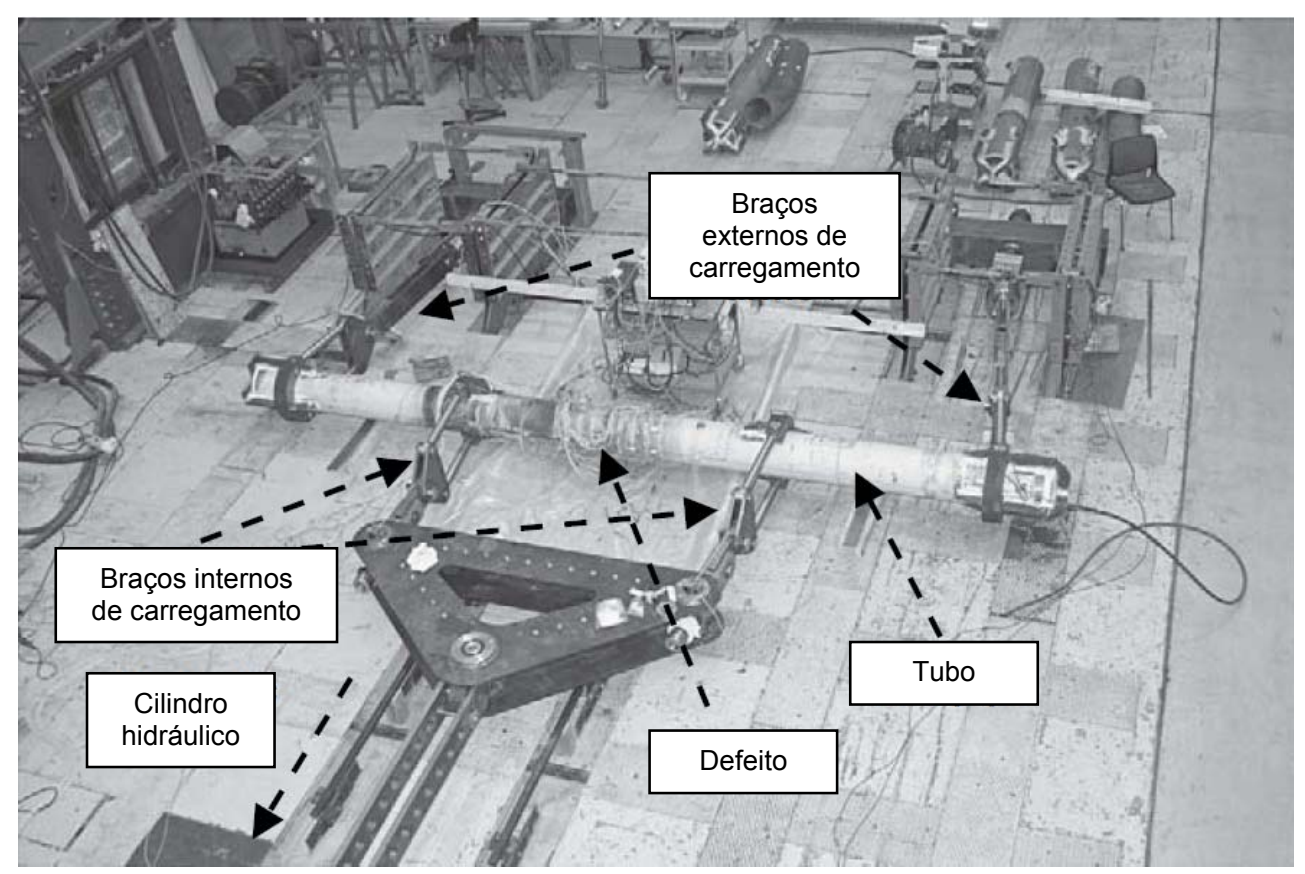

Figura 1 - Teste em escala real de tubos contendo defeitos circunferenciais [8] 
Esse cenário é particularmente importante em análises de dutos submersos de alta temperatura e alta pressão (ATAP) expostos ao leito marinho e sujeitos a flambagem lateral controlada durante a operação para acomodar a expansão do duto, onde o duto pode apresentar níveis elevados de deformação (de 0,5 a $2 \%$ ) desde que permaneça íntegro na condição pós-flambagem. Uma avaliação de integridade nesse cenário envolve no mínimo três modos de falhas concorrentes: flambagem localizada, fratura e fadiga [5]. Devido aos recentes desenvolvimentos na análise da flambagem localizada, existe uma tendência da fadiga e fratura governarem o modo de falha desses dutos. Essa constatação motiva o presente estudo em buscar uma alternativa para estender o limite convencional de 0,4-0,5\% de deformação na condição extrema.

O objetivo desse trabalho é explorar de maneira sistemática a avaliação de integridade de dutos sujeitos a flambagem controlada em um estudo de caso de ECA onde o foco será dado ao efeito da pressão interna na capacidade de deformação e nos procedimentos alternativos utilizados para superar as limitações dos procedimentos atuais. Isso será realizado através de uma revisão bibliográfica sobre os principais aspectos deste cenário particular bem como do efeito da pressão interna na comportamento a fratura e a viabilidade da adoção de corpos-de-prova SENT na avaliação crítica de engenharia em dutos sujeitos a esforços combinados.

Os procedimentos atualmente adotados e procedimentos alternativos serão discutidos e implementados em um problema prático envolvendo diferentes razões de diâmetros por espessuras, expoentes de encruamento, níveis de sobrepressão e deformação longitudinal. Alguns casos selecionados serão comparados com soluções elasto-plásticas de J, e.g. EPRI. Os resultados obtidos servirão de base para avaliar as vantagens e limitações de cada procedimento a fim de propor uma abordagem consistente e segura. Os benefícios esperados são um melhor entendimento sobre o comportamento a fratura destes dutos com potencial para superar o limite convencional de $0,4 \%$ de deformação longitudinal admissível promovendo um projeto de flambagem lateral controlada mais consistente e com menos intervenções no fundo do mar. 


\section{AVALIAÇÃO DE DEFEITOS UTILIZANDO OS PRINCÍPIOS DA MECÂNICA DA FRATURA}

Esse capítulo fornece uma breve revisão sobre os princípios básicos da mecânica da fratura aplicada à avaliação de integridade de componentes com defeitos planares, seguido da apresentação dos principais métodos de avaliação de defeitos em estruturas reais.

\subsection{CONCEITOS FUNDAMENTAIS DA MECÂNICA DA FRATURA}

Os princípios da mecânica da fratura envolvem dois conceitos fundamentais: força motriz da trinca e tenacidade à fratura. A força motriz caracteriza o estado de tensões na ponta da trinca, que por sua vez depende do carregamento remoto do componente e das dimensões do defeito. Por outro lado, a tenacidade à fratura representa a resistência à fratura do material e é obtida por intermédio de ensaios experimentais. Pelo princípio fundamental da mecânica da fratura, a falha ocorrerá quando a força motriz da trinca for maior que tenacidade à fratura, desde que as condições em que a tenacidade à fratura foi determinada apresentem severidade maior ou igual ao do que o componente estrutural, em termos de restrição à deformação na ponta da trinca (Figura 2).

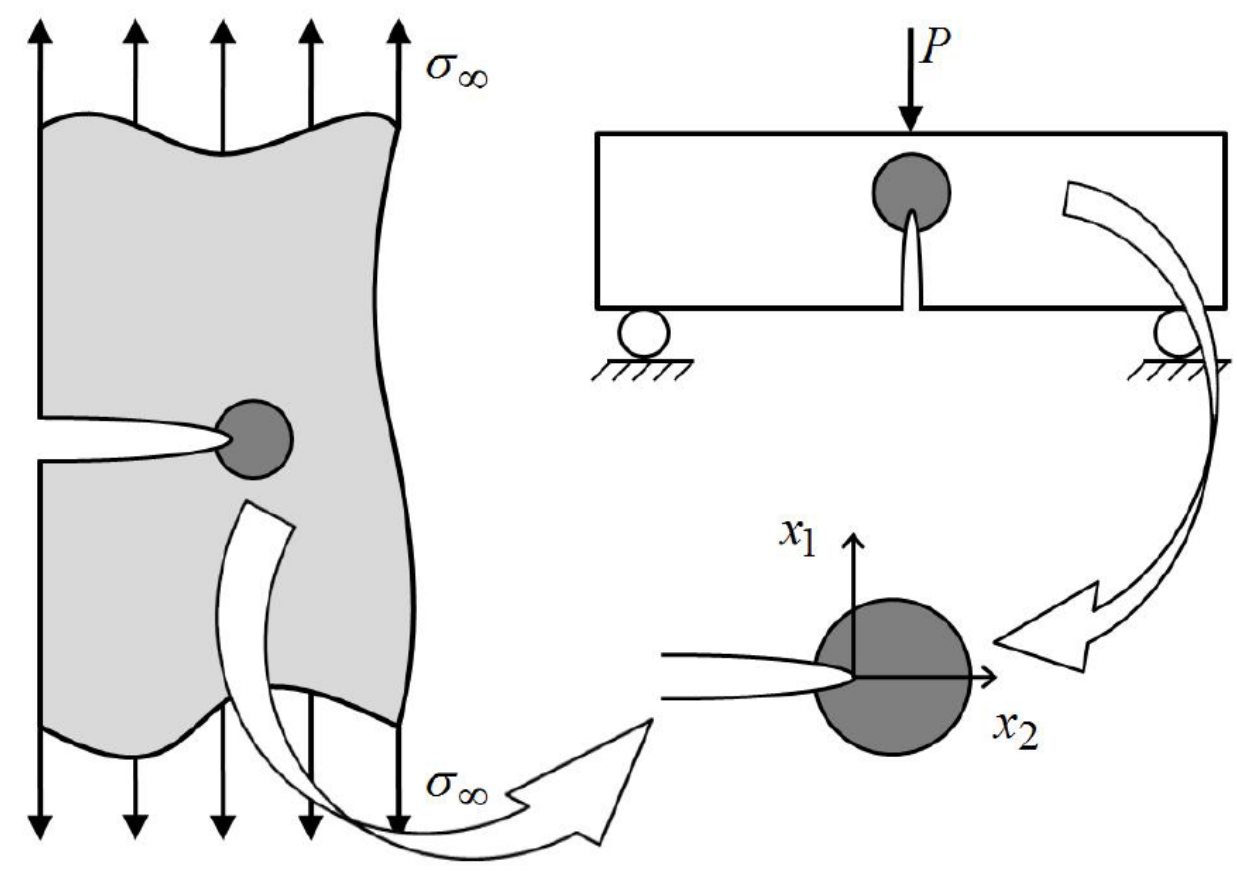

Figura 2 - Principio fundamental da Mecânica da Fratura [9] 
A Mecânica da Fratura pode ser dividida em Elástica-Linear (MFEL) e ElastoPlástica (MFEP), no que concerne ao regime de deformação do componente trincado. A seguir é apresentada uma breve revisão sobre os parâmetros utilizados para caracterizar a fratura na MFEL e MFEP.

\subsubsection{Parâmetro Elástico-Linear: Fator de intensidade de tensão $(K)$}

Por definição, existem três modos de carregamento em componentes trincados. O modo I se refere à tração atuando no plano perpendicular ao plano da trinca. Os modos II e III são caracterizados por tensões de cisalhamento no plano da trinca, sendo que o primeiro na direção do comprimento da trinca e o segundo, perpendicular ao mesmo. A Figura 3 ilustra os modos de carregamento:

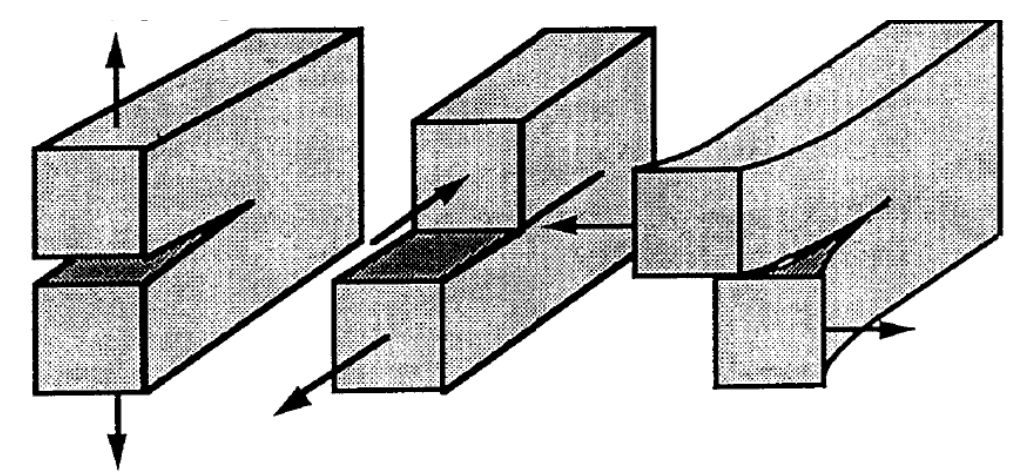

Figura 3 - Modos de carregamento I, II e III (da esquerda para direita) [10]

Um corpo trincado pode estar sujeito a um ou mais modos de carregamento. Em geral, é aceitável negligenciar os modos II e III quando o componente não está sujeito a solicitações fora do plano principal, pois estes modos contribuirão muito pouco para a falha em relação ao modo I.

Saxena [11] cita que Irwin foi um dos primeiros a descrever o estado de tensão em uma região próxima a ponta de uma trinca utilizando método desenvolvido por Westergaard. Posteriormente, Williams [12] derivou uma solução mais completa que incluía termos de ordem superior, caracterizando as tensões mais afastadas da ponta da trinca. Para regiões próximas à ponta da trinca $(r \rightarrow 0)$, ambas as soluções convergem para o mesmo valor. As equações 2.1 a 2.4 apresentam a solução de 
Westergaard-Irwin [11] em coordenadas polares (Figura 4) para trincas sujeitas ao Modo I no estado plano de deformações.

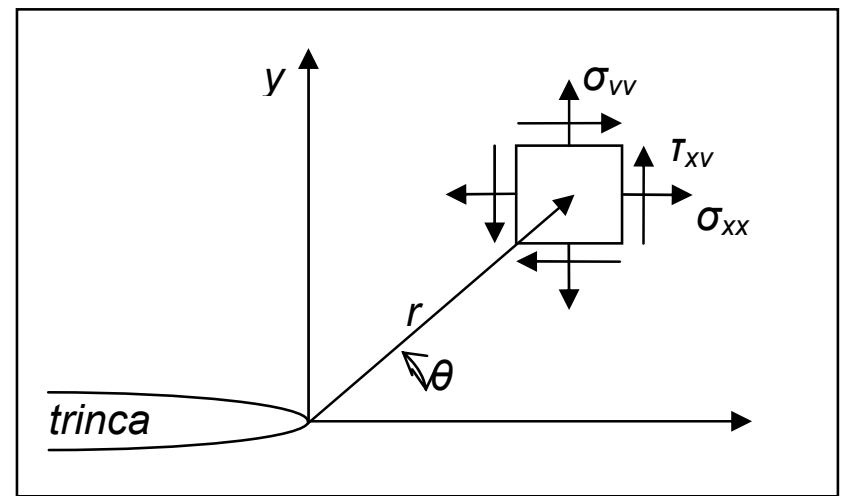

Figura 4 - Caracterização das tensões na ponta da trinca

$$
\begin{aligned}
& \sigma_{x x}=\frac{K_{I}}{\sqrt{2 \pi r}} \cos \left(\frac{\theta}{2}\right) \cdot\left[1-\sin \left(\frac{\theta}{2}\right) \cdot \sin \left(\frac{3 \theta}{2}\right)\right] \\
& \sigma_{y y}=\frac{K_{I}}{\sqrt{2 \pi r}} \cos \left(\frac{\theta}{2}\right) \cdot\left[1+\sin \left(\frac{\theta}{2}\right) \cdot \sin \left(\frac{3 \theta}{2}\right)\right] \\
& \sigma_{z}=v\left(\sigma_{x}+\sigma_{y}\right) \\
& \tau_{x y}=\frac{K_{I}}{\sqrt{2 \pi r}} \cos \left(\frac{\theta}{2}\right) \sin \left(\frac{\theta}{2}\right) \cos \left(\frac{3 \theta}{2}\right)
\end{aligned}
$$

onde:

$K_{I} \quad$ Fator de intensidade de tensão para o modo I de carregamento.

$\sigma_{x,} \sigma_{y}, \sigma_{z}$ Tensão normal na direção $\mathrm{x}, \mathrm{y} \mathrm{e} \mathrm{z}$, respectivamente.

$\tau_{x y} \quad$ Tensão de cisalhamento no plano $x y$.

$r, \theta \quad$ Coordenadas polares conforme Figura 4.

As tensões de cisalhamento em z ( $\tau_{x z}$ e $\tau_{y z}$ são nulas. Portanto, $K_{I}$ define de maneira inequívoca o estado de tensões na região onde o processo de fratura ocorre em componentes que exibem um comportamento linear-elástico, chamada de zona de dominância $K$, podendo assim ser utilizado como um parâmetro para caracterizar a fratura. 
Analisando as tensões em $\mathrm{y}=0$ de uma trinca passante em uma placa infinita, diversos autores, e.g. $[10,11]$, demonstraram que o fator de intensidade de tensão sob o modo I $\left(K_{\mathrm{I}}\right)$ pode ser expresso como:

$$
K_{I}=\sigma \sqrt{\pi a}
$$

onde:

$\begin{array}{ll}\sigma & \text { Tensão remota aplicada. } \\ \pi & \text { Número PI (3.1415..) } \\ a & \text { Dimensão do defeito }\end{array}$

Em componentes de dimensões finitas, as soluções para $K_{\mathrm{I}}$ tomam geralmente a forma da equação 2.6 e 2.7, para um carregamento expresso pela tensão remota aplicada ou uma carga pontual, respectivamente. $Y$ e $F(a / W)$ são fatores que levam em consideração as dimensões do defeito e geometria do componente, disponíveis em compêndios para diversas geometrias e modos de carregamento [1-4].

$$
\begin{aligned}
& K_{I}=Y \sigma \sqrt{\pi a} \\
& K_{I}=\frac{P}{B \cdot W^{1 / 2}} \cdot F(a / W)
\end{aligned}
$$

onde:

$P \quad$ Carga remota aplicada.

$B, W \quad$ Espessura e Largura do componente, respectivamente.

$Y, F(a / W)$ Fator de forma

Não menos importante, a tenacidade à fratura na MFEL é representada pelo parâmetro $K_{I c}$, que representa o patamar inferior de resistência à fratura do material obtido sob o estado plano de deformações. Para caracterizar tal estado, as dimensões do corpo de prova devem satisfazer a seguinte relação:

$$
a, B,(W-a) \geq 2,5 \cdot\left(\frac{K_{I c}}{\sigma_{e}}\right)^{2}
$$

onde:

$K_{I c} \quad$ Tenacidade à fratura no estado plano de deformações.

$\sigma_{e} \quad$ Tensão de escoamento do material. 
Para materiais muito tenazes, tais como aços estruturais de boa ductilidade, as dimensões dos corpos de prova necessárias para satisfazer a equação 2.8 seriam tais que dificultariam a viabilização do ensaio e subestimariam sua resistência à fratura. Por esse motivo, a MFEL é especialmente adequada para a avaliação de fratura em materiais de baixa tenacidade à fratura (frágeis) ou em componentes estruturais com alto nível de triaxialidade, ou seja, onde o escoamento do material se restringe a uma pequena região a frente da ponta da trinca.

\subsubsection{Parâmetro Elasto-Plástico: Integral $J$}

A motivação para o desenvolvimento de um parâmetro elasto-plástico deve-se à aplicação de materiais de alta ductilidade em componentes estruturais com baixo nível de triaxialidade, onde a resistência a fratura aparente era muito superior àquela obtida nos ensaios de $K_{I c}$. Isto foi observado por meio de ensaios experimentais onde a fratura final em corpos de prova de tenacidade à fratura $K_{I c}$ com dimensões reduzidas, i.e. não satisfazendo a equação 2.8 , era sempre acompanhada de uma extensiva deformação plástica (fratura dúctil) [11].

Para o desenvolvimento da MFEP, a contribuição de três artigos [13-15] publicados em 1968 foi fundamental. No primeiro, Rice [13] apresenta uma integral de linha que, independente do caminho de integração escolhido ao redor da ponta da trinca (Figura 5), caracteriza a taxa de liberação de energia potencial em um material elástico não-linear ${ }^{2}$. A essa integral é dada o nome de $J$,e é expressa como:

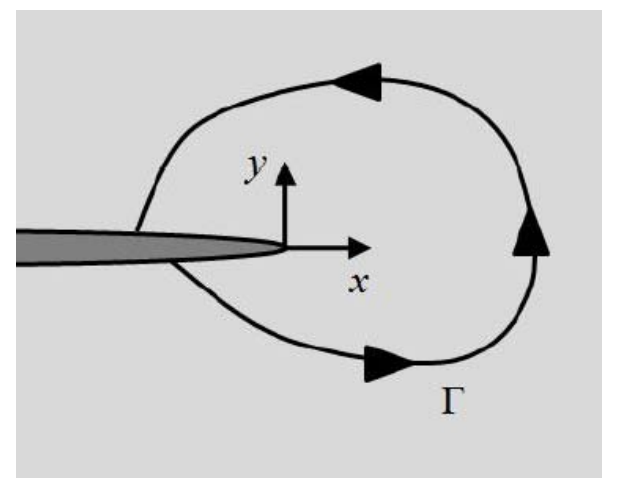

Figura 5 - Caminho de integração de $\mathrm{J}$ ao redor da ponta da trinca [9]

\footnotetext{
2 Um material que exibe um comportamento semelhante a um material elasto-plástico quando o carregamento é crescente, mas difere-se no descarregamento uma vez que não apresenta deformação permanente.
} 
$J=\int_{\Gamma}\left(W_{e} d y-T \frac{\partial u}{\partial x} d s\right)$

onde:

$\Gamma \quad$ Caminho de integração anti-horário ao redor da trinca.

$W_{e} \quad$ Energia de deformação.

$T \quad$ Vetor de tração normal ao caminho de integração.

$u \quad$ Vetor de deslocamento.

$x, y \quad$ Direções ortogonais no plano cartesiano.

ds $\quad$ Elemento de comprimento do caminho de integração.

Em seu artigo original, Rice discute a relação entre $J$ e o fator de intensidade de tensões $K_{I}$ da MFEL em materiais elásticos lineares sob escoamento em pequena escala, corroborando assim a interpretação de $J$ como um parâmetro energético de fratura, uma vez que, nessas circunstâncias, a relação entre $J$ e $K_{I}$ (equação 2.10) é idêntica àquela demonstrada por Irwin na $\mathrm{MFEL}^{3}$, como expresso a seguir:

$J_{e}=\frac{K_{I}^{2}}{E^{\prime}}$

com

$E^{\prime}=\frac{E}{\left(1-v^{2}\right)}$

onde:

$J_{e} \quad$ Parcela elástica da integral $J$

E $\quad$ Módulo de elasticidade do material ou módulo de Young.

$v \quad$ Coeficiente de Poisson.

A equação 2.11 é válida para o estado plano de deformações, sendo que, no estado plano de tensões, $E$ ' assume o valor do módulo de elasticidade do material $\left(E^{\prime}=E\right)$. No mesmo ano, Hutchinson [14], Rice e Rosengren [15] demonstraram que existe uma relação única entre $J$ e o campo de tensões e deformações em uma região próxima à ponta da trinca que satisfaz a independência do caminho de integração. Esta relação ficou conhecida como solução HRR (de Hutchinson, Rice e Rosengren) e se estende além dos limites da MFEL:

${ }^{3}$ Para maiores detalhes, vide referência [10] 
$\sigma_{i j} \varepsilon_{i j}=\frac{J}{r} f_{i j}(\theta, n)$

onde:

$\sigma_{i j}, \varepsilon_{i j} \quad$ Tensor de tensões e deformações.

$f_{i j} \quad$ Função angular de $\theta$ e $n$

Em seus estudos, os autores adotaram uma lei de potência para descrever o comportamento não linear uniaxial do material, tal como o modelo de RambergOsgood [16], onde a deformação $(\varepsilon)$ é dividida entre uma parcela elástica $\left(\varepsilon_{e}\right)$ e outra plástica $\left(\varepsilon_{p}\right)$ :

$$
\frac{\varepsilon}{\varepsilon_{0}}=\frac{\varepsilon_{e}}{\varepsilon_{0}}+\frac{\varepsilon_{p}}{\varepsilon_{0}}=\frac{\sigma}{\sigma_{0}}+\alpha\left(\frac{\sigma}{\sigma_{0}}\right)^{n}
$$

onde a tensão normalizadora $\sigma_{0}$ é geralmente associada ao valor da tensão de escoamento do material, a deformação normalizadora é a deformação elástica no ponto de escoamento $\left(\varepsilon_{0}=\sigma_{0} / E\right)$, por fim, as constantes do material $\alpha$ e $n$ podem ser obtidas a partir de resultados de ensaios experimentais ou estimadas a partir das propriedades mecânicas do material.

Manipulando as equações 2.12 e 2.13, obtém-se uma relação entre $J$ e os campo de tensões e deformações na ponta da trinca em um material elástico-plástico quando sujeito a um carregamento crescente [11]:

$$
\begin{gathered}
\sigma_{i j}=\sigma_{0}\left(\frac{J}{\alpha \sigma_{0} \varepsilon_{0} I_{n} r}\right)^{\frac{1}{n+1}} \hat{\sigma}_{i j}(\theta, n) \\
\varepsilon_{i j}=\alpha \varepsilon_{0}\left(\frac{J}{\alpha \sigma_{0} \varepsilon_{0} I_{n} r}\right)^{\frac{n}{n+1}} \hat{\varepsilon}_{i j}(\theta, n)
\end{gathered}
$$

com

$$
I_{n}=6.568-0,4744 n+0,0404 n^{2}-0,001262 n^{3} \text { (estado plano de deformação) }
$$


onde:

$I_{n} \quad$ Constante de integração.

$\hat{\sigma}_{i j}, \hat{\varepsilon}_{i j} \quad$ Funções angulares de $\theta$ e $n$.

Para um material elástico linear $(n=1), J$ caracteriza o campo de tensões na ponta da trinca de maneira similar ao $K$ na MFEL. Posteriormente, Begley e Landes [17] confirmaram o potencial de $J$ como um parâmetro de fratura em condições elastoplásticas, fazendo dele um parâmetro de fratura adequado tanto para o regime elástico quanto para o regime elasto-plástico do material. No entanto, à medida que a deformação no componente passa a ser generalizada, o colapso plástico da seção remanescente passa a governar o modo de falha.

\subsection{METODOLOGIA PARA AVALIAÇÃO DE DEFEITOS EM ESTRUTURAS}

Como mencionado anteriormente, a resistência à fratura é garantida quando a força motriz atuante no componente é menor do que a tenacidade à fratura do material. Esta tarefa relativamente simples pode se tornar extremamente complexa quando aplicada em estruturas "leves" fabricadas com materiais dúcteis e submetidas a carregamentos elevados onde a interação entre fratura e colapso plástico é evidente. Felizmente, a MFEP fornece o arcabouço teórico necessário para análise de tais componentes. A Figura 6 ilustra o parâmetro $J$ da MFEP como agente integrador entre fratura e colapso plástico.

Diversos procedimentos fornecem métodos analíticos para a avaliação de defeitos em componentes estruturais dos quais se destacam a BS-7910 [1], API-579 [2], R6 [3], SINTAP [4], entre outros. Tais procedimentos se baseiam em duas filosofias distintas: o FAD (Failure Assessment Diagram) e o CDFD (Crack Driving Force Diagram), que serão apresentados a seguir. Essas metodologias evoluíram bastante nas últimas décadas e continuam evoluindo. Atualmente, a opção por uma ou por outra é uma mera questão de praticidade, uma vez que as duas abordagens são compatíveis desde que a forças motrizes e tenacidade à fratura sejam determinadas de maneira adequada. 


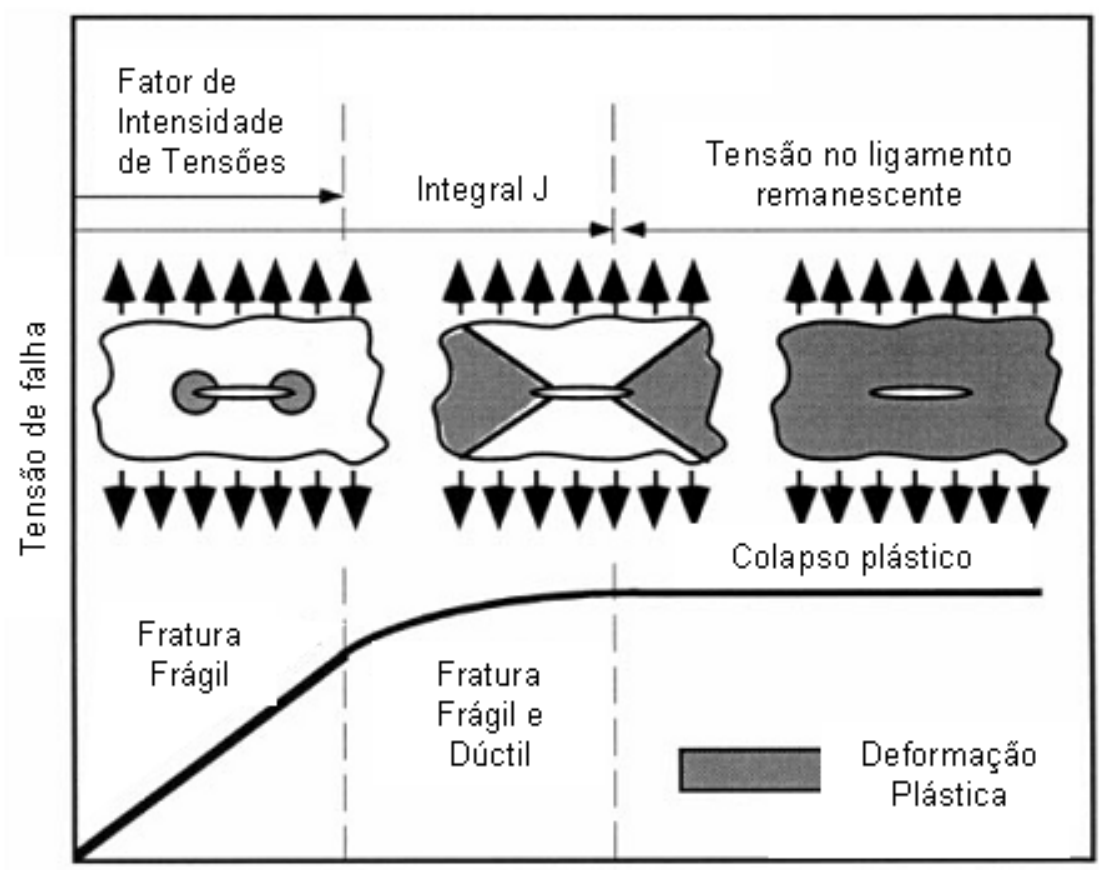

Resistência à fratura

Figura 6 - Faixa de aplicação dos conceitos da mecânica da fratura [18]

\subsubsection{Diagrama de Forças Motrizes (CDFD)}

A abordagem CDFD consiste na avaliação direta da força motriz elasto-plástica em um componente com geometria e material específico em função da carga ou da razão de carga aplicada. O CDFD proporciona uma fácil interpretação da tenacidade à fratura mínima necessária $\left(J_{\text {mat }}\right)$ para um determinado carregamento ou razão de carga $(L r)$, e vice-versa. Na Figura 7 são apresentadas as três situações de ocorrência possíveis no CDFD onde o critério de falha é a iniciação da propagação da trinca: A) Aceitável; B) Crítico; e C) Inaceitável.

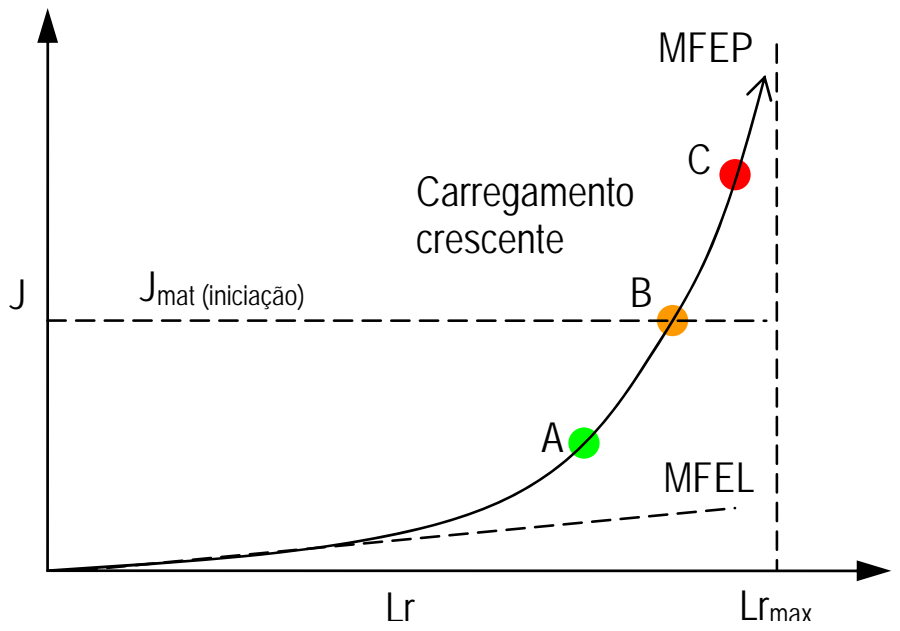

Figura 7 - Diagrama de força motriz (CDFD) 
Para tornar o diagrama menos dependente da geometria do componente, é conveniente expressar o carregamento como uma razão de carga $\left(L_{r}\right)$, definida como o quociente da carga aplicada $(P)$ por uma carga limite $\left(P_{0}\right)$. Por carga limite entende-se a maior carga que um material elástico-perfeitamente plástico pode suportar sem apresentar colapso [11]. Em materiais que apresentam encruamento, a carga limite representa uma estimativa da carga mínima que resulta na deformação plástica da seção remanescente do componente, sendo assim necessário estabelecer um limite superior para esta razão de carga $\left(L r_{\max }\right)$.

Ao contrário do fator de intensidade de tensão $\left(K_{I}\right)$, existe um número limitado de situações onde é possível estimar a integral $J$ analiticamente. A elaboração de tais compêndios é uma tarefa trabalhosa uma vez que o campo de tensões depende também do comportamento elasto-plástico do material. Exemplos de tais compêndios são as soluções tipo EPRI [19-23]. Na ausência de tais curvas, análises dedicadas de elementos finitos são utilizadas para caracterizar a força motriz. Tais análises utilizam modelos com uma malha suficientemente refinada na trinca para calcular $J$.

As chamadas soluções tipo EPRI, se baseiam em um trabalho publicado em 1976 por Shih e Hutchinson [19], onde os autores propuseram uma nova metodologia para cálculo de $J$ em materiais elasto-plásticos que obedecem a uma lei de potência como a de Ramberg-Osgood. A princípio, o método foi aplicado para defeitos em chapas e cilindros por Kumar et al [20], e posteriormente estendido por Zahoor [21] para outras configurações.

A metodologia consiste em dividir $J$ em uma parcela elástica e outra plástica: a parcela elástica $\left(J_{e}\right)$ é computada a partir do fator de intensidade de tensões elástico $\left(K_{I}\right)$ na configuração de interesse por meio da equação 2.9. O $K_{I}$ é obtido em compêndios de soluções elásticas lineares. A parcela plástica $\left(J_{p}\right)$ é derivada da equação abaixo [20]:

$J=J_{e}+J_{p}$

$J_{p}=\alpha \varepsilon_{0} \sigma_{0} b h_{1}\left(\frac{a}{W}, L, n\right)\left(\frac{P}{P_{0}}\right)^{n+1}$ 
Onde $\alpha, n, \sigma_{0}$ e $\varepsilon_{0}$ são parâmetros do material, $b$ é a dimensão do ligamento remanescente, $L$ uma dimensão característica adimensional, e por fim, $h_{l}$ que é um fator adimensional função de razão da dimensão do defeito e expoente de encruamento do material. $O$ fator $h_{1}$ é geralmente obtido por meio da regressão linear dos resultados de $J$ levantados a partir de análises dedicadas de elementos finitos (Figura 8). Compêndios de $h_{1}$ estão disponíveis em [20-23].

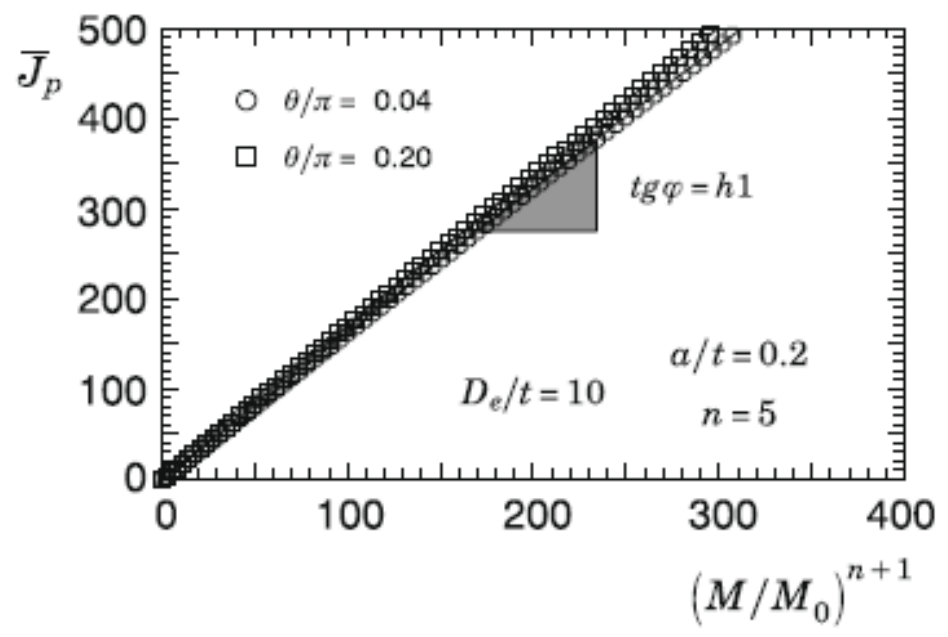

Figura 8 - Princípios básicos da metodologia EPRI [22]

Em 2010, Chiodo e Ruggieri [22] apresentaram soluções para defeitos circunferenciais em tubos sujeitos a flexão. Soluções para defeitos circunferenciais em tubos sujeitos a combinação de flexão e pressão interna estão em desenvolvimento, mas alguns resultados foram recentemente publicados por Parise e Ruggieri [23].

\subsubsection{Diagrama de Avaliação de Falhas (FAD)}

A proposta do FAD é abordar simultaneamente dois modos de falha - fratura e colapso plástico - por meio de um ponto de avaliação único e uma curva que incorpora o efeito da interação entre esses dois mecanismos relacionando a razão de fratura $\left(K_{r}\right)$ com a razão de carga $\left(L_{r}\right)$. Esta curva é chamada de curva FAD, e desempenha um papel importante na análise uma vez que divide o diagrama em duas regiões: aceitável e inaceitável. A Figura 9 apresenta as situações possíveis de ocorrer no FAD: A) Aceitável; B) Crítico; e C) Inaceitável. 


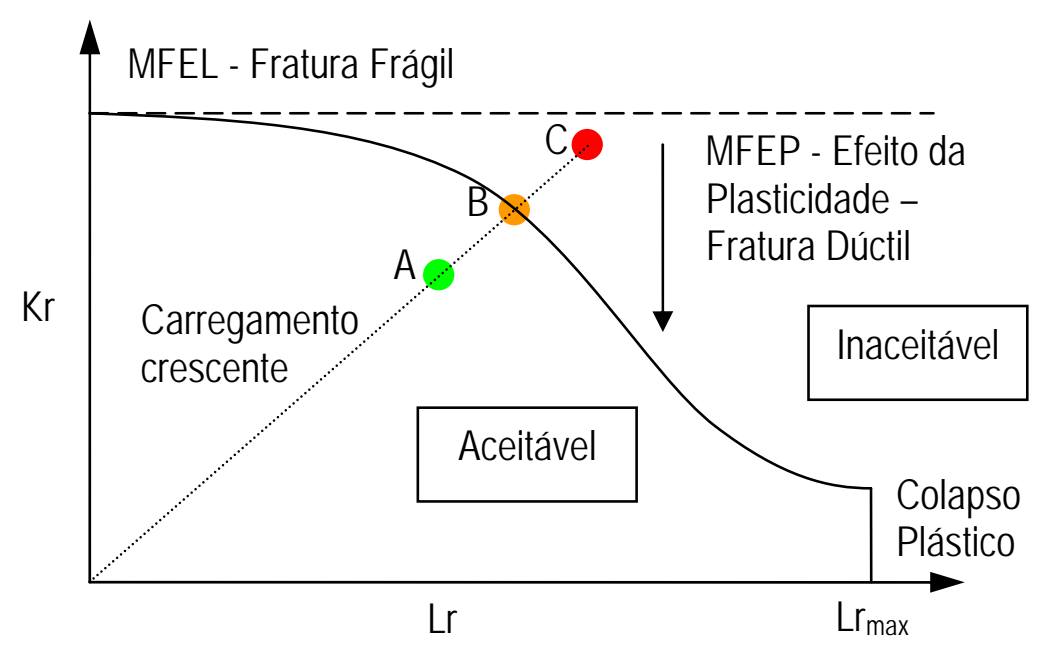

Figura 9 - Diagrama de avaliação de falhas (FAD)

Na Figura 9, os pontos de avaliação (e.g. A, B e C) são determinados como:

$$
\begin{aligned}
& K_{r}=\frac{K_{I}}{K_{\text {mat }}}=\sqrt{\frac{J_{e}}{J_{\text {mat }}}} \\
& L_{r}=\frac{P}{P_{0}}
\end{aligned}
$$

onde $K_{\text {mat }}, J_{\text {mat }}$ representam a tenacidade à fratura do material. As demais variáveis já foram apresentadas anteriormente. Analisando a curva FAD (figura 8), pode-se observar o efeito da plasticidade na forma da curva comparando-a com uma linha horizontal imaginária que representa a MFEL, assim como observado na abordagem CDFD (figura 6). Portanto a curva FAD nada mais é que uma relação entre uma força motriz elástica-linear (MFEL) e uma força motriz elasto-plástica (MFEP) para cada incremento de carregamento $\left(L_{r}\right)$, ou seja, pelo princípio da similitude:

$$
K_{r}=f\left(L_{r}\right)=\left.\sqrt{\frac{J_{e}}{J}}\right|_{L r}
$$

onde $J_{e}$ é obtido por meio das equações 2.10 e 2.11, ou simplificando:

$$
J_{e}=\frac{K_{I}^{2}\left(1-v^{2}\right)}{E}
$$


Essa é a forma mais exata de expressar a curva FAD, sendo denominada curva FAD "baseada em $J$ ". Observa-se que conhecendo os valores do fator de intensidade de tensão $\left(K_{I}\right)$ e o valor correspondente de $K_{r}$ da curva FAD para um dado carregamento é possível determinar o valor de $J$ através das equações 2.21 e 2.22, tornando esta abordagem totalmente compatível com a abordagem CDFD:

$$
J=\frac{K_{I}^{2}\left(1-v^{2}\right)}{E \cdot K_{r}^{2}}
$$

No entanto, como mencionado anteriormente, soluções elasto-plásticas para $J$ nem sempre estão disponíveis. Desde os meados da década de 70 , quando os primeiros documentos sobre a abordagem FAD foram publicados [18], e.g. o procedimento R6 [3] da indústria nuclear britânica, diversos esforços foram realizados para desenvolver uma curva FAD independente da geometria e tipo de carregamento do componente.

Atualmente, existem dois tipos básicos de curva FAD que foram adotados pela maioria dos procedimentos modernos [1-4]: a curva FAD genérica e a curva FAD especifica do material. A curva FAD genérica foi originalmente publicada no procedimento R6 [3] em 1976 e se baseia na teoria da faixa de escoamento de Dugdale [10] para computar o efeito da plasticidade na força motriz. Observa-se que esta curva independe da geometria e material do componente:

$$
K_{r}=S_{r}\left[\frac{8}{\pi^{2}} \cdot \ln \sec \left(\frac{\pi}{2} S_{r}\right)\right]^{-1 / 2}
$$

onde $S_{r}$ é a razão entre o carregamento aplicado e a carga última da estrutura.

No entanto, essa curva é apropriada apenas para problemas que envolvem a plastificação de uma pequena região na ponta da trinca em comparação com as dimensões do componente, assim como a validade do modelo de Dugdale [10]. Com a difusão dos conceitos da MFEP e o desenvolvimento da curva FAD específica do material que será discutida a seguir, a curva apresentada na equação 2.24 foi substituída por uma estimativa do patamar inferior da resistência à fratura com base 
em resultados experimentais [24]. Atualmente, a curva FAD genérica adotada pela maioria dos procedimentos de análise é definida como:

$$
K_{r}=\left(1-0,014 L_{r}^{2}\right)\left[0,3+0,7 \exp \left(-0,65 L_{r}^{6}\right)\right]
$$

Essa curva semi-empírica passou por um extensivo programa de validação em chapas de grandes dimensões contendo defeitos de diversos tipos de materiais ${ }^{4}$ (Figura 10 e Figura 11) e apresenta um histórico de aplicação bem sucedida na avaliação de componentes em serviço. Devido ao fato da curva genérica não apresentar relação com o comportamento à deformação do componente analisado e à disponibilidade de dados reais do material, a curva FAD genérica é pouco utilizada em análises de ECA de dutos submersos.

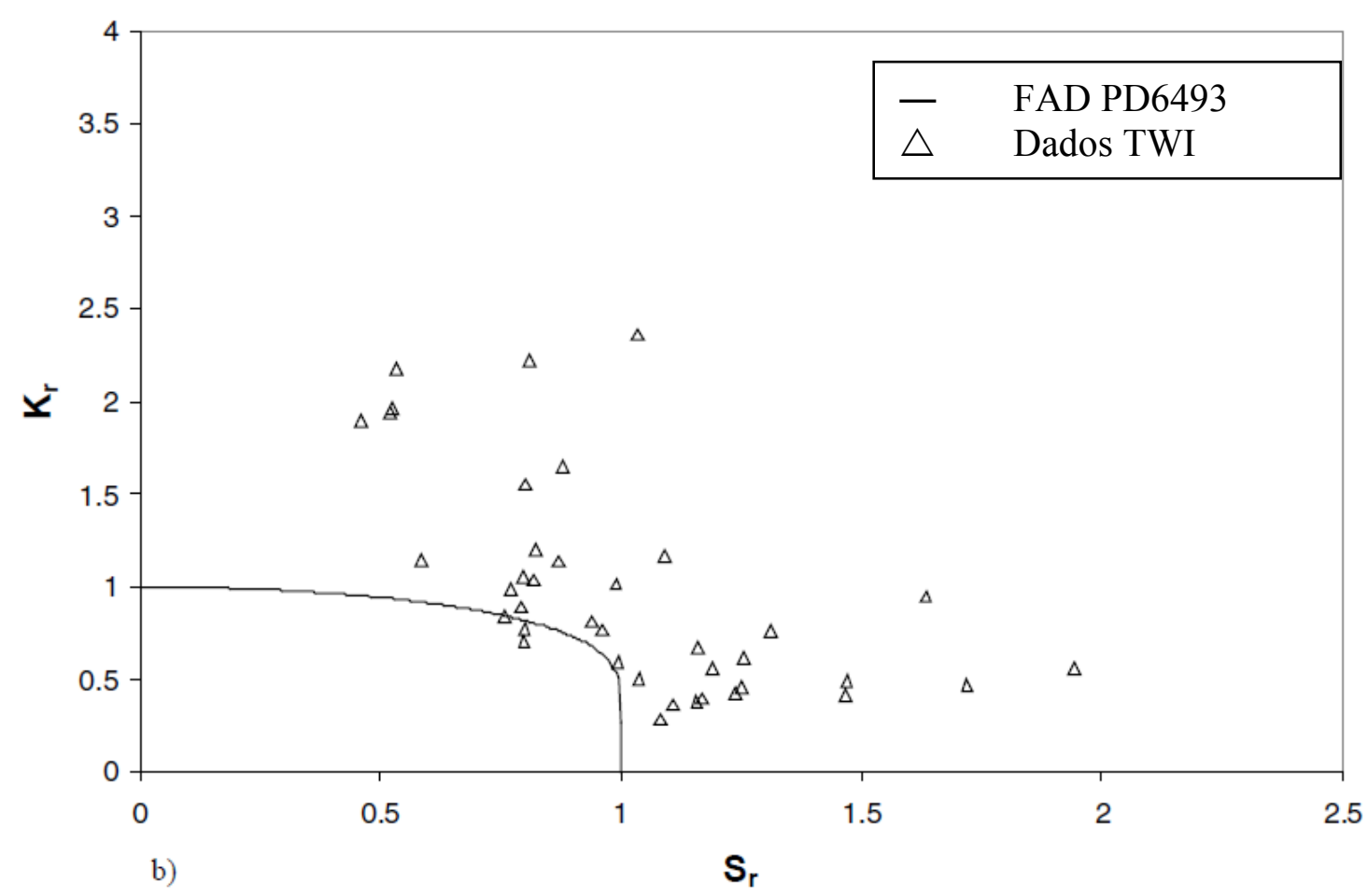

Figura 10 - Validação do FAD do PD6493 com resultados de testes em chapas de grandes dimensões [24]

${ }^{4}$ Os materiais utilizados incluem aços para fabricação de vasos de pressão, aços C-Mn para estruturas, aços para dutos (e.g. API SPEC 5L), ligas de alumínio e aços inoxidáveis, bem como as soldas desses materiais [24]. 


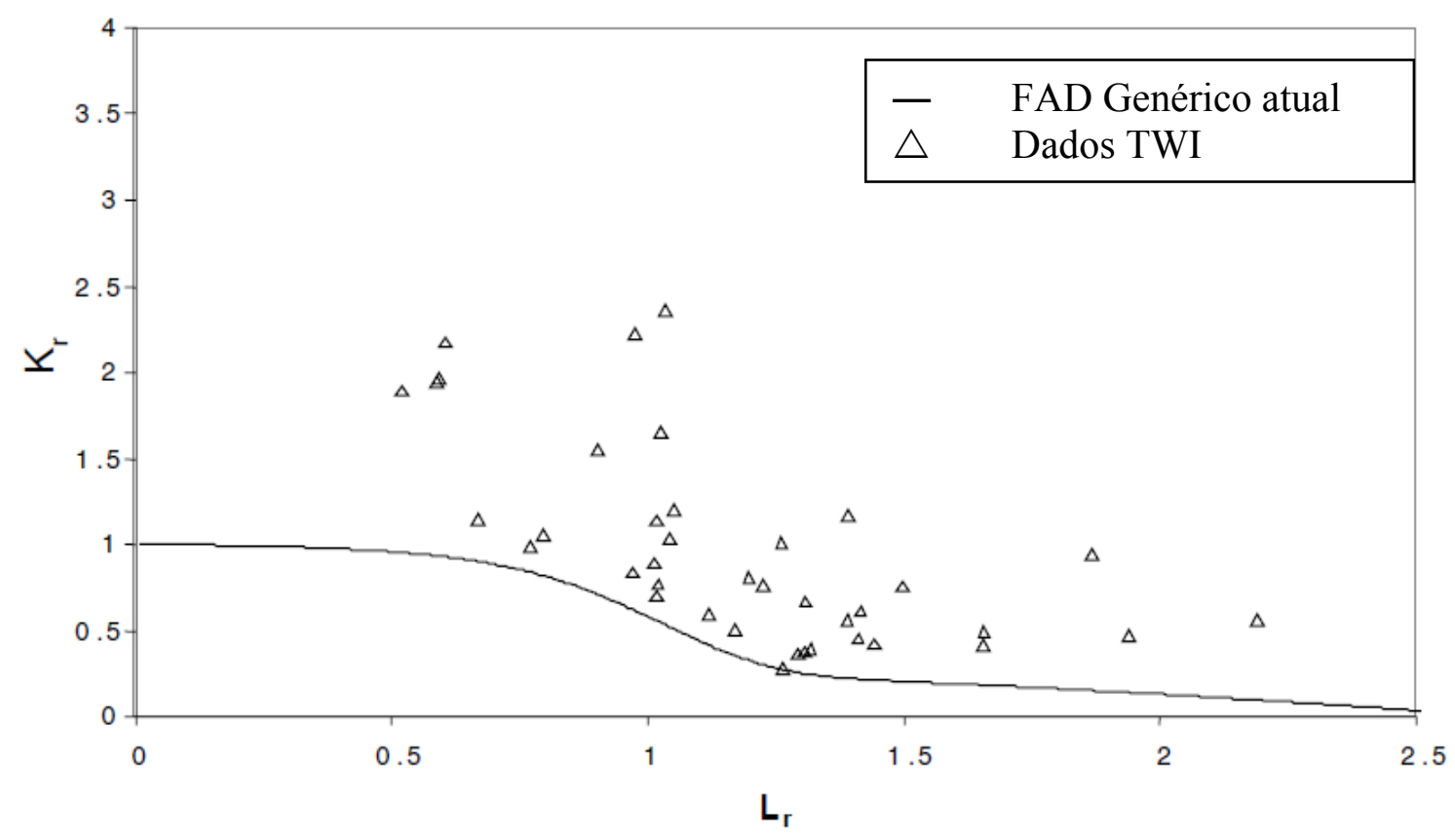

Figura 11 - Validação do FAD genérico com resultados de testes em chapas de grandes dimensões [24]

Por outro lado, a curva FAD "específica do material" apresenta uma abordagem teórica mais consistente e é, provavelmente, a abordagem analítica mais utilizada na avaliação crítica de engenharia de defeitos em soldas circunferenciais de dutos submersos. Essa abordagem se baseia no método da tensão de referência [25], definida originalmente como:

$$
\sigma_{r e f}=\sigma_{0} \frac{P}{P_{0}}
$$

O método da tensão de referência é baseado na metodologia EPRI apresentada anteriormente. No entanto, duas modificações o tornaram independente de análises de elementos finitos [18]. A primeira se refere à derivação da parcela plástica de $J$ em função da tensão de referência utilizando as equações 2.17 e 2.24:

$$
J_{p}=\sigma_{r e f} b h_{1}\left(\varepsilon_{r e f}-\frac{\sigma_{r e f} \varepsilon_{0}}{\sigma_{0}}\right)
$$

onde $\varepsilon_{r e f}$ é a deformação de referência obtida a partir do cruzamento da tensão de referência $\left(\sigma_{r e f}\right)$ da curva tensão-deformação verdadeira do material. A segunda e mais importante modificação foi retirar a dependência do material de $h_{l}$ adotando um 
expoente de encruamento $n=1$ (i.e. material elástico-linear) relacionando assim $h_{1}$ com o $K_{I}$ da MFEL. Depois de algumas correções, ajustes e simplificações, a curva FAD específica do material pode ser finalmente expressa como:

$$
K_{r}=\left(\frac{E \cdot \varepsilon_{r e f}}{L_{r} \sigma_{0}}+\frac{L r^{3} \sigma_{0}}{2 E \varepsilon_{r e f}}\right)^{-0,5}
$$

onde o primeiro termo se refere ao efeito da plasticidade na força motriz sob condições de deformação plástica e o segundo termo uma correção semi-empírica da força motriz sob condições intermediárias de deformação (escoamento em pequena escala) [26]. Nas equações 2.25 e 2.28, $L_{r}$ é definido como:

$$
L_{r}=\frac{\sigma_{r e f}}{\sigma_{0}}
$$

Assim como o fator de intensidade de tensão, existem diversos compêndios de tensão de referência $\left(\sigma_{\text {ref }}\right)$ [1-4].

No entanto, o método FAD sofre de uma série de limitações, mesmo se uma análise elástico-plástica de elementos finitos for realizada para a configuração de interesse. A abordagem FAD exige a classificação das tensões em primárias e secundárias, sendo esta última auto-equilibrada e aliviada com a deformação plástica. Além disso, quando várias cargas primárias estão presentes, elas devem aumentar e diminuir em fase uma com a outra, o que nem sempre condiz com a situação real de carregamento [2]. Nesses casos especiais, a abordagem CDFD fornece uma avaliação direta da resistência à fratura do material. 


\section{ECA EM DUTOS SUJEITOS A FLAMBAGEM LATERAL CONTROLADA}

Este capítulo é dedicado a uma revisão sobre a avaliação crítica de engenharia em dutos sujeitos a flambagem lateral. $O$ fenômeno da flambagem global em dutos submersos e os principais estados limites associados a eles são apresentados. É dado um foco especial sobre o estado limite de fratura e sobre o procedimento para a avaliação crítica de engenharia (ECA) em dutos submersos. Por fim, são discutidos os efeitos da pressão interna na capacidade de deformação de dutos em operação e os métodos utilizados para superar as limitações dos procedimentos atuais.

\subsection{FLAMBAGEM GLOBAL E FLAMBAGEM LATERAL CONTROLADA}

A flambagem global é um fenômeno recorrente em projetos de dutos submersos de alta pressão e alta temperatura, ocorrendo quando um trecho de duto tem suas extremidades restringidas mecanicamente pela interação com o solo impedindo que a expansão devido à temperatura e pressão ocorra. O duto então se comporta como se fosse uma viga em compressão de Euler [27] onde a força axial efetiva que governa o comportamento do duto pode ser expressa por [28]:

$$
F_{a e}=F_{a}+p_{e} A_{e}-p_{i} A_{i}
$$

onde:

$F_{a e} \quad$ Força axial efetiva

$F_{a} \quad$ Força axial real

$p_{e}, p_{i} \quad$ Pressão externa e interna, respectivamente.

$A_{e} \quad$ Área do tubo em contato com a pressão externa

$A_{i} \quad$ Área do tubo em contato com a pressão interna

A flambagem global não é um estado limite propriamente dito: o duto pode flambar tanto em dutos enterrados quanto em dutos expostos ao leito marinho. No caso de dutos enterrados, a flambagem ocorre no plano vertical e é geralmente mitigada por meio do controle da altura da camada de terra necessária para acomodar as forças radiais geradas pela expansão. Já em dutos expostos ao leito 
marinho, a flambagem lateral é geralmente permitida desde que o duto permaneça íntegro na condição pós-flambagem. A Figura 12 ilustra os dois cenários.

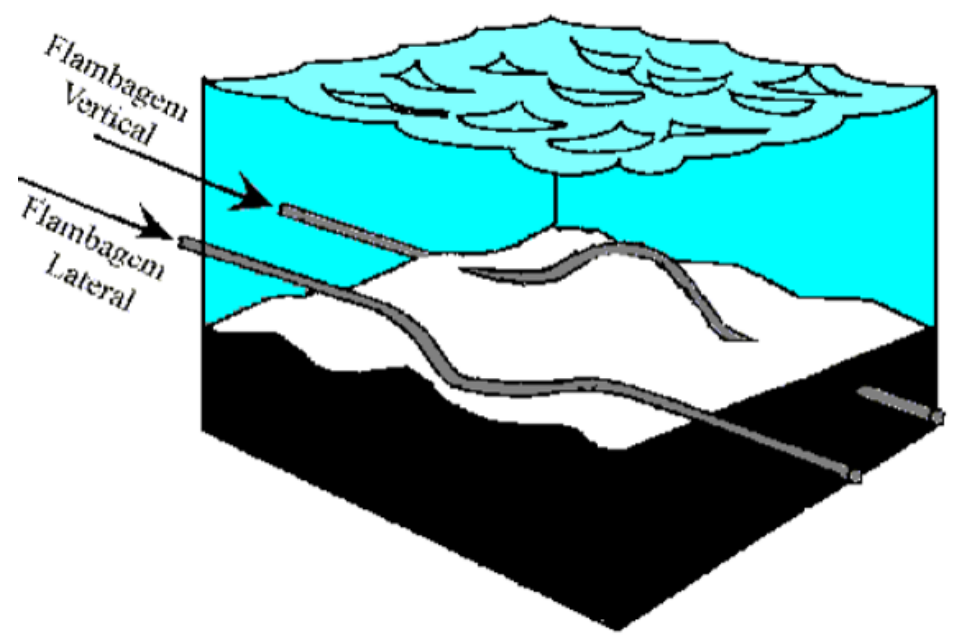

Figura 12 - Tipos de flambagem em dutos submersos: Flambagem Vertical e Lateral

Dutos de alta pressão e alta temperatura geralmente desenvolvem elevadas forças axiais efetivas. Para evitar a concentração de deformação em pontos de iniciação naturais, tais como irregularidades no solo marinho ou mesmo a falta de retidão dos tubos em um solo regular, o projeto se preocupa em garantir que a expansão realizar-se-á de maneira distribuída ao longo do duto adotando-se triggers ${ }^{5}$ para controlar o local de iniciação da flambagem. Caso a confiabilidade desses pontos de iniciação seja garantida, a flambagem lateral controlada pode ser um método seguro e eficaz para reduzir as forças axiais e acomodar as expansões.

O comportamento do duto no solo é simulado por meio de análises numéricas de elementos finitos (Figura 13), pois envolve diversas não linearidades tais como no comportamento do material (plasticidade), no contato (tubo-solo) e na geometria (grandes rotações e grandes deslocamentos). A análise depende da definição das propriedades mecânicas do tubo, perfil batimétrico do solo e características do contato tubo-solo, o que nem sempre é algo trivial. Diversas incertezas como os parâmetros do solo e a configuração final do duto no leito marinho após instalação podem influenciar fortemente o comportamento à flambagem lateral.

${ }^{5}$ Triggers são pontos de iniciação de flambagem lateral, tais como dormentes, bóias ou outras imperfeições impostas no duto, projetados para evitar que a flambagem ocorra de maneira não controlada comprometendo sua integridade. 


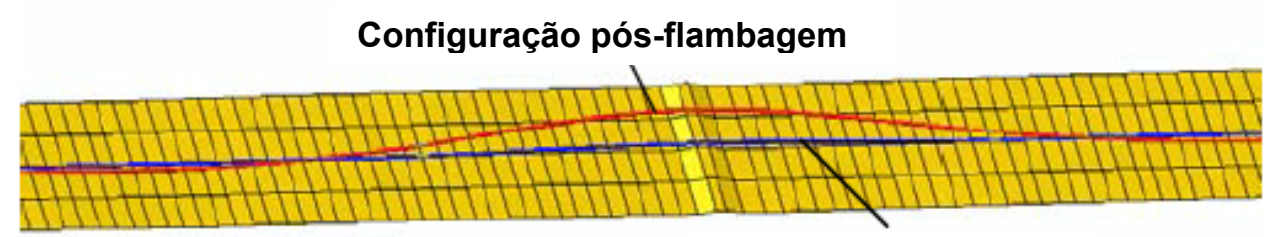

Configuração inicial

Figura 13 - Modelo de elementos finitos da flambagem lateral [29]

É recomendado que o projeto inicial determine o espaçamento máximo entre iniciadores por meio da simulação de VAS, abreviatura em inglês de "espaçamento por ancoragem virtual", em um solo plano [30]. A simulação de VAS, proposta oriunda do projeto Safebuck [31-33], consiste na simulação numérica de um trecho de duto restringido mecanicamente nas extremidades e com uma imperfeição na metade do comprimento para determinação da curvatura ou momento máximo desenvolvido na alça de flambagem, caso ela ocorra.

Com base nos resultados dessa análise, é realizada uma avaliação da integridade de ponto crítico da alça de flambagem onde cada estado limite é avaliado separadamente. Os principais estados limites envolvidos com os carregamentos extremos nas alças são a flambagem localizada da seção transversal, a fratura instável ou colapso plástico em defeitos de fabricação. Caso algum destes estados limites seja excedido, as seguintes ações podem ser realizadas:

- Refinamento da análise numérica ou da análise de integridade;

- Mudança da rota do duto e/ou serpenteamento ${ }^{6}$ na instalação do duto;

- Adoção de outros métodos de iniciação como a utilização de dormentes ou bóias de flutuação para garantir a formação da alça.

- Redução do espaçamento entre pontos de iniciação.

- Aumento da espessura do duto;

O espaçamento máximo é obtido por meio de um processo interativo entre as simulações numéricas e análises de integridade na condição pós flambagem. Tal análise é considerada conservadora uma vez que não considera a formação natural de alças de flambagem devido ao relevo do leito marinho. Quanto maior a curvatura

\footnotetext{
${ }^{6}$ Consiste na instalação do duto em trajetória não retilínea para introduzir imperfeições na linha.
} 
desenvolvida na alça de flambagem, maior é a criticidade dos carregamentos extremos na análise de integridade do duto. Além disso, as partidas e paradas operacionais são consideradas nesta fase uma vez que impõem uma carga cíclica severa no duto. No entanto, o efeito das cargas cíclicas não será abordado neste trabalho.

\subsubsection{Avaliação da integridade sob carregamentos extremos}

Antes de prosseguir com a avaliação de integridade é importante definir quando a flambagem é controlada por carregamento ou por deslocamento. A condição de carregamento controlado é governante quando o carregamento aplicado independe da deflexão do duto. Já na condição de deslocamento controlado, a maior parte do carregamento aplicado depende da deflexão do duto. A expansão devido à pressão e temperatura que resulta na flambagem lateral é, na maioria dos casos, um exemplo de condição controlada por deslocamento. Para que isso seja verdade, os triggers devem garantir a formação distribuída das alças de flambagem como mencionado anteriormente.

Independente da condição considerada, a relação entre momento aplicado $(M)$ e curvatura do duto ( $\kappa$ ) é única, ou seja, a resposta do duto não é dependente da condição que controla a flambagem. A Figura 14 ilustra a relação momento curvatura, caracterizado por relação " $M-\kappa$ " ou " $M-\varepsilon$ ", onde os pontos críticos $\left(\varepsilon_{c}, M_{c}\right)$ e os limites admissíveis $\left(\varepsilon_{a d}, M_{a d}\right)$ representam o estado limite de flambagem localizada para cada condição de carregamento. Estes limites equivalem a uma mesma probabilidade de falha calculada através dos princípios de confiabilidade estrutural adotados na norma DNV-OS-F101 [5]. Observa-se que, para um ponto arbitrário $\left(\varepsilon_{1}, M_{1}\right)$, o fator de segurança remanescente para a condição de deslocamento controlado é maior do que na condição de carregamento controlado. Em outras palavras, sob condições controladas por deformação, o material pode trabalhar além do regime elástico do material sem que haja prejuízo ao nível de segurança do projeto. 


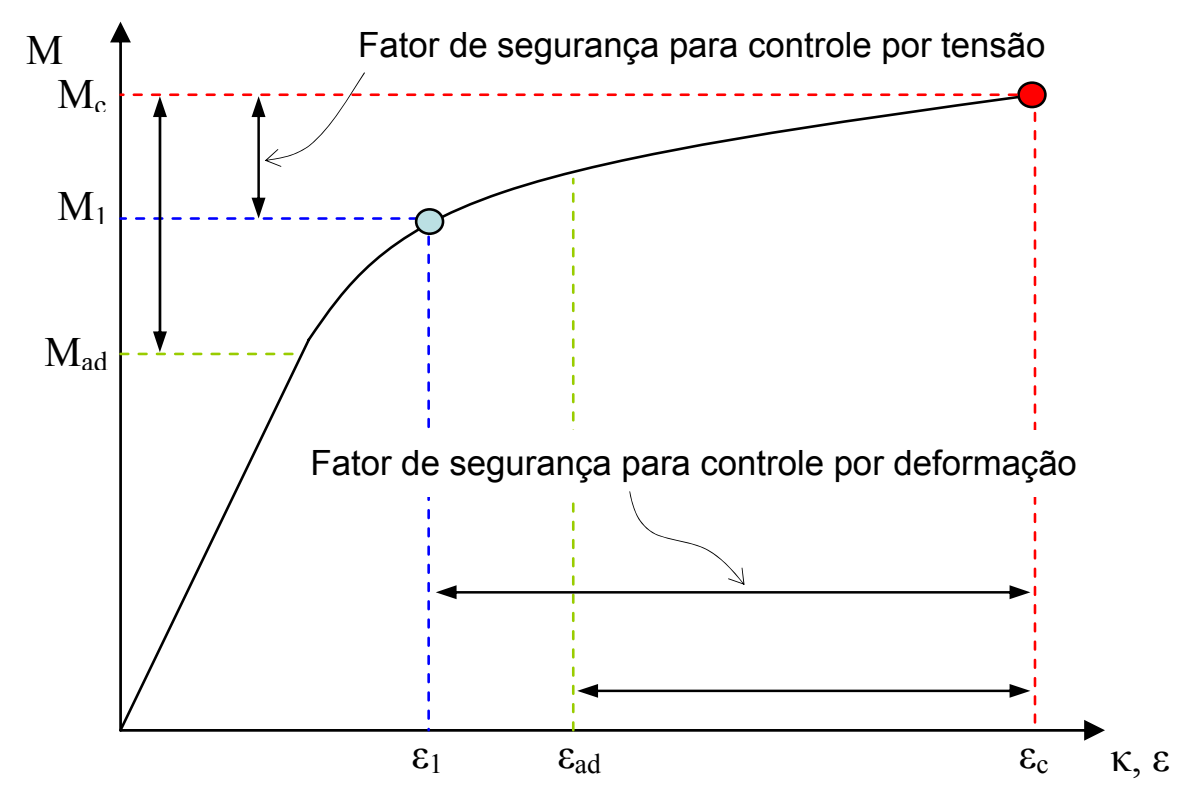

Figura 14 - Resposta momento-curvatura e definição dos fatores de segurança.

Sob condições com deslocamento controlado, a resistência a flambagem localizada é maior quanto maior for o nível de sobrepressão interna. Existem fórmulas do estado limite de flambagem localizada para condições de sobrepressão interna positiva, negativa ou nula. No caso de sobrepressão nula, i.e. flexão pura, a deformação longitudinal máxima deve satisfazer o seguinte critério [5]:

$$
\varepsilon_{a d}=\frac{\varepsilon_{c}}{\gamma_{\varepsilon}}
$$

com

$$
\varepsilon_{c}=0,78 \cdot\left(\frac{t}{D}-0,01\right) \cdot \alpha_{h}^{-1,5} \cdot \alpha_{g w}
$$

onde:

$\varepsilon_{a d} \quad$ Deformação compressiva admissível.

$\varepsilon_{c} \quad$ Deformação compressiva crítica.

$\gamma_{\varepsilon} \quad$ Fator de resistência a deformação (2,5 para classe de segurança média).

t, $D \quad$ Espessura e diâmetro externo do duto.

$\alpha_{h} \quad$ Razão máxima entre tensão de escoamento e ruptura do material.

$\alpha_{g w} \quad$ Fator de correção para soldas circunferenciais (1 para $D / t \leq 20$ ).

No entanto, esse modo de falha geralmente governa o lado sujeito a deformação compressiva, i.e. intradorso, da alça de flambagem. No extradorso, onde o duto está 
sujeito à deformações trativas, os principais modos de falha são a fratura dúctil e o colapso plástico. Diferente da flambagem localizada, a resistência à fratura nem sempre é abordada explicitamente no projeto. A seção 5 da DNV-OS-F101 estabelece os critérios para a resistência à fratura instável em função da deformação nominal longitudinal $\left(\varepsilon_{l, n o m}\right)$ e deformação plástica acumulada $\left(\varepsilon_{p, a c u m}\right)$ do duto conforme apresentado na Tabela 1:

\begin{tabular}{|c|c|c|}
\hline$\varepsilon_{l, \text { nom }}$ & $\varepsilon_{p, a c u m}$ & Requisito \\
\hline$\leq 0,4 \%$ & & $\begin{array}{l}\text { A resistência à fratura de um duto é garantida por meio da } \\
\text { seleção de materiais com boa tenacidade e do controle de } \\
\text { qualidade durante a soldagem. Isso é verificado através de } \\
\text { ensaios destrutivos na fase de qualificação e ensaios não } \\
\text { destrutivos na fase de produção, utilizando critérios de } \\
\text { aceitação convencionais ou alternativos baseados em } \\
\text { avaliação crítica de engenharia (ECA) conforme Apêndice A } \\
\text { da norma DNV-OS-F101. }\end{array}$ \\
\hline$>0,4 \%$ & & A avaliação crítica de engenharia (ECA) é obrigatória. \\
\hline
\end{tabular}

O requisito suplementar $\mathrm{P}$ da DNV-OS-F101 [5] se refere aos ensaios adicionais requeridos em tubos sujeitos à deformação plástica durante instalação ou operação. Isso inclui ensaios de tração dos tubos após fabricação para garantir que: a) a diferença entre a tensão de escoamento mínima e máxima não seja superior a 100 $\mathrm{MPa}$; b) a razão entre tensão de escoamento e ruptura do material $\left(\alpha_{h}\right)$ não seja superior a 0,90 e; c) o alongamento seja superior a $20 \%$. Adicionalmente, devem ser realizados ensaios de tração, impacto e dureza na condição deformado e envelhecido ${ }^{7}$, onde o objetivo é garantir propriedades adequadas após grandes deformações plásticas.

Diferente do modo de falha por flambagem localizada da seção tranversal, não existe um limite bem determinado sobre a capacidade de deformação de dutos

\footnotetext{
${ }^{7}$ Por envelhecido entende-se a simulação da degradação do material pela temperatura e tempo por meio do tratamento térmico do corpo de prova por uma hora à temperatura de $250^{\circ} \mathrm{C}$ [5].
} 
sujeitos a carregamentos trativos, sendo este um campo de extensa pesquisa nos últimos anos dada a forte interação entre os modos de falha de fratura e colapso plástico. Para deformações maiores que $0,4 \%$, a norma requer a execução do ECA - uma metodologia para avaliação de defeitos planares baseada nos conceitos da mecânica da fratura. O apêndice A da norma DNV-OS-F101 [5] fornece os requisitos e recomendações para elaboração do ECA em dutos submersos.

\subsection{ECA EM DUTOS SUBMERSOS}

Atualmente, o ECA é um procedimento relativamente usual na instalação de dutos submersos e risers rígidos. Isso se deve parte ao aumento da complexidade dos projetos de dutos offshore, i.e. alta temperatura e alta pressão, profundidades elevadas, fluídos agressivos, etc., e parte à popularização da inspeção por ultrassom automatizada (AUT) como substituto da radiografia na inspeção de soldas circunferenciais de campo, um método rápido e relativamente preciso para a detecção e dimensionamento de defeitos em soldas [34].

No entanto, é importante destacar que o produto do ECA não é o critério de aceitação final para defeitos em soldas: do envelope crítico de defeitos determinado pelo ECA é descontada a parcela referente ao erro de dimensionamento do sistema de inspeção por ultrassom automatizado. Esse sistema deve possuir uma probabilidade de detecção maior ou igual a $90 \%$ para o menor defeito calculado deterministicamente pelo ECA, com um intervalo de confiança de $95 \%$ na medida conforme requerido pela norma DNV-OS-F101 [5].

\subsubsection{Histórico de desenvolvimento}

O ECA geralmente adota a abordagem FAD para avaliação da integridade estrutural de componentes com defeitos. No entanto a abordagem FAD não foi desenvolvida para a avaliação de condições controlada por deslocamento, principalmente quando envolve grandes deformações plásticas no componente. $O$ melhor exemplo de tais situações é a instalação de dutos pelo método do bobinamento, ou reeling, onde o duto é fabricado em um canteiro em terra e transportado em um carretel para ser instalado no mar (Figura 15). Outras situações 
que podem levar a grandes deformações são curvaturas nas alças de flambagem lateral controlada, deslocamentos de terra ou movimentações de gelo (frost heave).
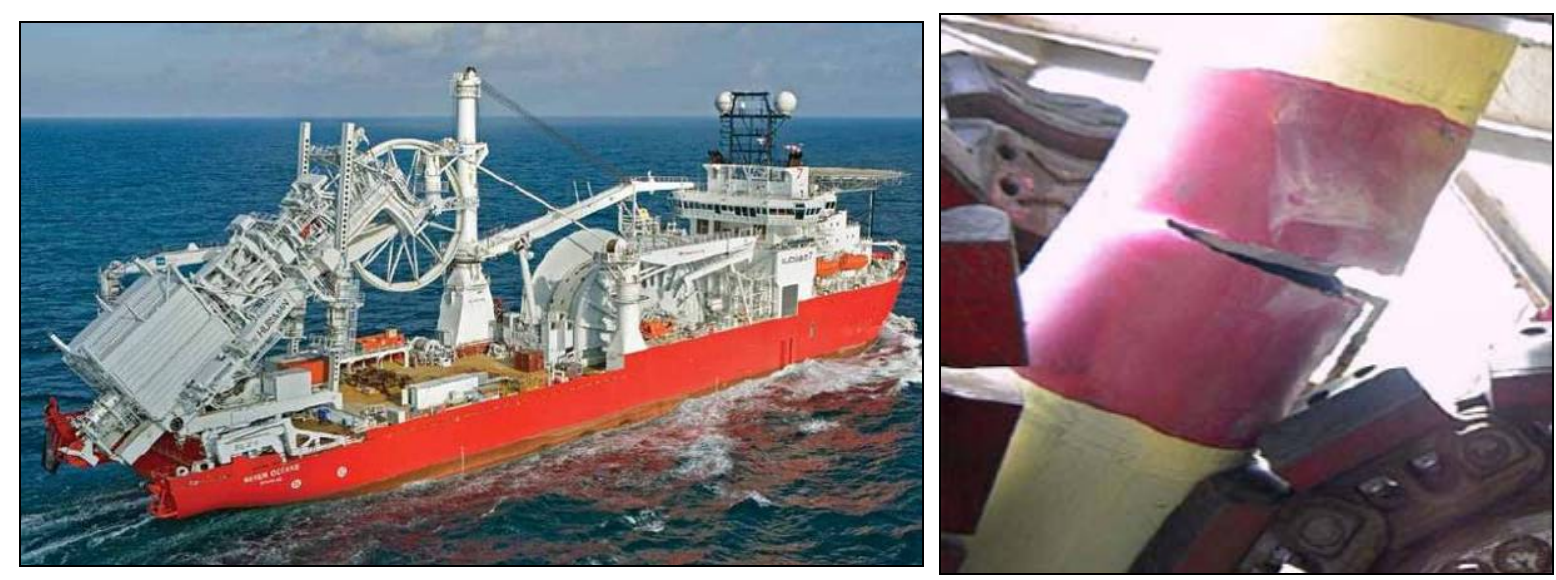

Figura 15 - Falha por fratura instável durante o lançamento de um duto.

Em 2000, a norma DNV-OS-F101 incluiu orientações gerais para a execução de ECA em dutos submersos. No mesmo ano, a DNV em conjunto com o SINTEF, um instituto de pesquisa norueguês, e o TWI, instituto de pesquisa aplicada do Reino Unido, iniciaram um grande projeto de pesquisa sobre controle da fratura em dutos sujeitos a grandes deformações plásticas que culminou na publicação de um procedimento para avaliação de integridade de dutos instalados por reeling em 2003 [6] que, três anos depois, foi disponibilizada ao público na forma de uma recomendação prática da DNV, a RP-F108 [7]. Em 2007, a DNV publicou uma revisão da norma OS-F101 incorporando e estendendo a metodologia da RP-F108 para os demais cenários governados por deslocamento. Desde então, a norma sofreu alterações mínimas e vem sendo amplamente utilizada para a elaboração de ECA em dutos submersos.

\subsubsection{Metodologia de ECA conforme Apêndice A da DNV-OS-F101}

O objetivo principal do ECA é determinar a aceitabilidade de descontinuidades encontradas durante a inspeção das soldas circunferenciais, seja em termos de dimensões críticas (Figura 16) ou em termos da tenacidade mínima requerida para a solda. Além de avaliar a integridade de dutos sujeitos a grandes deformações, 0 ECA pode subsidiar a adoção de critérios de aceitação menos severos do que se 
baseado no requisito de qualidade convencional, contribuindo assim para diminuição do número de reparos desnecessários e aumento da produtividade.

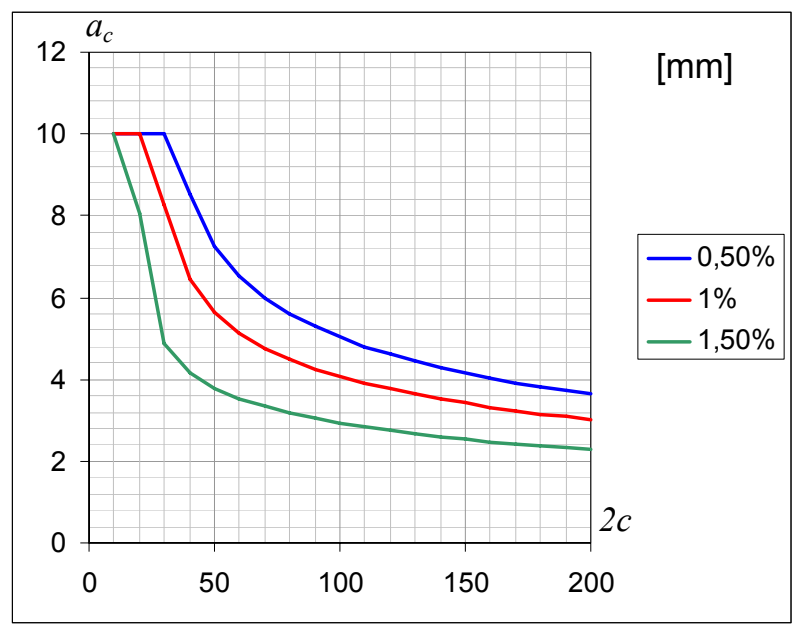

Figura 16 - Ilustração de envelope crítico de defeito em função da altura crítica $\left(a_{c}\right)$ versus comprimento $(2 c)$ sob diferentes níveis de deformação longitudinal remota

A norma apresenta duas opções de análise: o ECA Genérico e o ECA Completo. O ECA Genérico é uma abordagem simplificada e conservadora que fornece as dimensões críticas dos defeitos de solda em função da tenacidade mínima requerida para um determinado nível de deformação nominal longitudinal máxima que a solda estará sujeita. O ECA Genérico requer um escopo de testes menor do que no ECA completo e não requer a realização de cálculos. Por outro lado, o ECA Genérico não é aplicável em situações que envolvem deformações longitudinais associadas à sobrepressão interna positiva, invalidando sua utilização na maioria dos cenários de flambagem lateral controlada.

Portanto, no restante do texto a palavra ECA fará referência apenas ao procedimento de ECA completo que será descrito a seguir. O ECA avalia os seguintes modos de falha:

- Rasgamento dúctil excessivo;

- Crescimento do defeito pela ação de cargas cíclicas;

- Fratura instável.

A metodologia de ECA requer uma etapa de ensaios experimentais e uma etapa de cálculos numéricos. A etapa experimental é realizada por meio de ensaios destrutivos que incluem ensaios de tração do material do tubo para levantamento da 
curva tensão-deformação do material e ensaios de tenacidade à fratura que serão discutidos no item 3.2.3. É importante ressaltar que o procedimento descrito no apêndice A da DNV-OS-F101 [5] só é valido em casos onde a resistência mecânica da solda é maior ou igual à resistência mecânica do tubo em termos de tensão de escoamento e ruptura, i.e. overmatching.

A segunda etapa envolve um procedimento de cálculo numérico baseado na abordagem FAD para determinar as dimensões críticas dos defeitos de soldagem. Essa etapa leva em consideração os carregamentos nas diversas fases da vida de um duto, tais como: instalação, teste hidrostático, temporária e operação. Usualmente, o teste hidrostático e a fase temporária podem ser negligenciados quando o ambiente operacional desenvolver solicitações longitudinais mais elevadas por um período bem maior de duração.

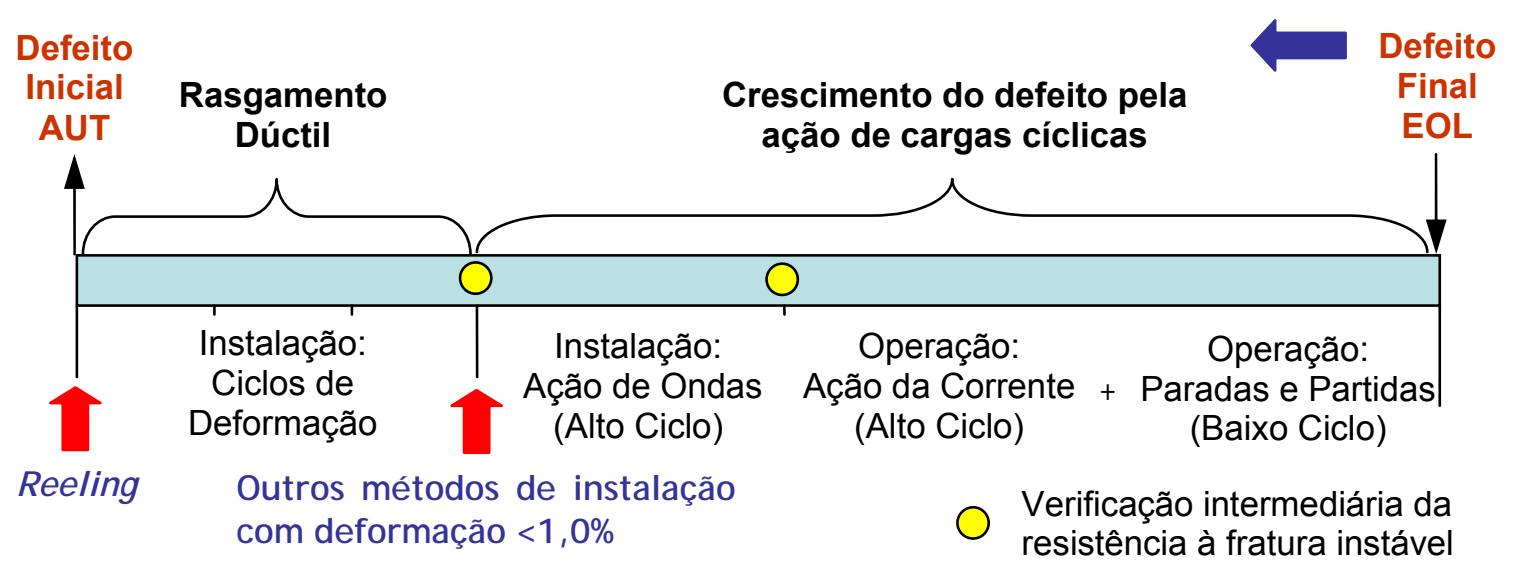

Figura 17 - Fases analisadas no ECA

A Figura 17 resume a seqüência de análise: partindo do envelope crítico de defeitos da análise de final de vida (EOL), o objetivo é determinar a dimensão dos defeitos iniciais, i.e. após soldagem e inspeção por AUT, que resistirá as cargas cíclicas e extremas no qual o duto será submetido ao longo de sua vida de projeto. Isso é realizado retirando as parcelas correspondentes ao crescimento dos defeitos por fadiga nas fases de operação e instalação do duto, e por rasgamento dúctil, caso o método de instalação imponha ciclos de deformação plástica (e.g. reeling), do envelope crítico de defeitos de final de vida. Para o objetivo deste trabalho, somente o procedimento para obtenção do envelope crítico de defeitos no final de vida será abordado, isto é, os maiores defeitos que resistirão a carregamentos operacionais. 
Como mencionado anteriormente, o apêndice A da norma DNV-OS-F101 fornece os requisitos e recomendações para a elaboração de ECA para dutos submersos. Para o cálculo do envelope crítico de defeitos, a norma DNV-OS-F101 indica a adoção da abordagem FAD da BS-7910 [1]. A BS-7910 é estruturada em três níveis de análise, que vão se tornando mais sofisticados e menos conservadores quanto maior for a quantidade de informações disponíveis.

O nível 1 da BS-7910 é uma análise simplificada e se aplica a componentes com deformação plástica limitada. O nível 2 é a opção normal de avaliação e mínima requerida para avaliações críticas de engenharia em dutos submersos. Esse nível é adequado para análises de fim de vida onde a deformação longitudinal nominal é menor ou igual a $1 \%$, pois não é esperado crescimento do defeito por rasgamento dúctil significativo nesse nível de deformação. Acima de 1\%, a DNV-OS-F101 requer análise de nível 3 , pois esta considera o crescimento do defeito por rasgamento dúctil (ductile tearing).

Por sua vez, a curva-tensão deformação verdadeira do material é necessária para a definição da curva FAD uma vez que não é permitida a utilização da curva FAD genérica na elaboração de ECA em dutos submersos de acordo com o apêndice $A$ da OS-F101. A curva FAD específica para o material é denotada pelo sufixo "B", ou seja, uma análise normal utilizando o $F A D$ específico do material (equação 2.28) é denominada uma análise nível 2B na BS-7910.

A principal diferença entre a abordagem FAD para elaboração de ECA em dutos submersos conforme o apêndice A da OS-F101 [5] e uma análise conforme nível 2B da BS-7910 [1] é a definição do limite de colapso plástico, denominado $L_{r \max } . \mathrm{Na}$ norma BS-7910 [1], o limite de colapso plástico é definido como:

$$
L_{r \max }=\frac{\left(\sigma_{e}+\sigma_{u}\right)}{2 \cdot \sigma_{e}}
$$

Sob condições de carregamento controladas por deslocamento, este limite pode ser calculado diretamente do resultado do ensaio de tenacidade à fratura como a razão entre a carga máxima obtida no ensaio e a área da seção remanescente do 
corpo-de-prova. $\mathrm{Na}$ ausência dos dados de ensaio, a OS-F101 [5] permite que o limite de colapso plástico seja definido como:

$$
L_{r \text { max }}=\frac{\sigma_{u}}{\sigma_{e}}
$$

Observando as equações 2.29 e 3.5, percebe-se que o limite de colapso plástico é atingido em situações de deformação controlada quando a tensão de referência atinge o valor da tensão de ruptura do material. Definida a curva FAD (2B) e o limite de colapso plástico $\left(L_{r \max }\right)$, o diagrama FAD está pronto, restando definir o ponto de avaliação $\left(L_{r}, K_{r}\right)$ :

$$
\begin{aligned}
& L_{r}=\frac{\sigma_{r e f}}{\sigma_{e}} \\
& K_{r}=\frac{K_{I}}{K_{\text {mat }}}+\rho
\end{aligned}
$$

Onde $\rho$ é um fator de correção de plasticidade utilizado quando há presença de tensões secundárias, e.g. tensões residuais de soldagem. $O$ apêndice $A$ da OSF101 recomenda adoção da solução da tensão de referência de Kastner para descontinuidades superficiais em cilindros [36]:

$$
\sigma_{\text {ref }}=\frac{P_{m}\left[\pi\left(1-\frac{a}{B}\right)+2\left(\frac{a}{B}\right) \operatorname{sen}\left(\frac{c}{r}\right)\right]}{\left(1-\frac{a}{B}\right)\left[\pi-\left(\frac{c}{r}\right)\left(\frac{a}{B}\right)\right]}+\frac{2 P_{b}}{3\left(1-\alpha^{\prime \prime}\right)^{2}}
$$

Para $\pi \cdot r \geq c+B$ :

$$
\alpha^{\prime \prime}=\frac{\frac{a}{B}}{\left[1+\left(\frac{B}{c}\right)\right]}
$$

onde:

$P_{m} \quad$ Tensão primária de membrana devido ao carregamento longitudinal.

$P_{b} \quad$ Tensão primária de flexão devido ao desalinhamento da junta. 
Para condições de carregamento controladas por deslocamento, as tensões primárias são obtidas a partir da curva tensão-deformação do material (Figura 18). A tensão primária de membrana $\left(P_{m}\right)$ é obtida a partir do cruzamento do valor de deformação longitudinal nominal aplicada $\left(\varepsilon_{1}\right)$ com a curva tensão-deformação do material. A tensão primária de flexão $\left(P_{b}\right)$ é calculada a partir do fator de concentração de tensão elástico linear devido ao desalinhamento das soldas circunferenciais $^{8}(S C F)$ por meio da regra de Neuber [16], onde:

$$
P_{m} \cdot \varepsilon_{1} \cdot S C F^{2}=\left(P_{m}+P_{b}\right) \cdot \varepsilon_{2}
$$

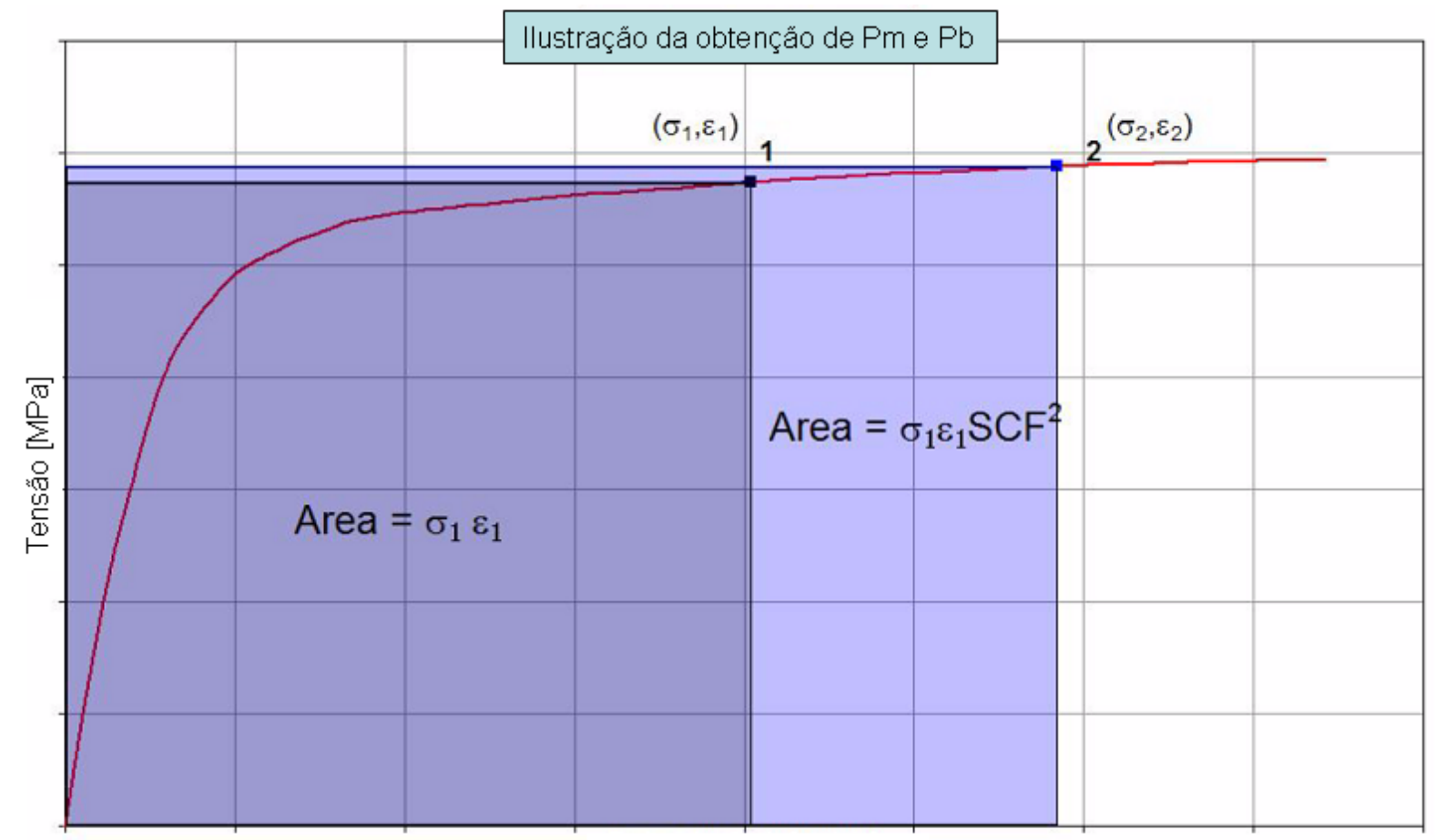

Deformação $[\mathrm{mm} / \mathrm{mm}]$

Figura 18 - Determinação das tensões primárias de membrana e primária de flexão por meio da aplicação da regra de Neuber [5]

Para o cálculo do fator de intensidade de tensão $\left(K_{I}\right)$, a BS-7910 adota a forma geral definida na equação 2.6, onde o produto de $Y$ e $\sigma$ é definido como:

$$
Y \sigma=(Y \sigma)_{p}+(Y \sigma)_{s}
$$

\footnotetext{
${ }^{8}$ A recomendação prática DNV-RP-C203 [37] fornece os valores para SCF em soldas circunferenciais de tubos.
} 
onde os índices subscritos " $p$ " e " $s$ " se referem às cargas primárias e secundárias, respectivamente. Para defeitos circunferenciais onde não há desalinhamento da junta soldada ou atuação de tensões secundárias, a solução de $Y \sigma$ pode ser reescrita como:

$Y \sigma=f_{w}\left(M_{k m} \cdot M_{m} \cdot P_{m}\right)$

onde:

$f_{w} \quad$ Fator de correção para componentes com geometria finita.

$M_{k m} \quad$ Fator de magnificação para defeitos localizados na margem da solda.

$M_{m} \quad$ Fator de forma que depende da espessura e dimensão do defeito.

O fator $f_{w}$ é aplicável quando a área da trinca é maior que $10 \%$ da seção transversal do duto [1]. Já o fator $M_{k}$ somente se aplica quando o nível de deformação é menor ou igual a $0,4 \%$ ou quando a altura do defeito é menor que $10 \%$ da espessura da parede [5]. Para definição de $f_{w}$ e $M_{m}$ para defeitos superficiais, geralmente se adota a solução de Raju e Newman [38] para defeitos superficiais em chapas planas uma vez que a faixa de aplicação das soluções para cilindros e cascas sujeitos a esforços mecânicos remotos é muito limitada:

$f w=\left\{\sec \left[(\pi c / W)(a / B)^{0,5}\right]\right\}^{0,5}$

e

$$
M_{m}=\left\lfloor M_{1}+M_{2}(a / B)^{2}+M_{3}(a / B)^{4} \mid g f_{\theta} / \Phi\right.
$$

Para $a \leq c$ :

$$
\begin{aligned}
& M_{1}=1,13-0,09(a / c) \\
& M_{2}=\{0,89 /[0,2+(a / c)]\}-0,54 \\
& M_{3}=0,5-1 /[0,65+(a / c)]+14[1-(a / c)]^{24} \\
& \Phi=\left[1+1,464(a / c)^{1,65}\right]^{0,5}
\end{aligned}
$$


onde $g$ e $f_{\theta}$ é igual a um no ponto mais profundo do defeito em relação a superfície, e largura da chapa $W$ é igual ao perímetro do duto $(2 \pi r)$. Por fim, a altura crítica do defeito $\left(a_{c}\right)$ é calculada para um determinado comprimento de defeito $(2 c)$ tal que:

$$
\frac{K_{I}}{K_{r}} \leq K_{\text {mat }}
$$

Observa-se ainda na equação 3.19 que, enquanto $K_{\text {mat }}$ representa a resistência à fratura do material, $K_{I} / K_{r}$ representa a força motriz onde $K_{r}$ é o ponto na curva FAD (equação 2.28) referente à razão de fratura para uma dada geometria e carregamento (equação 2.29). O envelope crítico de defeitos, i.e. altura crítica pelo comprimento, pode ser obtida através de cálculos numéricos alcançando a igualdade na equação 3.19 por meio da variação das dimensões do defeito $(a, c)$. Assim, só falta caracterizar a tenacidade à fratura do material $K_{\text {mat }}$.

\subsubsection{Estimativa da tenacidade à fratura em dutos conforme RP-F108}

Como mencionado anteriormente, $K_{\text {mat }}$ é obtido por meio de ensaios experimentais. A BS 7910 [1] oferece duas opções para obtenção da tenacidade à fratura $\left(K_{\text {mat }}\right)$ que são aceitáveis em um procedimento de ECA:

- Adotar o resultado de ensaio de tenacidade à fratura no estado plano de deformações $\left(K_{I c}\right)$, i.e. que atendam os requisitos da equação 2.8 , ou

- Converter o resultado de ensaio de $J$ utilizando a seguinte equação:

$K_{\text {mat }}=\sqrt{\frac{J_{\text {mat }} \cdot E}{1-v^{2}}}$

onde $J_{\text {mat }}$ é a tenacidade à fratura do material obtida experimentalmente. Na prática, é pouco provável que se obtenha valores de $K_{I c}$ válidos em materiais para dutos (materiais com elevados requisitos de tenacidade e ductilidade) utilizando corpos-deprova na espessura máxima do tubo, conforme requerido pela BS-7910 [1], sendo assim, geralmente são adotados os valores de $J_{\text {mat }}$. 
A norma indica a adoção de procedimentos padronizados de ensaio, em especial o da BS-7448 [39], que apresenta requisitos específicos para o teste de juntas soldadas. Esta norma fornece os procedimentos de ensaio de tenacidade à fratura em corpos de prova padronizados, e.g. Compact Tension (CT) e Single Edge Notch Bending (SENB). Os corpos-de-prova SENB possuem entalhe lateral submetidos à flexão em três pontos com trinca profunda. Estes corpos-de-prova possuem elevada triaxialidade, uma vez que os mesmos podem ser utilizados para caracterizar a tenacidade à fratura crítica em componentes estruturais de quaisquer dimensões.

No entanto, a utilização de corpos de prova de alta triaxialidade para caracterizar a tenacidade à fratura em materiais de alta ductilidade aplicados em componentes com baixa triaxialidade e espessura limitada, tais como vasos de pressão e dutos, estava sendo questionada no meio acadêmico e indústria. Nyhus et al. [40] observaram através de ensaios experimentais e análises de elementos finitos que corpos-de-prova com entalhe lateral submetido a tração - SENT - se aproximavam mais da resistência a fratura em dutos sujeitos a grandes deformações uma vez que não é esperada fratura frágil nessa situação. A Figura 19 apresenta um esquema ilustrativo do efeito da geometria e do nível de triaxialidade na tenacidade à fratura para os tipos corpos-de-prova mencionados e um tubo carregado em flexão.

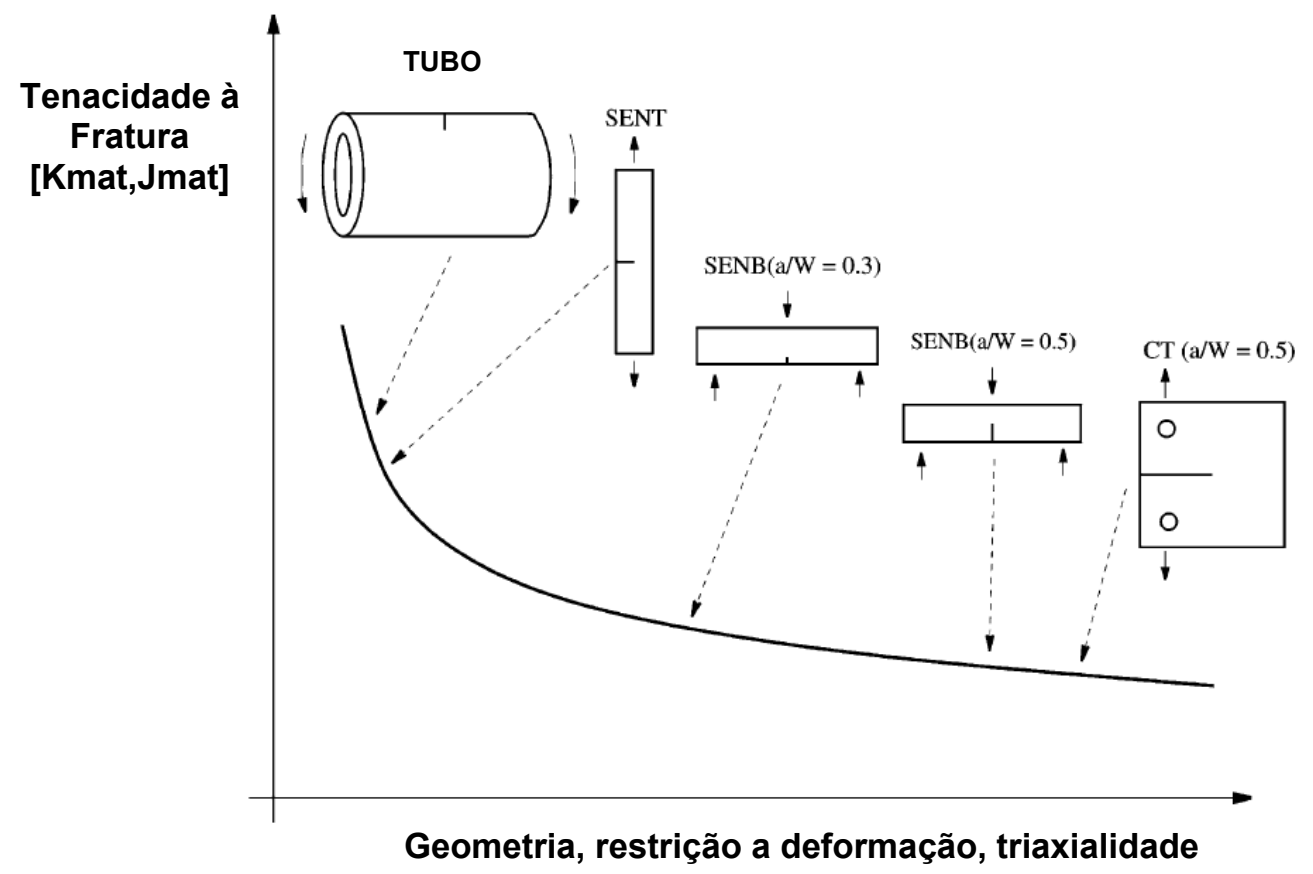

Figura 19 - Esquema ilustrativo do efeito da geometria na tenacidade à fratura [40] 
Vale ressaltar que a tenacidade à fratura superior obtida por corpos de prova tipo SENT pode ser atribuída a sua elevada resistência ao rasgamento dúctil, uma vez que a resistência à iniciação da fratura é praticamente indiferente do tipo de corpo de prova utilizado, como observado por Joyce e Link [41]. Essa resistência à fratura instável aparentemente superior obtida em corpos de prova tipo SENT pode ser transferida para dutos com defeitos circunferenciais sujeitos a carregamentos de tração ou flexão, que são essencialmente uniaxiais, caso haja similaridade entre os campos de tensão e deformação à frente da ponta do defeito.

Com o projeto de pesquisa sobre o controle da fratura em dutos sujeitos a grandes deformações plásticas, que deu origem a um procedimento de ECA para dutos instalados por reeling [6], extinguiu-se a necessidade de realização de análises de elementos finitos para justificar a adoção de corpos de prova SENT em dutos sujeitos a carregamentos uniaxiais desde que e a altura do entalhe no corpode-prova fosse maior ou igual à altura do defeito avaliado na estrutura (Figura 20).
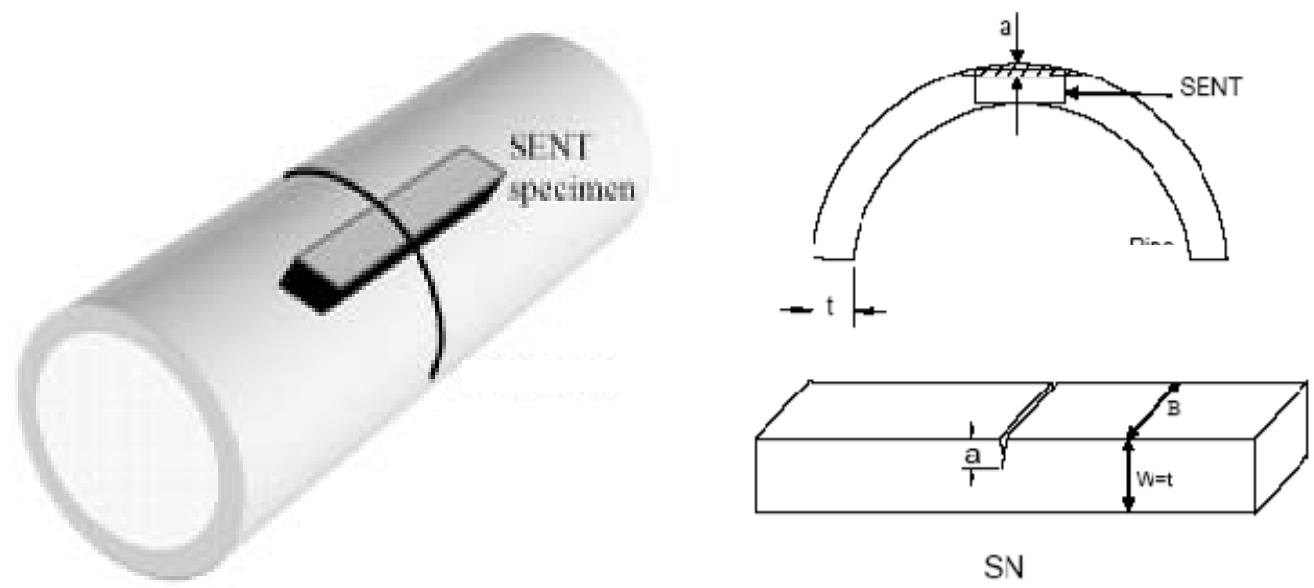

SN

Figura 20 - Remoção do corpo de prova SENT e altura do entalhe no corpo de prova [7].

Posteriormente, a publicação da recomendação prática DNV-RP-F108 [7] permitiu que a tenacidade à fratura obtido em corpos-de-prova SENT com entalhes entre 20 e $50 \%$ da espessura do tubo fosse transferida diretamente para o duto em qualquer cenário da análise de instalação, independente do modo de carregamento. Desde então os corpos de prova SENT vem sendo largamente utilizados na elaboração de ECA de dutos submersos. No entanto, a DNV-OS-F101 [5] e a DNVRP-F108 [7] continuam sendo os únicos documentos que tratam deste ensaio, não havendo nenhum outro procedimento de ensaio SENT publicado como norma técnica até o presente momento. 


\subsection{ECA NO FINAL DE VIDA E O EFEITO DA PRESSÃO INTERNA}

Até agora foi descrito um procedimento de ECA para condições de carregamento controladas por deslocamento/deformação e realizada uma discussão sobre a caracterização da tenacidade à fratura em dutos sujeitos a carregamentos uniaxiais. Esta combinação é particularmente importante na análise do cenário de instalação de dutos, uma vez que este envolve os maiores carregamentos longitudinais em que o duto estará sujeito ao longo da sua vida. Entretanto, as cargas cíclicas podem levar os defeitos a crescerem ao longo da vida e falhar sob cargas relativamente menores, fazendo-se necessário algumas considerações adicionais para a análise do envelope de defeitos críticos no final de vida do duto.

A principal consideração é o efeito da pressão interna na tensão longitudinal que o duto estará sujeito. A pressão interna gera além de uma tensão circunferencial, uma tensão longitudinal cuja magnitude irá depender das condições de restrição do duto, mas que em geral assume o valor de $50 \%$ da tensão circunferencial para dutos expostos e $30 \%$ para dutos enterrados [42]. No entanto este efeito é de uma ordem menor que os carregamentos longitudinais normalmente experimentados em dutos sujeitos a grandes deformações longitudinais uma vez que são provenientes de tensões circunferenciais essencialmente elásticas.

No caso especial de dutos submersos, a tensão circunferencial não é função apenas da pressurização interna do duto, mas também da pressão hidrostática causada pela coluna de fluído, seja ele a água que envolve o duto ou o peso do fluído transportado. Por ser uma tensão essencialmente elástica linear, as tensões circunferenciais podem ser calculadas como:

$$
\begin{aligned}
& \sigma_{C}=\sigma_{\text {int }}-\sigma_{\text {ext }} \\
& \sigma_{\text {ext }}=\frac{L D A \cdot \rho_{\text {agua }} \cdot g \cdot R_{e}}{t} \\
& \sigma_{\text {int }}=\frac{\left(p_{\text {op }}+L D A \cdot \rho_{\text {fluido }} \cdot g\right) \cdot R_{i}}{t}
\end{aligned}
$$


onde:

$\begin{array}{ll}\sigma_{C} & \text { Tensão circunferencial } \\ \sigma_{i n t} & \text { Tensão circunferencial devido à pressão interna } \\ \sigma_{\text {ext }} & \text { Tensão circunferencial devido à pressão externa } \\ R_{e} & \text { Raio externo } \\ R_{i} & \text { Raio interno } \\ L D A & \text { Lâmina d'água } \\ \rho_{\text {água }} & \left.\text { Massa específica da água (e.g. } 1025 \mathrm{~kg} / \mathrm{m}^{3}\right) \\ \rho_{\text {fluido }} & \left.\text { Massa específica do fluído (e.g. } 894 \mathrm{~kg} / \mathrm{m}^{3}\right) \\ g & \text { Gravidade }(9,806 \mathrm{~m} / \mathrm{s}) \\ p_{o p} & \text { Pressão de operação no nível do mar }\end{array}$

No entanto, o comportamento do duto não é governado pelo nível de pressão interna ou externa, mas sim pelo nível de sobrepressão interna, seja ela positiva, isto é, a pressão interna é maior que a pressão externa, ou negativa. Ao contrário do que foi mencionado para o estado limite de flambagem localizada, a sobrepressão interna positiva reduz a capacidade de deformação longitudinal de um duto no estado limite de fratura como será observado e discutido a seguir. Para o efeito deste texto, a tensão resultante do nível de sobrepressão interna $(X)$ será sempre expressa em função da tensão de escoamento do material como:

$$
\sigma_{C}=X \sigma_{0}
$$

Quando $X$ assume um valor diferente de zero, o duto estará sujeito ao que é chamado de "estado biaxial de tensões", onde as tensões radiais são relativamente pequenas comparadas às tensões longitudinais e circunferenciais do duto. Essa consideração é particularmente relevante na análise de dutos submersos submetidos à flambagem lateral, ou seja, na atuação de pressão interna com carregamentos longitudinais causados pela expansão lateral de dutos devido a temperatura e pressão. Além do termo "estado biaxial de tensões", o termo "biaxialidade" também será utilizado neste texto e se referirá à relação entre as tensões longitudinais e circunferenciais do duto. 
Importante também diferenciar o significado do termo biaxialidade utilizado neste texto com aquele utilizado na MFEL para caracterizar uma condição em que dois ou mais modos de carregamento estão presentes [10]. A força motriz resultante é um somatório da contribuição de cada modo de carregamento que por sua vez depende da orientação do defeito no campo de tensões, e a falha se propaga na direção de maior relação entre força motriz e resistência à fratura. No entanto, isto não explica o aumento nas forças motrizes de um defeito circunferencial observado em um duto sujeito a pressão interna e carregamentos longitudinais uma vez que a orientação do defeito é perpendicular às tensões longitudinais e, conseqüentemente, a influência das tensões circunferenciais em qualquer modo de propagação é nula.

\subsubsection{Efeito da pressão interna no comportamento à fratura do duto}

O efeito da pressão interna não é muito explorado no apêndice A da OS-F101 [5]. A norma cita que resultados de pesquisas recentes demonstraram que a combinação de sobrepressão interna positiva e carregamentos longitudinais podem ser mais onerosos para o duto do que a carga longitudinal sozinha. A norma adverte que atualmente não há nenhum procedimento validado e amplamente aceito para avaliar esse cenário de carregamento combinado e cada caso deve ser avaliado separadamente. Por fim, a norma cita que tais pesquisas indicam que a redução da capacidade de deformação do duto é causada pelo aumento na força motriz da trinca, mas que a tenacidade à fratura do material não é influenciada.

Acredita-se que esta preocupação é oriunda de estudos numéricos e experimentais que indicam um aumento da força motriz causado pela pressão interna em função da deformação aplicada, o que não seria captado nos modernos procedimentos baseados em deformação descritos na norma. Øtsby e Hellesvik [8] realizaram uma investigação experimental do efeito de carregamentos biaxiais na capacidade de deformação de dutos com defeitos utilizando testes em escala real (Figura 1). Os autores adotaram o parâmetro CTOD, do inglês Crack Tip Opening Displacement, pela facilidade de obtenção experimental, sendo este parâmetro totalmente compatível e proporcional com a Integral J [11]. 
Analisando os resultados, os autores concluíram que a capacidade de deformação longitudinal dos tubos foi significantemente reduzida com a aplicação da pressão interna quando comparado com um caso sem pressão interna (Figura 21). No entanto, a resistência à fratura do material não aparentou ser significantemente influenciada, sendo que o principal efeito observado foi atribuído ao aumento da força motriz em função da deformação aplicada, quando comparado com os casos sem pressão interna (testes 2 e 5 ).

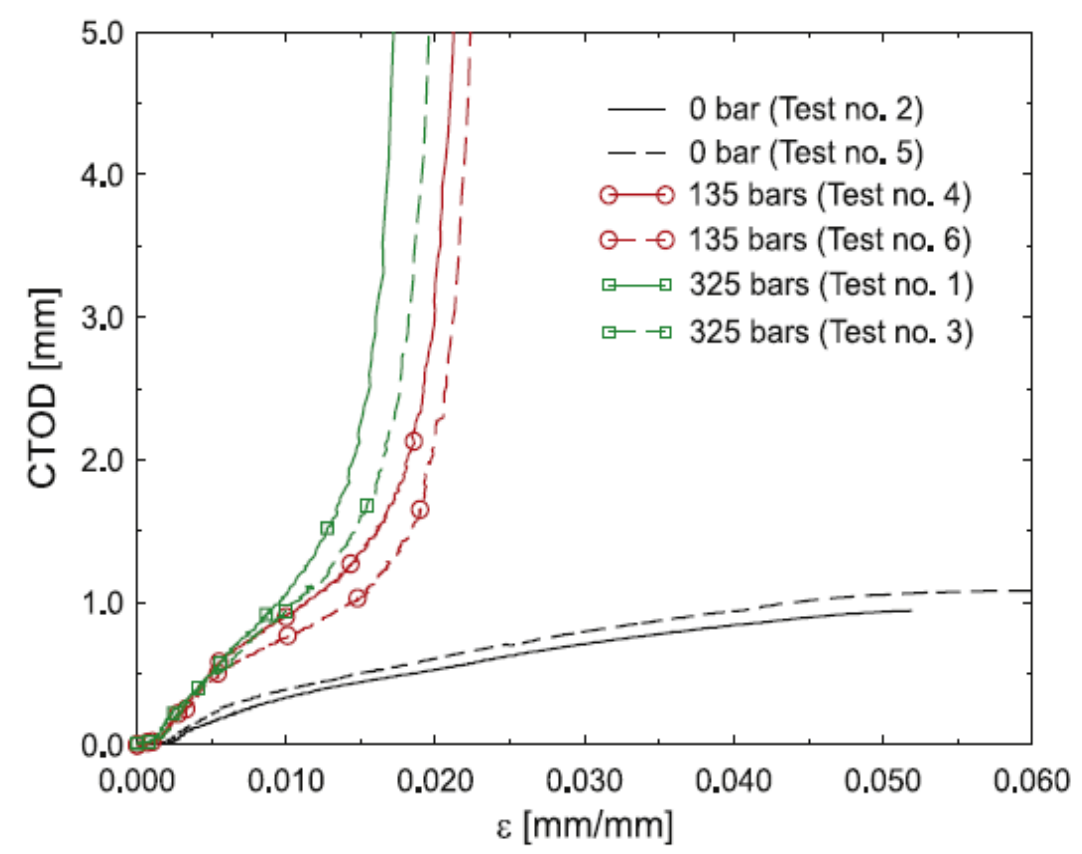

Figura 21 - Resultados dos ensaios experimentais realizados por Østby et al. [8].

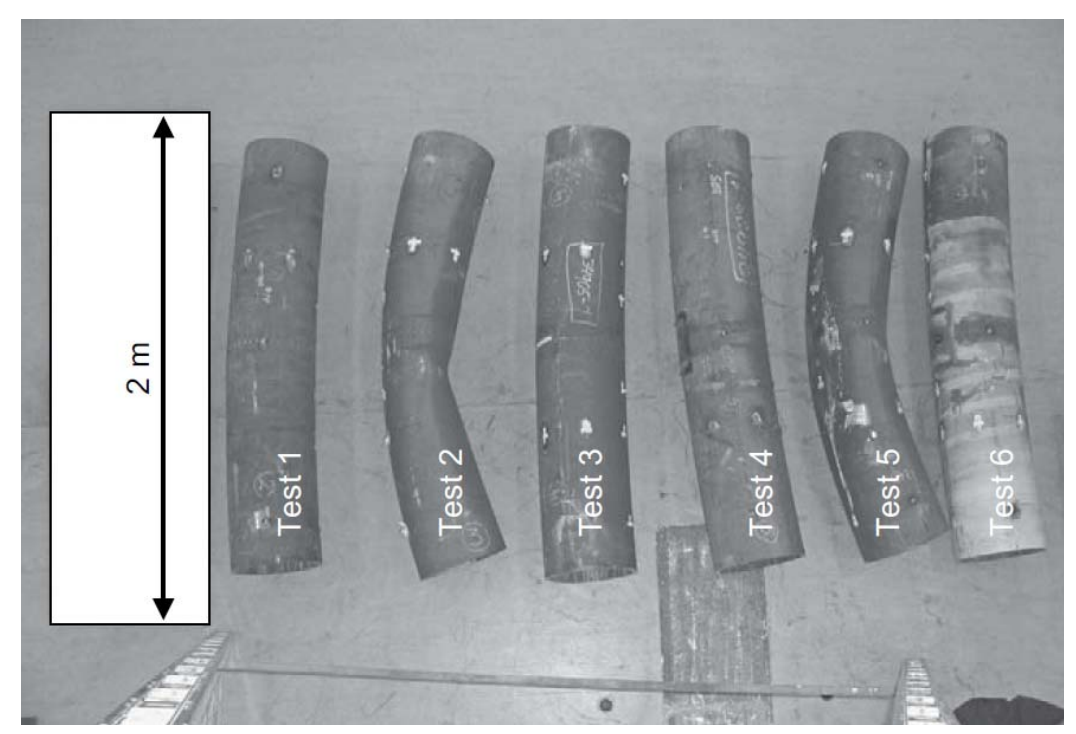

Figura 22 - Fotos dos corpos de prova após falha dos ensaios experimentais realizados por Østby et al. [8]. 
Analisando a Figura 22, percebe-se nitidamente o colapso da seção transversal do duto nos testes 2 e 5 indicando que o estado limite que governou a falha na ausência de pressão interna foi a flambagem localizada da seção transversal. $\mathrm{Na}$ aplicação da pressão interna, o modo de falha por fratura dúctil passou a governar. Por fim, Øtsby e Hellesvik [8] recomendam que o efeito da pressão seja levado em conta explicitamente na avaliação da fratura em tubos sujeitos a estes carregamentos combinados quando sujeitos a grandes deformações.

Øtsby et al. [44] observaram por meio de estudos numéricos que a força motriz aumenta proporcionalmente a tensão circunferencial aplicada até que esta atinja a metade do limite de escoamento do material. Acima deste valor, a força motriz da trinca parece estabilizar com o aumento do nível de sobrepressão interna. A Figura 23 ilustra o disposto acima para um caso genérico.

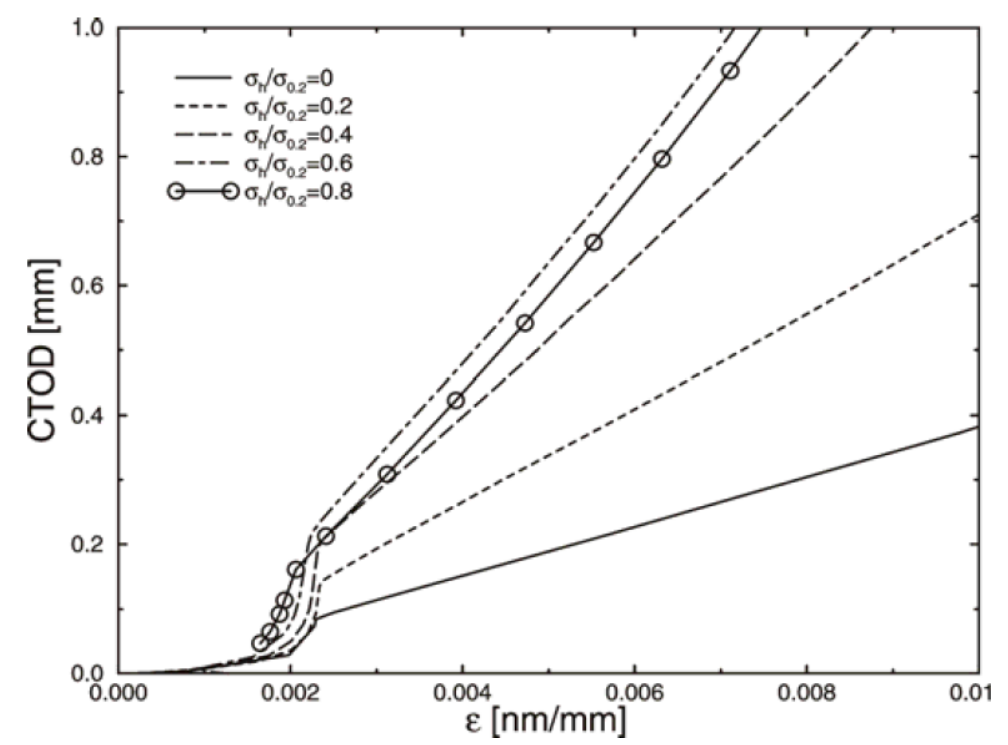

Figura 23 - Efeito da sobrepressão interna positiva na força motriz elasto-plástica [44].

Øtsby et al. [44] atribuíram o aumento da força motriz ao aumento da tensão longitudinal necessária para escoar o material em casos onde a sobrepressão interna é positiva, ou seja a tensão na direção circunferencial irá dificultar o escoamento conforme o critério de escoamento de von Mises. Portanto, a tensão longitudinal para um determinado nível de deformação será maior na presença de sobrepressão interna positiva. Essa relação pode ser deduzida da equação da tensão equivalente de von Mises $\left(\sigma_{e q}\right)$ em um material elástico perfeitamente plástico sujeito a um estado biaxial de tensões (considerando tensão radial nula) como: 
$\sigma_{e q}=\sqrt{\sigma_{L}^{2}+\sigma_{C}^{2}-\sigma_{L} \cdot \sigma_{C}}$

Isolando as variáveis:

${\sigma_{L}^{2}}^{2}-\sigma_{L} \cdot \sigma_{C}+{\sigma_{C}}^{2}-{\sigma_{e q}}^{2}=0$

Resolvendo a equação de segundo grau e substituindo a tensão equivalente pela tensão longitudinal uniaxial obtida a partir do nível de deformação aplicada e da curva tensão deformação uniaxial do material ${ }^{9}\left(\sigma_{L-u}\right)$, no caso de um material elástico perfeitamente plástico, a tensão longitudinal atuante em função do nível de tensão circunferencial por ser expressa como:

$$
\sigma_{L-b}=\frac{\sigma_{C}}{2}+\sqrt{\sigma_{L-u}^{2}-\frac{3}{4} \cdot \sigma_{C}^{2}}
$$

Onde $\sigma_{L-b}$ é a tensão longitudinal corrigida para computar o efeito da tensão circunferencial no comportamento a deformação do duto. No entanto isso não explica o efeito de saturação observado na Figura 23 para tensões circunferenciais acima de $50 \%$ do escoamento, pois contradiz o previsto pela equação 3.27 uma vez que ela prevê a diminuição da tensão longitudinal acima deste valor. Øtsby [44] cita que uma possível explicação seria que com o aumento tensão axial devido ao encruamento do material na direção longitudinal, e conseqüentemente, a redução da razão de biaxialidade uma vez que as tensões circunferenciais são constantes (Figura 24). Essa relação parece depender fortemente do expoente de encruamento do material, representado pela letra " $n$ " no modelo de Ramberg-Osgood.

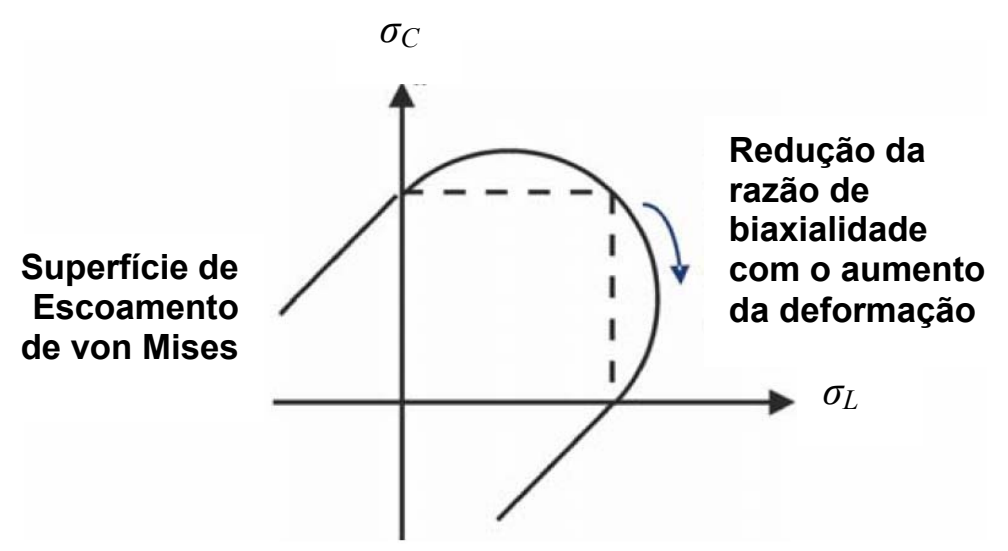

Figura 24 - Redução da razão de biaxialidade em função do aumento da deformação [44].

\footnotetext{
${ }^{9}$ No caso de um material elástico perfeitamente plástico, $\sigma_{L-u}$ equivale a tensão de escoamento $\sigma_{e}$.
} 
Diversos autores optaram por uma abordagem alternativa cada vez mais utilizada que são as investigações numéricas por meio de análises de elementos finitos que incorporam modelos micromecânicos para avaliação do efeito da pressão interna no comportamento à fratura em materiais dúcteis. Maiores detalhes sobre tais análises podem ser encontrados em Ruggieri et al. [45]. Dentre estes autores podemos citar Tyson e Shen. [46,47], Bravo, Ernst e Cravero [48], Taheri e Noupanah [49], bem como Øtsby et al. [50].

Tyson e Shen [46] desenvolveram um método analítico para computar o efeito da tensão biaxial na força motriz em um material elasto-plástico descrito pelo modelo de Ramberg-Osgood (equação 2.13) utilizando a metodologia EPRI discutida no capítulo 2.2.1. Sob carregamentos uniaxiais, a relação entre tensão e deformação do modelo de Ramberg-Osgood pode ser reescrita como:

$$
\varepsilon_{L}=\varepsilon_{e}+\varepsilon_{p}=\frac{\sigma_{L}}{E}+\alpha \varepsilon_{0}\left(\frac{\sigma_{L}}{\sigma_{0}}\right)^{n}
$$

Entretanto, em um estado multiaxial a equação acima não é válida. Os autores então propuseram uma maneira simples de descrever a relação entre tensão e deformação ajustando a tensão normalizadora $\left(\sigma_{0}\right)$ no modelo de Ramberg-Osgood por meio de análises não lineares de elementos finitos que incorporem o efeito da plasticidade, i.e. teoria da deformação. Descontando a parcela de deformação devido ao efeito Poisson, a relação entre tensão e deformação em um estado biaxial de tensões pode ser escrita como:

$$
\varepsilon_{L}=\varepsilon_{e}+\varepsilon_{p}=\frac{\sigma_{L}}{E}-v \frac{\sigma_{C}}{E}+\alpha \varepsilon_{0}\left(\frac{\sigma_{L}}{\sigma_{0}^{\prime}}\right)^{n}
$$

onde a tensão normalizadora modificada $\sigma_{0}$ ' é função do expoente de encruamento do material e da tensão circunferencial aplicado. A Figura 25 apresenta valores de $\sigma_{0}$ ' para quatro materiais diferentes e níveis de sobrepressão interna que aderem bem a resultados de análises de elementos finitos [46]. Para níveis de sobrepressão interna maior que 0,5 e valores de $n$ menores ou igual a 20 , observa-se que não há redução da tensão normalizadora, o que equivale ao efeito de saturação constatado anteriormente na Figura 23. 


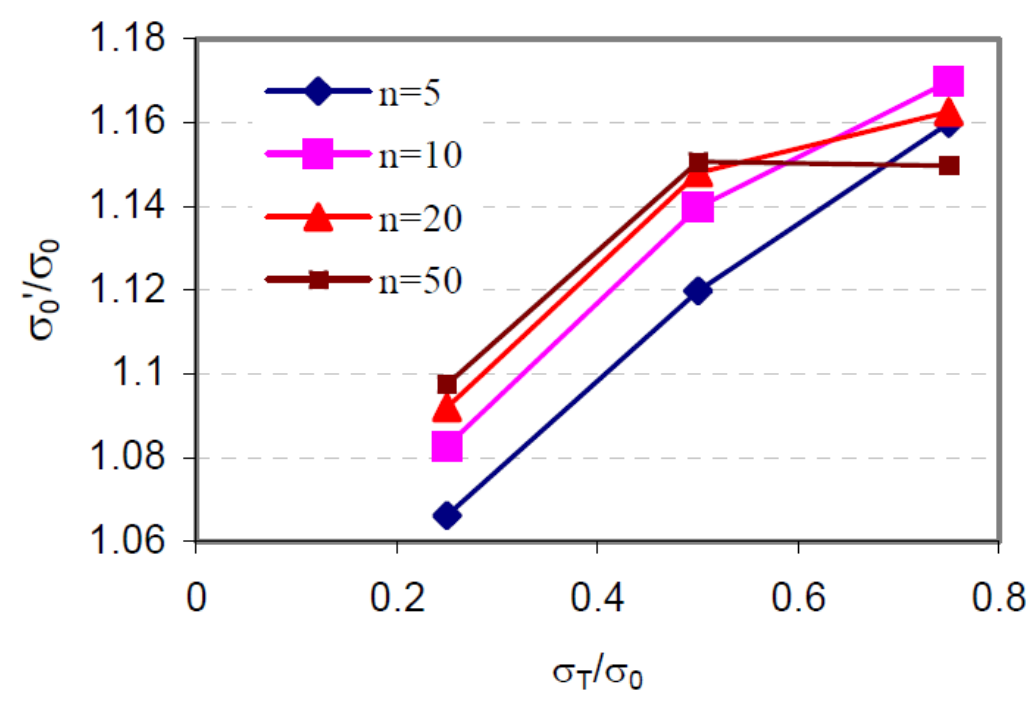

Figura 25 - Relação da tensão normalizadora modificada $\left(\sigma_{0}{ }^{\prime}\right)$ com a tensão circunferencial normalizada.

Assumindo que a tensão normalizadora $\sigma_{0}$ é igual à tensão de escoamento $\sigma_{e}$, observa-se que para um material com expoente de encruamento elevado $(n=50)$, isto é, um material que se aproxima de um comportamento elástico perfeitamente plástico, o valor da tensão normalizadora modificada $\sigma_{0}$ ' assume o valor de $\sigma_{L-b}$ na equação 3.27 quando $\sigma_{L-u}$ é igual a tensão de escoamento do material.

Tyson e Shen utilizaram o modelo descrito acima para expressar a força motriz em um tubo sujeito a pressão interna e tração em função da deformação longitudinal aplicada utilizando um trabalho anterior de Kumar [20] como base para calibração de novos fatores $h_{1}$ para a metodologia EPRI (Tabela 2), específico este caso, que diferem da solução original de Kumar [20] sem pressão interna.

$$
J_{p}=\alpha \varepsilon_{0} \sigma_{0}(t-a)\left(\frac{a}{t}\right) h\left(\frac{\sigma_{L}}{\sigma_{0^{\prime}}}\right)^{n+1}
$$

com:

$$
h=\left[\frac{\left(R_{e}^{2}-R_{i}^{2}\right) \sqrt{3}}{2\left(R_{e}^{2}-\left(R_{i}+a\right)^{2}\right)}\right]^{n+1}\left(\frac{\sigma_{0}^{\prime}}{\sigma_{0}}\right)^{n+1} h_{1}
$$

Tabela 2 - Valores de $h 1$ para cada nível de sobrepressão interna $(X)$

\begin{tabular}{l|llll}
\hline $\mathrm{X}$ & 0 & 0,25 & 0,5 & 0,75 \\
\hline$h_{1}$ & 2,86 (Kumar) & 2,36 & 2,28 & 2,28 \\
\hline
\end{tabular}


Isolando a parcela plástica da equação 3.30 tem-se:

$$
\frac{\sigma_{L}}{\sigma_{0}{ }^{\prime}}=(\alpha)^{-1 / n}\left(\frac{\varepsilon_{p}}{\varepsilon_{0}}\right)^{1 / n}
$$

Por fim, substituindo a parcela plástica da equação 3.30 em 3.31 tem-se:

$$
J_{p}=\alpha^{-1 / n} \varepsilon_{0} \sigma_{0}(t-a)\left(\frac{a}{t}\right) h\left(\frac{\varepsilon_{p}}{\varepsilon_{0}}\right)^{n+1 / n}
$$

O método foi validado através de análises de elementos finitos para um tubo de parede fina sujeito a carregamento longitudinal e pressão interna $(a / t=0,5, t / R i=20$, $n=10, X=0,25 / 0,50 / 0,75)$ apresentado na Figura 26. No entanto, a falta de compêndio de fatores $h_{1}$ que considerem o efeito da pressão interna para uma maior extensão de casos limita sua utilização em casos reais.

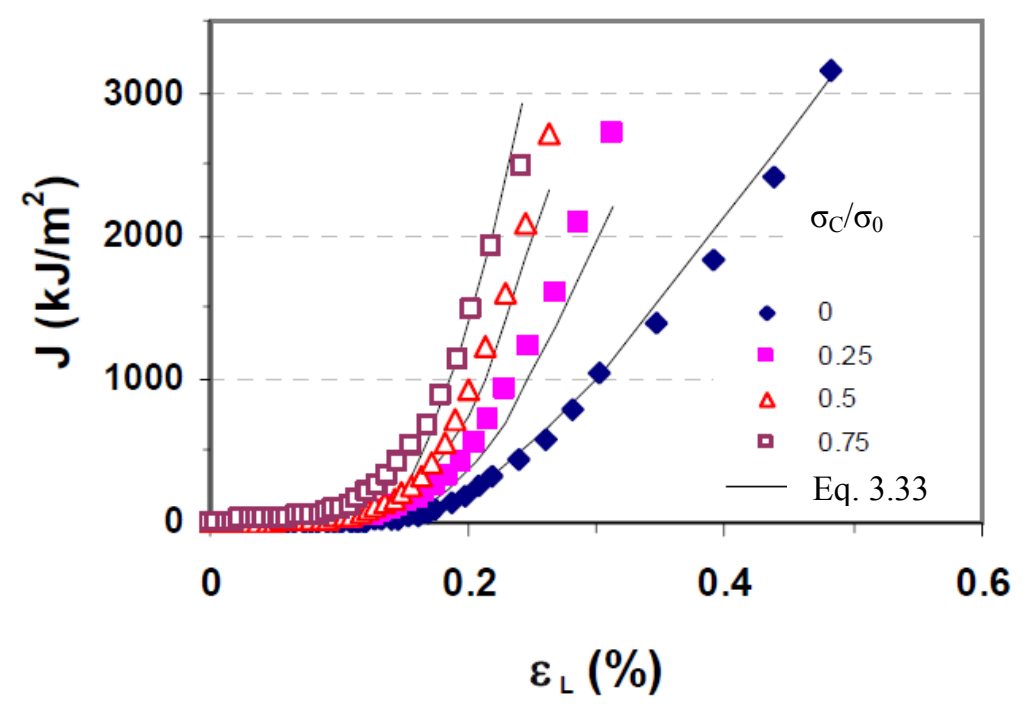

Figura 26 - Comparação da equação 3.33 com resultados de análises de elementos finitos [46].

Por meio da análise das equações 3.30 e 3.33 em conjunto com a Tabela 2 observa-se que a pressão interna, ou mais precisamente, a tensão circunferencial proporciona efeitos distintos na força motriz dependendo da abordagem que é feita: enquanto na abordagem baseada em deformações percebe-se uma forte influência na força motriz (Figura 23 e Figura 26) para um dado nível de deformação longitudinal, o mesmo não é observado na abordagem baseada em tensões onde o efeito é menos pronunciado. 
Em um trabalho posterior, Tyson e Shen [47] demonstraram por meio de análise de elementos finitos que incorporam modelos micromecânicos de nucleação e propagação de trincas que o efeito de uma tensão biaxial paralela ao plano da trinca na resistência à fratura do material pode ser negligenciado (Figura 27). Bravo, Ernst e Cravero [48], Taheri e Noupanah [49] e Øtsby et al. [50], chegaram às mesmas conclusões em estudos similares.

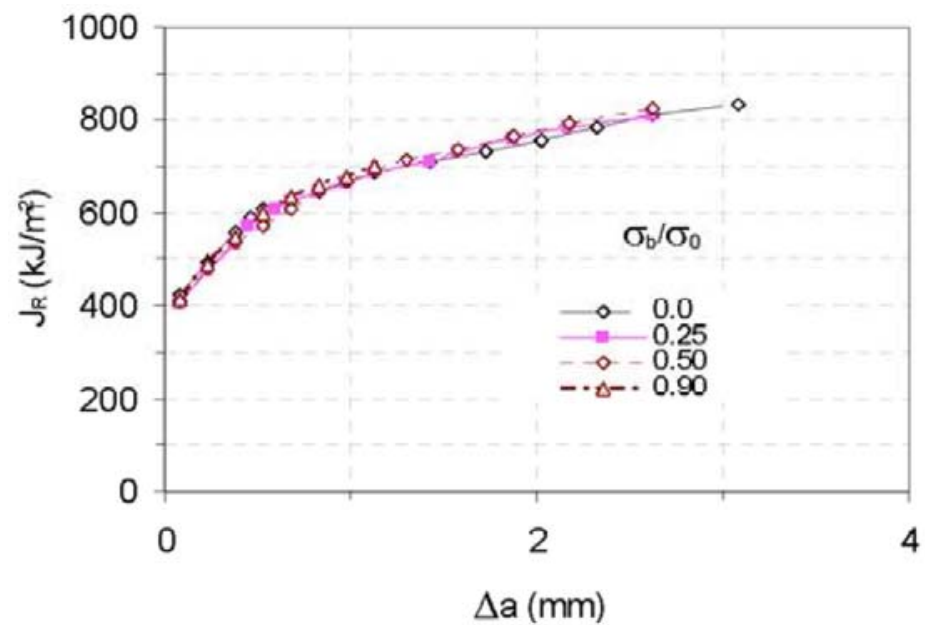

Figura 27 - Efeito da tensão biaxial na curva de resistência a fratura de um material.

Por fim, Parise e Ruggieri [23] apresentaram resultados preliminares de análises numéricas para caracterização das forças motrizes elasto-plásticas de um defeito superficial sujeito a pressão interna e flexão em função de um momento aplicado. Os resultados indicam que o efeito da pressão interna na força motriz não aparenta ser tão pronunciado quando expresso em função do momento aplicado, sendo que as maiores diferenças observadas são atribuídas à contribuição da pressão interna na tensão longitudinal (Figura 28b).

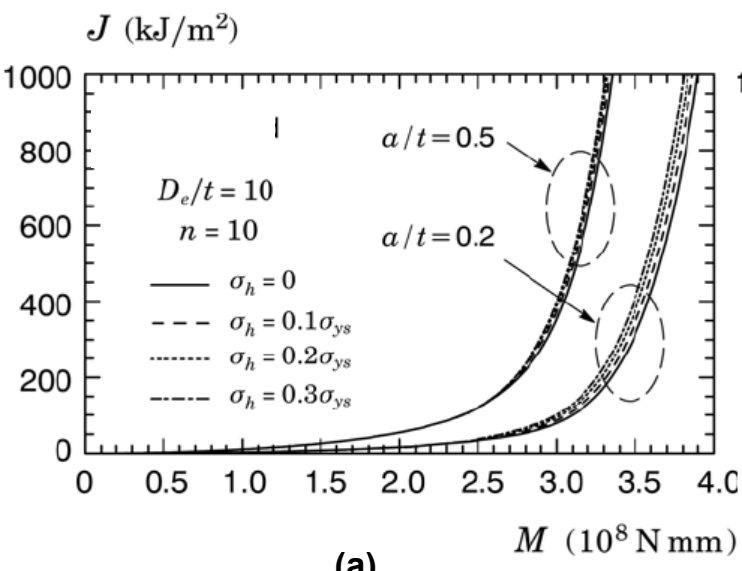

(a)

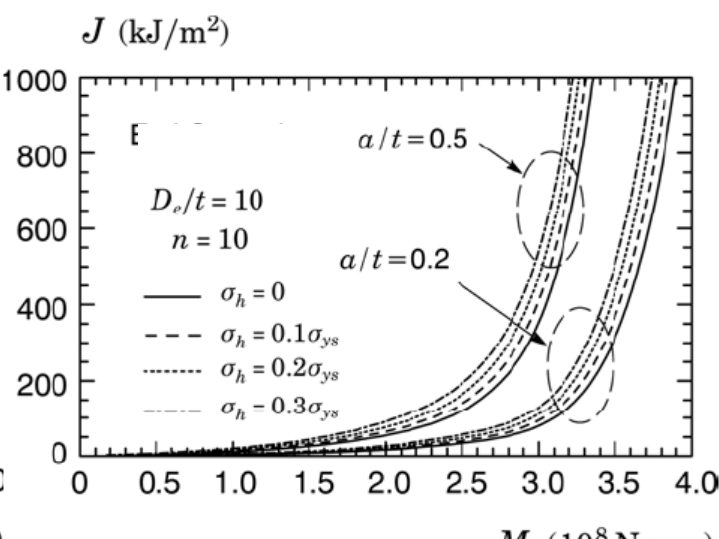

(b)

Figura 28 - Efeito da pressão interna na força motriz em função do momento aplicado: a) com extremidades abertas, b) com extremidades fechadas. 


\subsubsection{Procedimento padrão da OS-F101 e procedimentos alternativos}

A norma OS-F101 [5] permite a utilização do procedimento baseado em deformações descrito anteriormente na avaliação de dutos sujeitos a esforços combinados quando a deformação longitudinal nominal for igual ou inferior $0,4 \%$. No entanto a tenacidade à fratura deve ser obtida por corpos de prova tipo SENB maior triaxialidade - como um modo para compensar a subestimação da força motriz. Para deformações maiores, a OS-F101 [5] permite a utilização direta dos valores de tenacidade à fratura obtidos por corpos de prova tipo SENT desde que sejam realizadas análises dedicadas de elementos finitos, ou desde que sua utilização seja comprovada segura através de pesquisas bem documentadas.

Observe que esta abordagem vai contra o que foi discutido até o momento: um procedimento baseado em deformações que não leva em consideração o efeito da pressão interna na força motriz, mas que reduz a tenacidade à fratura do material, que não é afetada pelas tensões biaxiais, adotando corpos de prova com maior triaxialidade. Olsø et al. [51] questionaram se esta prática era realmente conservadora, comparando os resultados obtidos pelo procedimento da DNV com resultados baseados em análises de elementos finitos para um caso onde a tenacidade à fratura obtida por SENT é $60 \%$ maior que aquela obtida pelo SENB e o material apresentava um patamar de escoamento bem definido (Figura 29).

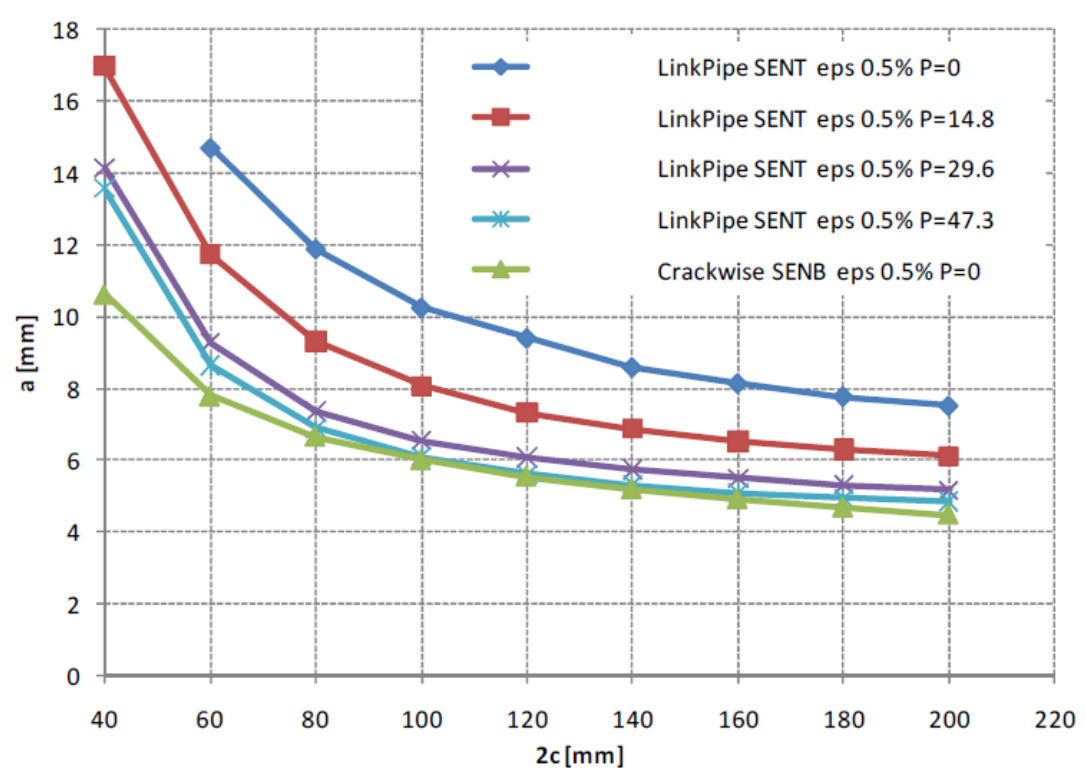

Figura 29 - Envelope crítico de defeitos para deformação longitudinal de 0,5\% e níveis de sobrepressão interna $(X)$ de $0,25 \%(P=14,8), 50 \%(P=29,6)$ e $80 \%(P=47,3)$ de $\sigma_{e}$ 
Para deformações até $0,5 \%$, os autores chegaram à conclusão que o procedimento da DNS parecia ser conservador. No entanto, acima deste valor de deformação longitudinal os resultados indicaram que não considerar a pressão interna na avaliação pode levar a situações inseguras. Essa abordagem simplificada de desconsiderar a pressão interna na análise e utilizar valores conservadores de tenacidade à fratura obtida de corpos de prova tipo SENB pode ser adequada em muitos casos, mas é possível que uma combinação de situações e diferentes propriedades de materiais possa levar a cenários inseguros ou, o que é mais provável, possa resultar em cenários onde o nível de conservadorismo da análise é totalmente desconhecido.

No caso especial de dutos submersos sujeitos a flambagem lateral controlada, é comum se obter a tensão aplicada diretamente de um modelo de elementos finitos ao invés de fazê-lo por meio da deformação longitudinal nominal em conjunto com a curva tensão-deformação do material conforme apresentado no item 3.2.2. Nesse caso, os modelos incorporam o efeito da pressão interna na deformação do material e conseqüentemente na resposta momento-curvatura do duto de acordo com uma superfície de escoamento adotada, e.g. Von Mises.

O critério de escoamento de Von Mises prevê que a tensão longitudinal pode ser superior a tensão de escoamento uniaxial do material na presença de tensões circunferenciais. Para manter a consistência com o procedimento da DNV-OS-F101 [5] e se beneficiar do aumento do limite de escoamento longitudinal na razão de colapso plástico da abordagem FAD $\left(L_{r}\right)$, o guia Safebuck [31] propõe a correção da tensão de escoamento na direção longitudinal em função da tensão circunferencial conforme discutido no item 3.3.1. Para uma dada tensão circunferencial $\left(\sigma_{c}\right)$, a tensão de escoamento uniaxial do material $\left(\sigma_{e}\right)$ pode ser corrigida como:

$$
\sigma_{e-b}=\frac{\sigma_{C}}{2}+\sqrt{\sigma_{e}^{2}-\frac{3}{4} \cdot \sigma_{C}^{2}}
$$

Onde $\sigma_{e-b}$ é a tensão longitudinal corrigida pela tensão circunferencial aplicada. Para manter a consistência da análise, a curva-tensão deformação e o valor da 
tensão de escoamento também deveriam ser corrigidos pela equação $3.34^{10}$. Observe que a correção da curva tensão-deformação do material não modifica a curva FAD uma vez que ela é influenciada apenas pelo comportamento elastoplástico do material. A Figura 30 apresenta a curva FAD obtida por duas curvas tensão-deformação com diferentes patamares de escoamento e mesmo comportamento elásto-plástico (fator de encruamento):

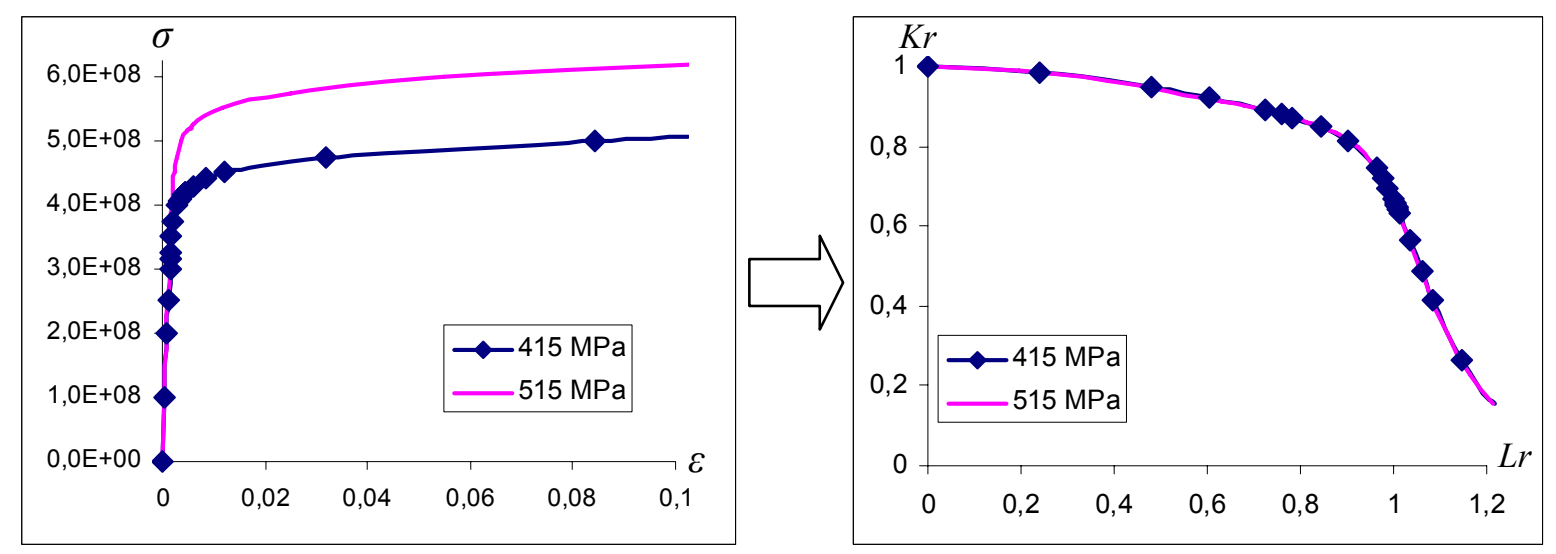

Figura 30 - Efeito da correção da curva tensão-deformação (Ramberg-Osgood a1 n20) na curva FAD.

Se por sua vez, a obtenção da tensão de membrana direto do modelo de elementos finitos resulta em um valor maior de $P_{m}$, e conseqüentemente $K_{I}$ e $\sigma_{r e f}$ maiores, o aumento da tensão de escoamento conforme a equação 3.34 leva a uma redução da razão de colapso plástico $L_{r}$ e, conseqüentemente, da força motriz elasto-plástica (equações 2.28, 2.29 e 3.19). Isto é contraditório com o efeito da pressão interna discutido no item 3.3.1, e, portanto este procedimento deve ser visto com cautela.

No entanto, tanto a DNV-OS-F101 [5] quanto o procedimento descrito no guia Safebuck [31] condiciona a utilização de SENT ou a extensão do limite de $0,4 \%$ à validação do procedimento por meio da comparação com análises de elementos finitos da força motriz para a configuração de interesse ou pesquisas bem documentadas e validadas. O guia Safebuck [31] ainda sugere que o ideal nesta situação seria análise $F A D$ nível $3 C$, isto é, análises utilizando a curva FAD baseada em J conforme o procedimento da BS-7910 [1].

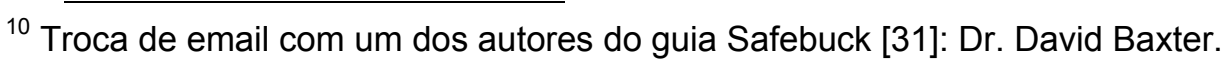




\section{ESTUDO DE CASO: ECA}

O procedimento ECA baseado em deformações apresentado na edição de 2007 da DNV-OS-F101 adota valores de tenacidade à fratura conservadores, e.g. SENB, para compensar os efeitos da pressão interna na força motriz, porém como demonstrado até agora, esta consideração pode ser potencialmente insegura, e é limitada pela norma para deformações longitudinais de até $0,4 \%$. Acima deste valor, a norma permite a utilização direta dos valores de tenacidade à fratura obtidos por corpos de prova tipo SENT desde que sejam realizadas análises dedicadas de elementos finitos, ou desde que sua utilização seja comprovadamente segura por meio de pesquisas bem documentadas.

Como foi apresentada nos capítulos anteriores, uma maneira de fazer isto é por meio de análises de elementos finitos de estruturas trincadas. No entanto, tais análises podem se tornar extremamente custosas uma vez que diversos cenários são avaliados e a obtenção do envelope crítico de defeitos pode requerer um grande número interações. Procedimentos analíticos relativamente simples foram descritos no capítulo anterior, que serão utilizados e modificados para posterior comparação dos resultados em termos de tamanho crítico de defeitos no fim de vida. A Figura 31 apresenta a estrutura adotada neste estudo de caso:

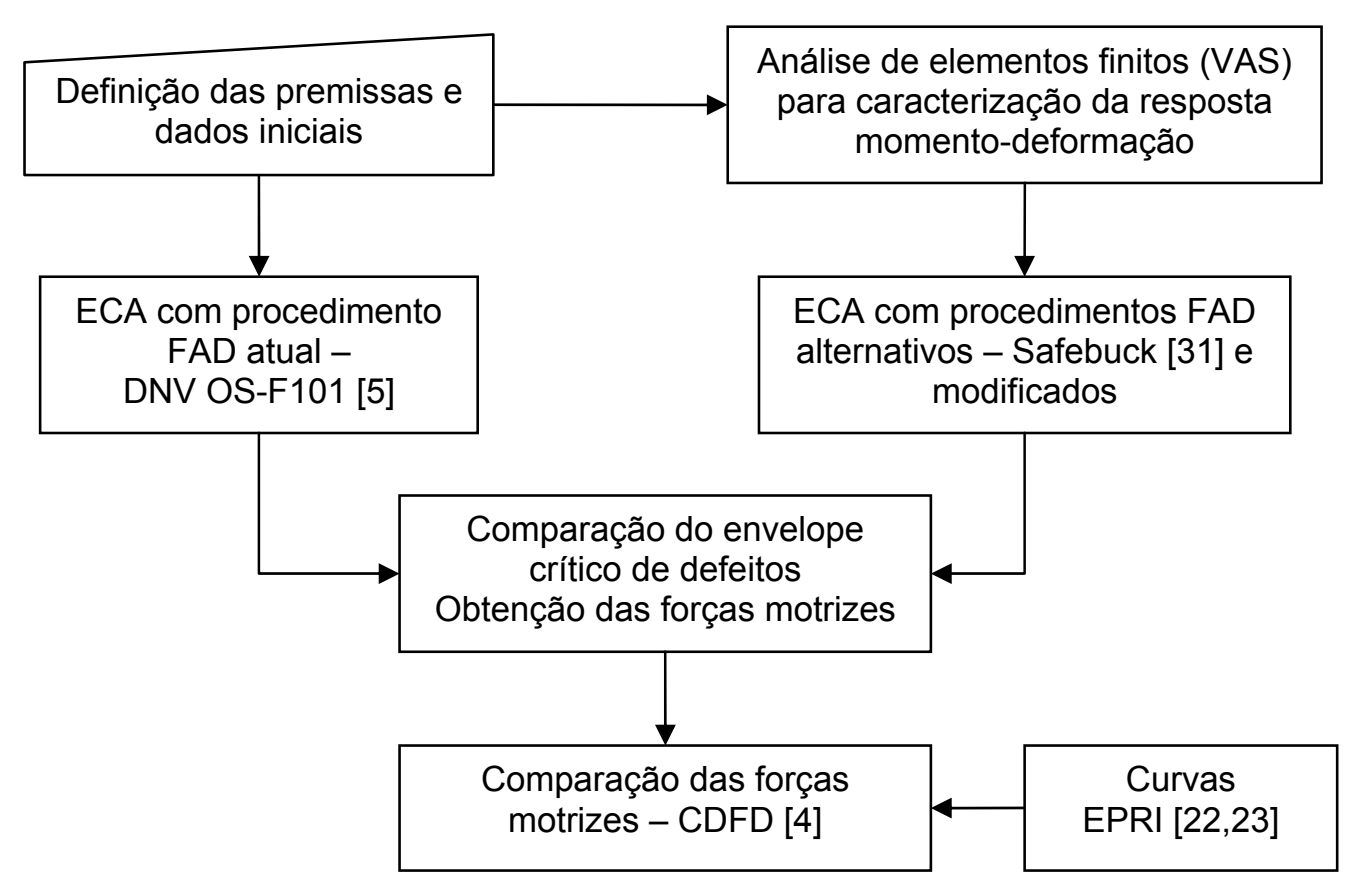

Figura 31 - Estrutura adotada para o estudo de caso. 
O objetivo é explorar as vantagens, desvantagens e limitações de cada procedimento, bem como avaliar a possibilidade de utilização além do limite convencional. Para validação das modificações implementadas no procedimento original da DNV-OS-F101 [5], serão utilizadas soluções analíticas de força-motriz elasto-plásticas tais como as desenvolvidas pela metodologia EPRI para dutos sujeitos à flexão de Chiodo e Ruggieri [22] e, à combinação de flexão e pressão interna de Parise e Ruggieri [23] por meio da abordagem CDFD [4].

Para realizar essa tarefa, lançou-se mão de análises de elementos finitos (VAS) discutida no capítulo 3.1 para caracterizar a resposta tensão-deformação no duto. Tais análises têm por objetivo simular o comportamento de duto no solo e incorporam as diversas não linearidade presentes. Nos próximos capítulos apenas os resultados dessas análises serão referenciados uma vez que o objetivo principal é a comparação dos procedimentos de ECA. No entanto, os detalhes de tais análises podem ser encontrados no Anexo A deste documento.

\subsection{PREMISSAS E DADOS INICIAIS}

O problema foi postulado de maneira consistente com as diretrizes e configurações típicas de dutos submersos de alta pressão e alta temperatura para definição do material, diâmetro e espessura. Isso significa considerar a utilização de tubos de aço carbono manganês com 415 450 MPa (60 65 ksi) de limite de escoamento, com diâmetros variando entre 10 e 24 ", espessura variando entre $3 / 4 \mathrm{e}$ $11 / 2$ de polegada, e níveis de sobrepressão interna menores que $5 \mathrm{ksi}$ para oleodutos e $10 \mathrm{ksi}$ para risers. Abaixo são apresentadas as premissas adotadas para definição dos dados iniciais da análise.

\subsubsection{Propriedades mecânicas do material}

Os materiais considerados na análise foram tubos de aço carbono que atendem as especificações DNV-OS-F101 [5] com limite de escoamento de 415 e $450 \mathrm{MPa}$. Abaixo são apresentadas as propriedades mínimas especificadas desses aços consideradas na análise (Tabela 3). Conforme discutido no capítulo 3.1.1, os tubos devem fornecidos com requisito suplementar $P$ sempre que a deformação 
longitudinal nominal for superior a $1 \%$ ou a deformação plástica acumulada for maior que $2 \%$. Nesse caso, a diferença entre tensão de escoamento máxima e mínima real dos tubos não deve exceder $100 \mathrm{MPa}$ e a razão entre tensão de escoamento e ruptura não deve exceder $90 \%$.

\begin{tabular}{c|ccccc} 
Tabela 3 - Tensão de escoamento e ruptura dos materiais adotados na análise \\
\hline \multirow{2}{*}{ Material } & \multicolumn{4}{|c}{ Escoamento } & \multicolumn{2}{c}{ Ruptura } & Razão \\
\cline { 2 - 6 } & $\min$ & $\max$ & $\min$ & $\max$ & $\max$ \\
$415 \mathrm{MPa}$ & 415 & 565 & 520 & 760 & 0,90 \\
$450 \mathrm{MPa}$ & 450 & 570 & 535 & 760 & 0,90 \\
\hline
\end{tabular}

Como o objetivo é obter deformações elevadas nas alças de flambagem, optouse por adotar o material de menor resistência ao escoamento, ou seja, o material com escoamento de $415 \mathrm{MPa}$. A curva tensão deformação desse material foi levantada a partir do modelo de Ramberg-Osgood (equação 3.28) onde a tensão de escoamento é a tensão normalizadora $\left(\sigma_{0}\right)$. Dois expoentes de encruamento foram considerados nas análises: $n=10$ e $n=20$, o que corresponde a um material com médio e baixo nível de encruamento, respectivamente. A constante $\alpha$ assumiu valor unitário por simplificação $(\alpha=1)$. As curvas adotadas são apresentadas Figura 32.

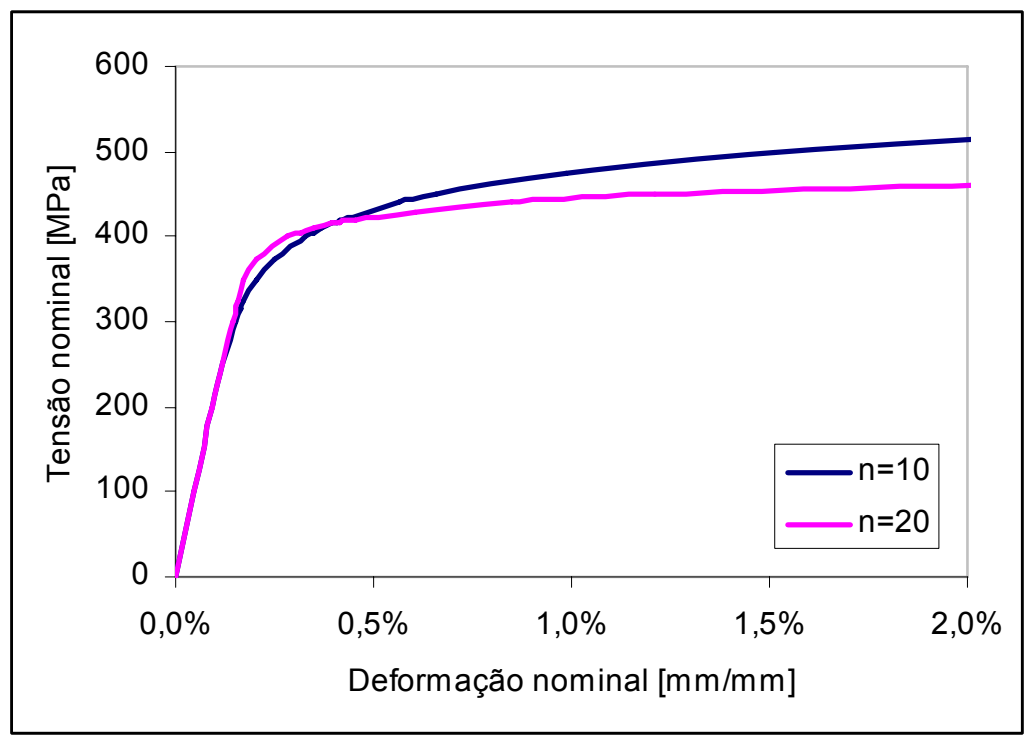

Figura 32 - Curvas tensão-deformação de material Ramberg-Osgood $415 \mathrm{MPa}$ e $\alpha=1$

11 Sempre que o requisito suplementar $P$ é mandatório, a diferença entre o limite de escoamento mínimo e máximo dos tubos não deve exceder $100 \mathrm{MPa}$. 
Os valores de módulo de elasticidade $(E)$ e coeficiente de Poisson (v), e dos coeficientes de expansão térmica ( $\left.\alpha^{\prime}\right)$ adotados são apresentados na Tabela 4. Observa-se que foi considerada a variação do coeficiente de expansão térmica com a temperatura uma vez que este somente será utilizado nas análises de elementos finitos descritas no Anexo A.

Tabela 4 - Módulo de elasticidade $(E)$, Poisson $(v)$ e Coeficiente de Expansão Térmica $\left(\alpha^{\prime}\right)$
\begin{tabular}{ccccc}
$E(\mathrm{GPa})$ & $\boldsymbol{v}$ & $\alpha^{\prime}\left({ }^{\circ} \mathrm{C}^{-1}\right)$ a $0^{\circ} \mathrm{C}$ & $\boldsymbol{\alpha}^{\prime}\left({ }^{\circ} \mathrm{C}^{-1}\right)$ a $200^{\circ} \mathrm{C}$ \\
\hline 210 & 0,3 & $11,0 \mathrm{E}-6$ & $12,6 \mathrm{E}-6$
\end{tabular}

É conhecido que a temperatura promove uma redução no limite de escoamento, limite de ruptura e módulo de elasticidade do material, o que conseqüentemente, levaria a uma maior deformação nas alças de flambagem. No entanto, a degradação das propriedades do material devido à temperatura não será considerada neste estudo uma vez que, por simplificação e para manter a consistência nos resultados, os procedimentos de ECA serão comparados a uma mesma temperatura.

\subsubsection{Diâmetro, espessura e nível de sobrepressão interna}

A relação $D / t$ foi escolhida de forma a proporcionar uma deformação da ordem de $1,5 \%$ na alça de flambagem sem que o estado limite de flambagem localizada fosse excedido. Os casos para D/t igual a 10 e 15, com diâmetros nominais de 12 e 10 polegadas respectivamente, foram escolhidos, pois representam um oleoduto de ATAP e um riser rígido, respectivamente, e são apresentados abaixo:

\begin{tabular}{|c|c|c|}
\hline $\mathrm{D} / \mathrm{t}$ & $\overline{\mathrm{D}}$ & $\mathrm{t}$ \\
\hline 15 & $12,75^{\prime \prime}$ & $21,6 \mathrm{~mm}$ \\
\hline 10 & $10,75 "$ & $27,3 \mathrm{~mm}$ \\
\hline
\end{tabular}

Considerando um tubo com requisito suplementar $\mathrm{P}$ e classe de segurança média, utilizam-se as equações 3.2 e 3.3 para definição do limite de deformação longitudinal nominal em compressão para evitar a flambagem localizada no caso de sobrepressão interna nula, considerado mais crítico. Observa-se na Tabela 6 que o 
limite de deformação longitudinal nominal é maior que 1,5\% para os casos analisados.

Tabela 6 - Limites de deformação longitudinal nominal

\begin{tabular}{c|cc}
\hline YS/UTS & D/t 10 & $D / t 15$ \\
\hline 0,9 & $3,29 \%$ & $2,07 \%$ \\
\hline
\end{tabular}

Quatro níveis de sobrepressão interna $(X)$ foram avaliados: 0\%, 10\%, 20\% e 30\% do escoamento do material. Para manter a consistência com o projeto, a pressão interna não deve exceder a $34,5 \mathrm{MPa}$ (5 ksi) para o diâmetro de 12" (oleoduto) e a $69 \mathrm{MPa}(10 \mathrm{ksi})$ para o diâmetro de 10" (riser), uma vez que não é comum a utilização de classes de pressão superiores em sistemas de dutos submersos. A Tabela 7 apresenta as propriedades utilizadas:

Tabela 7 - Parâmetros adotados no cálculo da pressão de operação

\begin{tabular}{ccc}
\hline Propriedade / Parâmetro & Símbolo & Valor adotado \\
\hline Massa específica da água do mar & $\rho_{\text {água }}$ & $1025 \mathrm{~kg} / \mathrm{m}^{3}$ \\
Massa específica do fluído & $\rho_{\text {fluído }}$ & $894 \mathrm{~kg} / \mathrm{m}^{3}$ \\
Gravidade & $g$ & $9,806 \mathrm{~m} / \mathrm{s}^{2}$ \\
Lâmina d'água & $L D A$ & $1300 \mathrm{~m}$ \\
\hline
\end{tabular}

Utilizando as equações 3.21 a 3.24 , foram calculadas as pressões de operação (conforme definida no item 3.3) necessária para atingir o nível de sobrepressão interna desejado. Os resultados são apresentados na Tabela 8, onde se observa que a pressão de operação não é nula para $X=0$ devido a diferença entre a massa específica da água e a do fluído.

Tabela 8 - Pressão de operação em função do nível de sobrepressão interna.

\begin{tabular}{c|cccccccc}
\hline & \multicolumn{1}{|c}{$D / t=10$} \\
\hline$X$ & 0 & $10 \%$ & $20 \%$ & $30 \%$ & 0 & $10 \%$ & $20 \%$ & $30 \%$ \\
$\sigma_{C}(\mathrm{MPa})$ & 0 & 41,5 & 83,0 & 125,0 & 0 & 41,5 & 83,0 & 125,0 \\
\hline $\boldsymbol{p}_{\text {op }}(\mathrm{MPa})$ & 4,9 & 15,3 & 25,7 & 36,1 & 3,7 & 10,1 & 16,5 & 22,9 \\
\hline
\end{tabular}




\subsubsection{Tenacidade à fratura SENT e SENB}

O valores de tenacidade à fratura foram obtidos de Nyhus et al. apud Olso et al [51], onde observa-se uma diferença de cerca de $60 \%$ na resistência à fratura obtida pelo corpo-de-prova SENT em comparação com os resultados do corpo-de-prova SENB. Os resultados adotados são apresentados abaixo:

$$
\begin{array}{ll}
\text { SENT: } & J=1183 \cdot \Delta a^{0,70} \\
\text { SENB: } & J=762 \cdot \Delta a^{0,70}
\end{array}
$$

Foram utilizados os valores de tenacidade à fratura de iniciação do rasgamento dúctil. O motivo para tal reside em resultados apresentados por Taheri e Nourpanah [49] no qual o rasgamento dúctil iniciou-se a partir da metade da capacidade de deformação do duto, o que equivale a um fator de segurança igual a 2 , algo similar ao adotado no estado limite de flambagem localizada mantendo a consistência da análise com o nível de segurança do projeto.

Os valores de tenacidade à fratura de iniciação foram estimados por $J_{0,2}$ e $J_{0,2 b l}$ e são apresentados na Tabela 9. Os valores de tenacidade à fratura $J_{0,2}$ e $J_{0,2 b l}$ se referem a tenacidade à fratura a um crescimento $(\Delta a)$ de $0,2 \mathrm{~mm}$ e a uma estimativa do embotamento da trinca (crack tip blunting) ${ }^{12}$, respectivamente. Para o efeito deste estudo de caso, o valor de $J_{0,2}$ será utilizado pois fornece uma estimativa conservadora do início do rasgamento dúctil [39]. Independente do valor adotado, a

\begin{tabular}{|c|c|c|}
\hline$\left[\mathrm{kJ} / \mathrm{m}^{2}\right]$ & SENB & SENT \\
\hline$J_{0,2}$ & 247 & 384 \\
\hline$J_{0,2 b l}$ & 449 & 697 \\
\hline
\end{tabular}
razão entre os valores de SENT e SENB permanece praticamente constante.

${ }^{12}$ Para maiores detalhes, consultar norma BS-7448 Part 4 [39]. 


\subsection{PROCEDIMENTOS DE ECA}

Os procedimentos utilizados no estudo de caso em nada diferem dos procedimentos apresentados nos itens 3.2.2 e 3.3.2, exceto que as tensões secundárias (e.g. tensões residuais de soldagem) e a tensão de flexão na espessura devido ao desalinhamento da junta soldada $\left(P_{b}\right)$ foram desconsideradas neste estudo de caso para efeito de comparação dos resultados. A tabela abaixo apresenta as principais diferenças entre os procedimentos avaliados:

Tabela 10 - Principais diferenças nos procedimentos de ECA avaliados

\begin{tabular}{|c|c|c|c|c|}
\hline & $\begin{array}{c}\text { A } \\
\text { Procedimento } \\
\text { atual baseado } \\
\text { em } \\
\text { deformações } \\
\text { OS-F101 [5] }\end{array}$ & $\begin{array}{c}\text { B } \\
\text { Procedimento } \\
\text { alternativo } \\
\text { baseado em } \\
\text { deformações } \\
\text { Safebuck [31] }\end{array}$ & $\begin{array}{c}\text { C } \\
\text { Procedimento } \\
\text { alternativo } \\
\text { baseado em } \\
\text { deformações } \\
\text { Modificado }\end{array}$ & $\begin{array}{c}\text { D } \\
\text { Procedimento } \\
\text { alternativo } \\
\text { baseado em } \\
\text { tensões } \\
\text { Modificado }\end{array}$ \\
\hline FAD BS-7910 & $\begin{array}{c}\text { Nível 2B } \\
\text { (Equação 2.28) }\end{array}$ & $\begin{array}{c}\text { Nível 2B } \\
\text { (Equação 2.28) }\end{array}$ & $\begin{array}{c}\text { Nível 2B } \\
\text { (Equação 2.28) }\end{array}$ & $\begin{array}{c}\text { Nível 2B } \\
\text { (Equação 2.28) }\end{array}$ \\
\hline $\begin{array}{l}\text { Curva tensão } \\
\text { deformação }\end{array}$ & Uniaxial & $\begin{array}{c}\text { Biaxial } \\
\text { (Equação 3.34) }\end{array}$ & Uniaxial & Uniaxial \\
\hline $\begin{array}{l}\text { Carga } \\
\text { longitudinal } \\
\text { aplicada } \\
P_{m}\end{array}$ & $\begin{array}{l}\text { Obtido da curva } \\
\sigma-\varepsilon \text { uniaxial } \\
\text { (Figura 18) }\end{array}$ & $\begin{array}{l}\text { Obtido da curva } \\
\sigma-\varepsilon \text { uniaxial e } \\
\text { corrigida pela } \\
\text { tensão } \\
\text { circunferencial } \\
\text { (Equação 3.34) }\end{array}$ & $\begin{array}{l}\text { Obtido da curva } \\
\sigma-\varepsilon \text { uniaxial e } \\
\text { corrigida pela } \\
\text { tensão } \\
\text { circunferencial } \\
\text { (Equação 3.34) }\end{array}$ & $\begin{array}{c}\text { Obtido de } \\
\text { modelo de } \\
\text { elementos finitos } \\
\text { que incorpora o } \\
\text { efeito da pressão } \\
\text { interna }^{13}\end{array}$ \\
\hline $\begin{array}{l}\text { Solução Tensão } \\
\text { de Referência }\end{array}$ & $\begin{array}{c}\text { Kastner } \\
\text { (Equação 3.8) }\end{array}$ & $\begin{array}{c}\text { Kastner } \\
\text { (Equação 3.8) }\end{array}$ & $\begin{array}{c}\text { Kastner } \\
\text { (Equação 3.8) }\end{array}$ & $\begin{array}{c}\text { Kastner } \\
\text { (Equação 3.8) }\end{array}$ \\
\hline $\begin{array}{l}\text { Solução Fator } \\
\text { Intensidade de } \\
\text { Tensão }\end{array}$ & $\begin{array}{l}\text { Newman e Raju } \\
\text { (Equação } 3.12 \text { ) }\end{array}$ & $\begin{array}{l}\text { Newman e Raju } \\
\text { (Equação } 3.12 \text { ) }\end{array}$ & $\begin{array}{l}\text { Newman e Raju } \\
\text { (Equação } 3.12 \text { ) }\end{array}$ & $\begin{array}{l}\text { Newman e Raju } \\
\text { (Equação } 3.12 \text { ) }\end{array}$ \\
\hline $\begin{array}{l}\text { Tenacidade à } \\
\text { Fratura }\end{array}$ & $\begin{array}{c}\text { SENB } \\
\text { (Tabela 9) }\end{array}$ & $\begin{array}{c}\text { SENB } \\
\text { (Tabela 9) }\end{array}$ & $\begin{array}{c}\text { SENT } \\
\text { (Tabela 9) }\end{array}$ & $\begin{array}{c}\text { SENT } \\
\text { (Tabela 9) }\end{array}$ \\
\hline
\end{tabular}

${ }^{13}$ Os detalhes das análises de elementos finitos são apresentados no Anexo A deste documento. 
O envelope crítico de defeitos foi calculado utilizando as soluções da Tabela 10, implementadas pelo programa de computador Crackwise da empresa TWI-Software, que automatiza análises de criticidade e sensibilidade e utiliza as soluções do procedimento da BS-7910 [1]. Além de poder inserir a curva tensão deformação nas análises nível 2B, o Crackwise possui opção para construção de FAD utilizando os parâmetros do modelo de Ramberg-Osgood. A Tabela 11 apresenta os valores da tensão de escoamento corrigida em função do nível de sobrepressão interna por meio da equação 3.34, referenciadas neste texto como a curva tensão-deformação biaxial do material, que serão utilizadas quando for indicado.

Tabela 11 - Tensão de escoamento corrigida pela equação 3.34 .

\begin{tabular}{c|c}
\hline Nível de sobrepressão interna & Tensão de escoamento corrigida \\
\hline $10 \%$ & $434 \mathrm{MPa}$ \\
$20 \%$ & $450 \mathrm{MPa}$ \\
$30 \%$ & $463 \mathrm{MPa}$ \\
\hline
\end{tabular}

A tabela 12 apresenta os dados geométricos das configurações avaliadas conforme Figura 33, onde a dimensão " $a$ " representa a altura do defeito e " $2 c$ " representa seu comprimento. Observe que a norma BS-7910 não possui solução de fator de intensidade de tensões $\left(K_{I}\right)$ para defeitos superficiais externos em tubos sendo necessária utilização da solução para chapas onde a largura da chapa $(W)$ é equivalente ao perímetro do tubo. Os resultados foram calculados para o ponto mais profundo do defeito em relação à superfície externa, i.e. $\theta$ igual a 90 graus.

Tabela 12 - Dados comuns a todas as análises

\begin{tabular}{c|cc}
\hline Parâmetro & $\boldsymbol{D} / \mathbf{t} \mathbf{1 0}$ & $\boldsymbol{D} / \mathbf{t} \mathbf{1 5}$ \\
\hline$B-$ Espessura & $27,3 \mathrm{~mm}$ & $21,6 \mathrm{~mm}$ \\
$W$ - Largura da chapa $(\pi \mathrm{D})$ & $771,89 \mathrm{~mm}$ & $949,55 \mathrm{~mm}$ \\
$R m-$ Raio médio & $122,85 \mathrm{~mm}$ & $151,12 \mathrm{~mm}$ \\
$2 c$ - Comprimento do defeito & & 40 a $200 \mathrm{~mm}$ \\
\hline
\end{tabular}
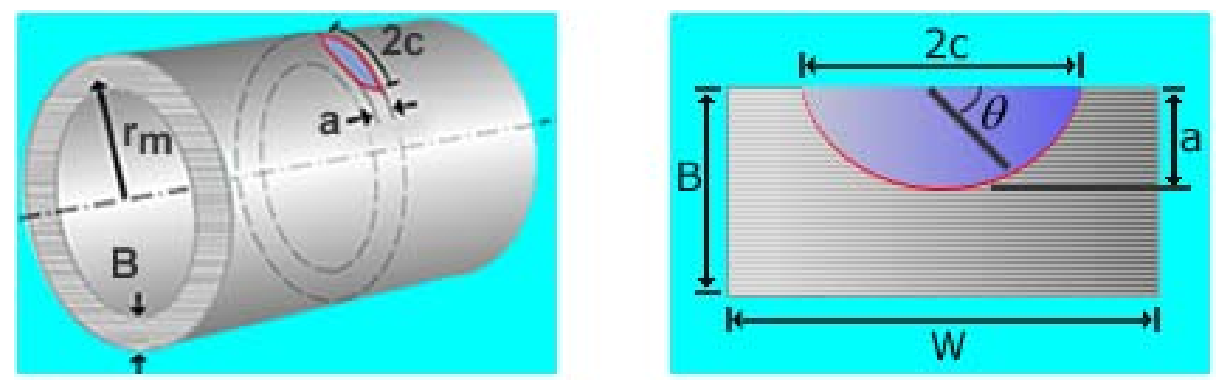

Figura 33 - Configuração geométrica do duto e posição do defeito avaliado no Crackwise 


\subsubsection{Validação dos resultados}

Para validar os resultados obtidos pelos procedimentos acima, foram realizadas comparações das forças motrizes obtidas pela abordagem FAD com forças motrizes elasto-plásticas derivadas de análises dedicadas de elementos finitos em termos do valor $J$ aplicado. Para extrair a força motriz do diagrama FAD nível 2B foram utilizadas as equações 2.23 e 2.28 , onde, rearranjando e simplificando, a força motriz é expressa como:

$$
J=\frac{K_{I}{ }^{2}\left(1-v^{2}\right)}{E} \cdot\left(\frac{E \cdot \varepsilon_{r e f}}{L_{r} \sigma_{Y S}}+\frac{L r^{3} \sigma_{Y S}}{2 E \varepsilon_{r e f}}\right)
$$

Portanto, para caracterizar a força motriz pela abordagem FAD é necessário definir a curva tensão deformação verdadeira do material e o valor da tensão de membrana $P_{m}$ da mesma forma utilizada para determinar o envelope crítico de defeitos (vide Tabela 10). Esses resultados foram comparados com as forças motrizes elasto-plásticas levantadas por Chiodo e Ruggieri [22] e Parise e Ruggieri [23] obtidos pela metodologia do EPRI através da regressão de resultados de análises de elementos finitos de dutos contendo defeitos superficiais ${ }^{14}$.

Os autores normalizaram as solicitações em função da razão de momento aplicado $\left(M / M_{0}\right)$, razão de altura do defeito (a/t) e razão de comprimento $(\theta / \pi)$, ilustrados nas Figura 34 e Figura 35.
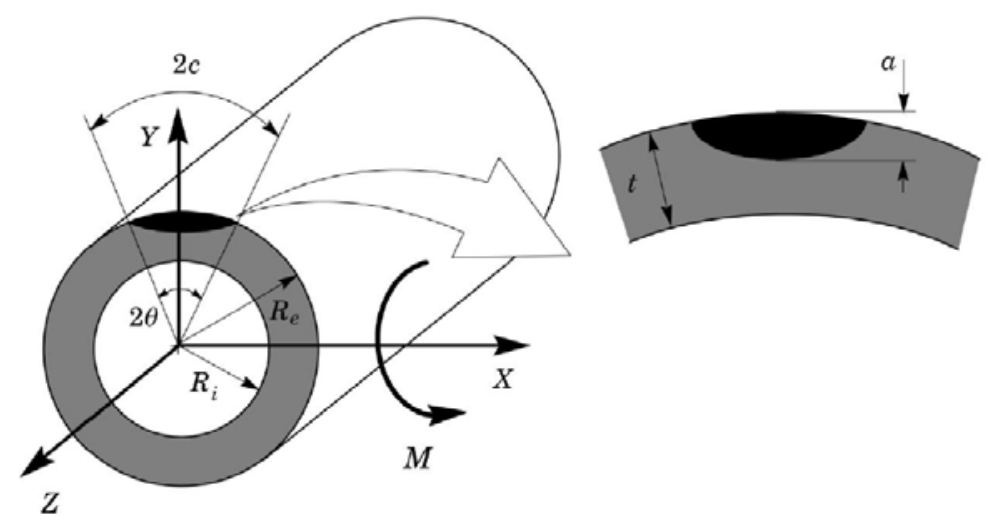

Figura 34 - Configuração do duto sujeito a flexão e posição do defeito avaliado [22]

\footnotetext{
${ }^{14}$ Para maiores detalhes, vide referências [22] e [23].
} 


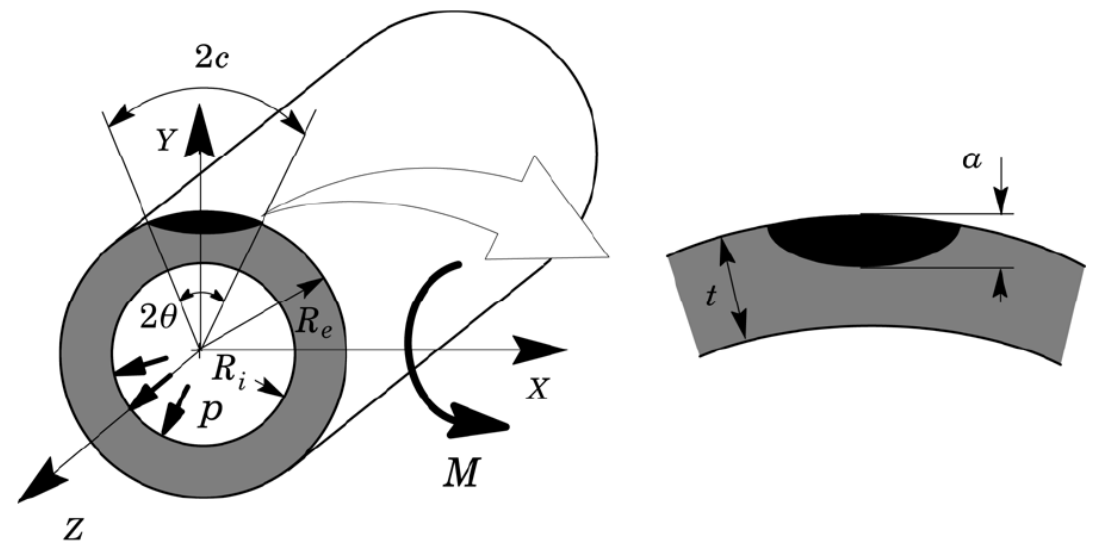

Figura 35 - Configuração de duto sujeito a carregamentos combinados [23]

As soluções em [22] e [23] tem a seguinte forma:

$J=J_{e}+J_{p}$

com

$J_{e}=\frac{K_{I}^{2}\left(1-v^{2}\right)}{E}$

$J_{p}=\alpha \varepsilon_{0} \sigma_{0} b h_{1}\left(\frac{M}{M_{0}}\right)^{n+1}$

onde $M$ é o momento aplicado e $M_{0}$ é solução de carga limite para combinação de flexão e pressão interna da API-579 [2] descrita como:

$M_{0}=\left[2 R_{m}^{2} t\left(2 \sin \beta-\frac{a}{t} \sin \theta\right)\right]\left(\sigma_{e}-Z P_{m}^{\prime}\right)$

onde as definições de $\beta, \theta$, e $Z$ podem ser encontradas no apêndice $D$ do procedimento API 579 [2], e $P_{m}$ ' é definido em função da pressão como:

$P_{m}^{\prime}=\frac{p R_{i}^{2}}{R_{e}^{2}-R_{i}^{2}}$

onde p é a pressão interna. A solução de $K_{I}$ adotada por Chiodo [22] e Parise [23] é a solução para defeitos superficiais em cilindros sujeitos a carregamentos aleatórios 
e flexão na seção transversal de Anderson apud API 579 [2]. Para carregamentos constantes ao longo da espessura, a solução pode ser escrita como:

$$
K_{I}=\left(P_{m}^{\prime} G_{0}+\sigma_{b} G_{5}\right) \sqrt{\frac{\pi a}{Q_{s}}}
$$

onde $G_{0}, G_{5}$ e $Q_{s}$ são parâmetros adimensionais fornecidos no apêndice $C$ do procedimento API 579 [2]. Por fim, a tensão devido ao momento de flexão $\left(\sigma_{b}\right)$ é definida como:

$$
\sigma_{b}=\frac{4 M \cdot R_{e}}{\pi\left(R_{e}^{4}-R_{i}^{4}\right)}
$$

A Tabela 13 apresenta os parâmetros $h_{1}$ da metodologia EPRI determinado por Chiodo e Ruggieri [22] e Parise e Ruggieri [23] que foram utilizados na análise bem como as dimensões do defeito avaliado.

Tabela 13 - h1 para as configurações de defeitos analisadas (d/t 10) [23]

\begin{tabular}{l|cc}
\hline$a \times 2 c$ & \multicolumn{2}{|c}{$8,19 \times 43,68$} \\
\hline$n$ & 10 & 20 \\
$h_{1}(X=0)$ & 2,90 & 2,81 \\
$h_{1}(X=10 \%)$ & 1,88 & 1,1 \\
$h_{1}(X=20 \%)$ & 1,25 & 0,5 \\
$h_{1}(X=30 \%)$ & 0,83 & 0,32 \\
\hline
\end{tabular}

Por simplificação, as forças motrizes elasto-plástica foram levantadas para o caso de flexão pura. Isso é consistente com os dados apresentados na Figura 28 e Tabela 13 uma vez que os carregamentos serão obtidos diretamente da análise de elementos finitos. Os resultados apresentados em função do momento aplicado foram convertidos para deformação por meio da resposta momento-curvatura do duto obtida na análise de elementos finitos (Anexo $A$ ). 


\section{RESULTADOS E DISCUSSÕES}

Esta seção descreve os resultados dos procedimentos de ECA utilizados na análise de final de vida (EOL) de dutos sujeitos a flambagem lateral controlada contendo defeitos circunferenciais superficiais externos conforme descrito nos capítulos anteriores. O objetivo é discutir as tendências observadas a cerca da influência do nível de sobrepressão interna nos resultados para um mesmo material (415MPa) com diferentes expoentes de encruamento $(n=10$ e $n=20)$ e diferentes razões $D / t(10$ e 15).

\subsection{ENVELOPE CRÍTICO DE DEFEITOS}

No total, 120 envelopes de defeitos críticos foram calculados distribuídos em três níveis de deformação longitudinal $(0,5 \%, 1,0 \%$ e $1,5 \%)$ e quatro níveis de tensão circunferencial $(0 \%, 10 \%, 20 \%$ e $30 \%$ do limite de escoamento do material) para dois materiais diferentes ( $n=10$ e $n=20$ ), utilizando os procedimentos sintetizados na Tabela 10. Os gráficos 1 a 10 apresentam os resultados das análises de ECA em termos de envelopes críticos de defeitos, onde eixo das ordenadas representa a altura crítica do defeito e o eixo das abscissas representa o comprimento do defeito. Os gráficos foram divididos por razão $D / t$, expoente de encruamento $n$ e nível de deformação longitudinal aplicada $(\varepsilon)$ onde cada curva recebe a seguinte identificação:

\section{$\underline{Z} \underline{Y Y} \%$}

onde:

$Z$ se refere ao procedimento utilizado conforme nomenclatura adotada na Tabela 10; YY se refere ao nível de sobrepressão interna $(X)$ conforme definido no capítulo 3.3.

Ex.: Gráfico 1 - Curva C 20\%: corresponde ao resultado do procedimento "C" da Tabela 10 que utiliza um FAD nível 2B construído com a curva-tensão deformação uniaxial do material, onde a tensão de membrana $P_{m}$ é corrigida pela equação 3.34 para computar o efeito da tensão circunferencial de $20 \%$ da tensão de escoamento do material, e, por fim, a tenacidade à fratura considerada na análise foi obtida por corpos-de-prova tipo SENT (Tabela 9). 


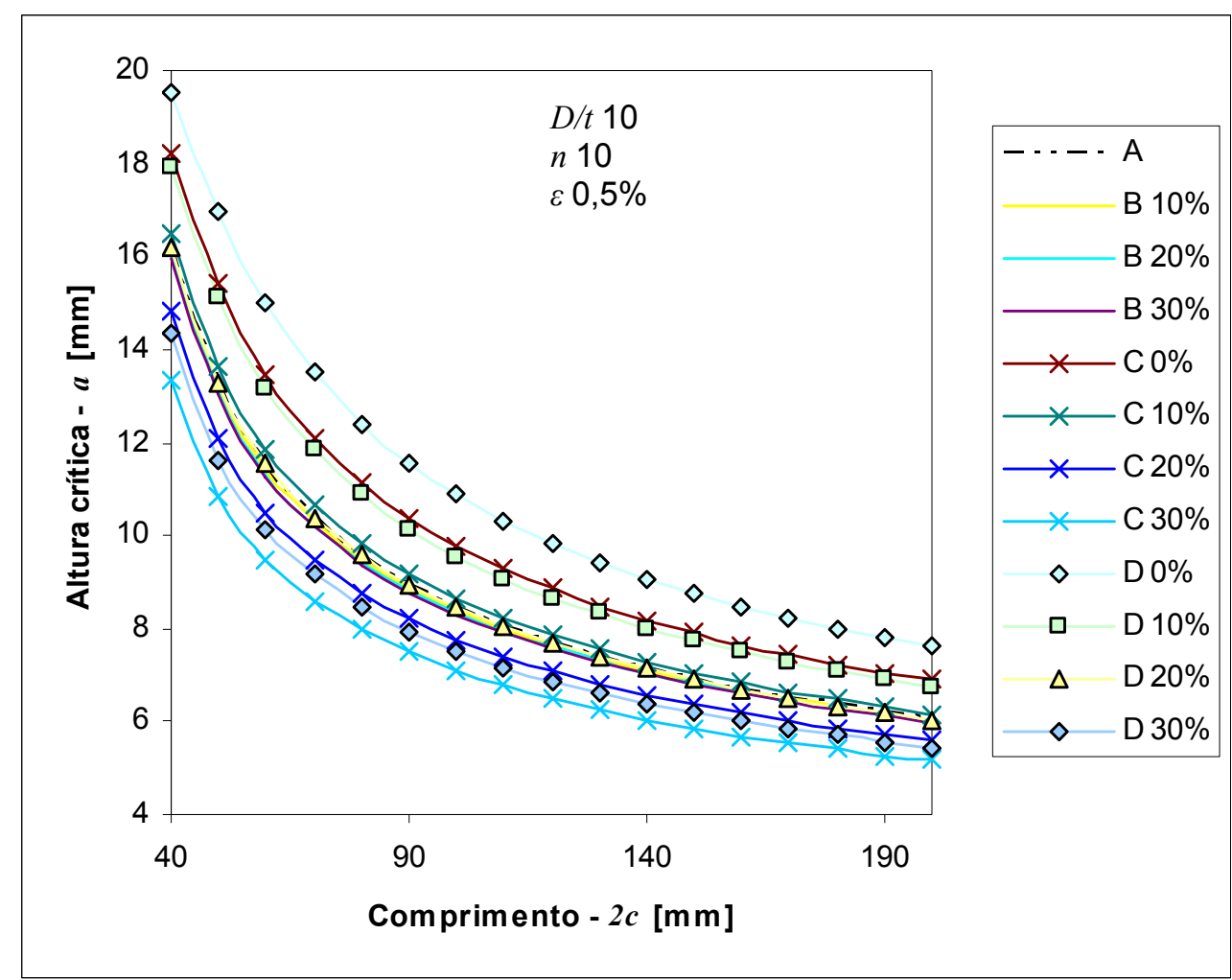

Gráfico 1 - Altura crítica versus comprimento do defeito - D/t 10, n 10, $\varepsilon$ 0,5\%

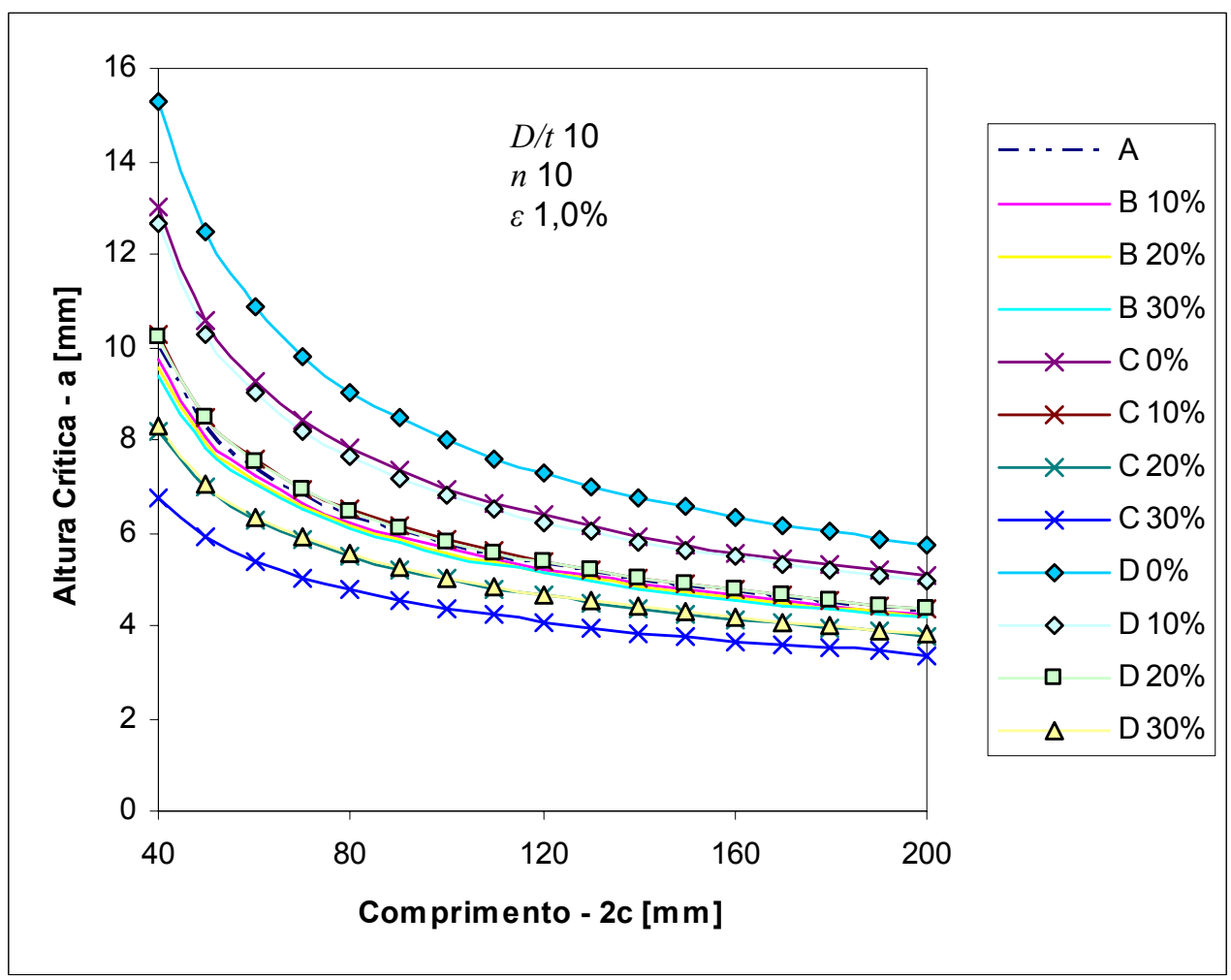

Gráfico 2 - Altura crítica versus comprimento do defeito - D/t 10, n 10, ع 1,0\% 
Os dois primeiros gráficos apresentam os resultados da análise de um duto com razão $D / t=10, n=10$ e deformações longitudinais nominais de $0,5 \%$ e $1,0 \%$, respectivamente. Atentando-se à diferença de escala no eixo das ordenadas, observa-se quanto o envelope crítico de defeitos é sensível em relação à deformação longitudinal. Esse efeito é observado por meio da comparação direta das dimensões do defeito em curvas com a mesma identificação. Por exemplo, utilizando o procedimento padrão baseado em deformações da DNV-OS-F101 [5] (Curva "A"), um defeito curto com comprimento igual a $40 \mathrm{~mm}$ possui altura crítica de $16,2 \mathrm{~mm}$ sob uma deformação longitudinal de $0,5 \%$ (Gráfico 1 ), enquanto à uma deformação longitudinal de $1,0 \%$, a uma altura crítica é reduzida para $9,9 \mathrm{~mm}$ utilizando o mesmo procedimento (Curva "A" do Gráfico 2). Esta diferença é menos pronunciada em defeitos mais longos.

Apesar de óbvia, esta observação é útil para que se possa prosseguir com efeitos menos evidentes tais como a comparação do procedimento padrão (curva "A") com os demais procedimentos adotados. Começando pela análise do procedimento "B", que se refere ao procedimento descrito no Safebuck [31], observa-se que a pressão interna exerce pouco efeito sobre a dimensão final do defeito. A Tabela 14 apresenta os resultados de altura crítica para um defeito de $100 \mathrm{~mm}$ de comprimento sujeito a $1,0 \%$ de deformação e diferentes níveis de sobrepressão interna. Observa-se que, para qualquer comprimento e nível de deformação, a diferença entre a altura crítica de defeitos para diferentes níveis de sobrepressão interna é marginal, o que difere dos resultados observados por Olsø et al. [51]. Portanto, é coerente que se mantenham os valores de tenacidade de corpos-de-prova SENB uma vez que tais procedimentos não consideram o efeito da pressão interna na amplificação da força motriz.

Tabela 14 - Altura crítica obtidas do Gráfico 2 para um defeito de comprimento $100 \mathrm{~mm}$.

\begin{tabular}{l|l}
\hline Caso & Altura crítica \\
\hline A & $5,73 \mathrm{~mm}$ \\
B 10\% & $5,64 \mathrm{~mm}$ \\
B 20\% & $5,57 \mathrm{~mm}$ \\
B 30\% & 5,51 \\
\hline
\end{tabular}


Analisando os resultados dos gráficos 1 e 2, observa-se ainda que os procedimentos baseados no Safebuck [31] (Casos "C" e "D"), onde as propriedades do material não foram corrigidas, apresentam grande dispersão dos resultados se comparados com os casos "A" e "B". Para um nível de tensão circunferencial nula (curvas "C 0\%" e "D 0\%") os resultados são superiores aos obtidos nos casos "A" e "B" uma vez que estes utilizam valores de tenacidade à fratura obtidos por corposde-prova SENT. Ainda comparando os resultados dos casos "C" e "D", existe uma tendência em todos os gráficos de que o envelope crítico de defeitos seja menor ou mais crítico para o caso "C", ou seja, uma vez que única diferença entre os dois procedimentos é a definição da tensão de membrana, a utilização da equação 3.34 fornece estimativas mais conservadoras do que os resultados das análises de elementos finitos.

Essa observação pode ser explicada a partir dos resultados de Tyson e Shen [45] apresentados na Figura 25 e discutidos no item 3.3.1. A utilização da equação 3.34 no caso "C" equivale a uma tensão normalizadora modificada para um $n \sim 50$, i.e. um material praticamente elástico perfeitamente plástico. Já para o caso "D", onde a tensão atuante é obtida do modelo de elementos finitos, a tensão normalizadora para $n=10$ é menor e, portanto menos severa do que o caso "C". Isto pode ser confirmado observando os resultados para $n=20$ (Gráficos 3,4 e 5), onde a diferença entre os casos "C" e "D" passam a ser menores a medida que a tensão normalizadora modificada (Figura 25) é maior quanto maior for o $n$ para $X<50 \%$.

Comparando os resultados dos casos "C" e "D" com os casos "A" e "B" logo percebe-se que para níveis de sobre pressão internas de 20 e $30 \%$ os envelopes críticos de defeitos são menores quando as tensões circunferenciais são consideradas na definição do carregamento longitudinal. Isso significa que o procedimento descrito na norma DNV-OS-F101 (Caso "A"), onde a tenacidade à fratura do material é subestimada pela utilização de valores de tenacidade à fratura obtidos por corpos-de-prova com maior triaxialidade (SENB) a fim de compensar o aumento da força motriz, pode levar a cenários potencialmente inseguros principalmente quando a tensão circunferencial for maior ou igual a $20 \%$ da tensão de escoamento. 
Os resultados apresentados nos gráficos a seguir revelam tendências gerais dos efeitos da pressão interna em diferentes materiais, diâmetros e espessuras.

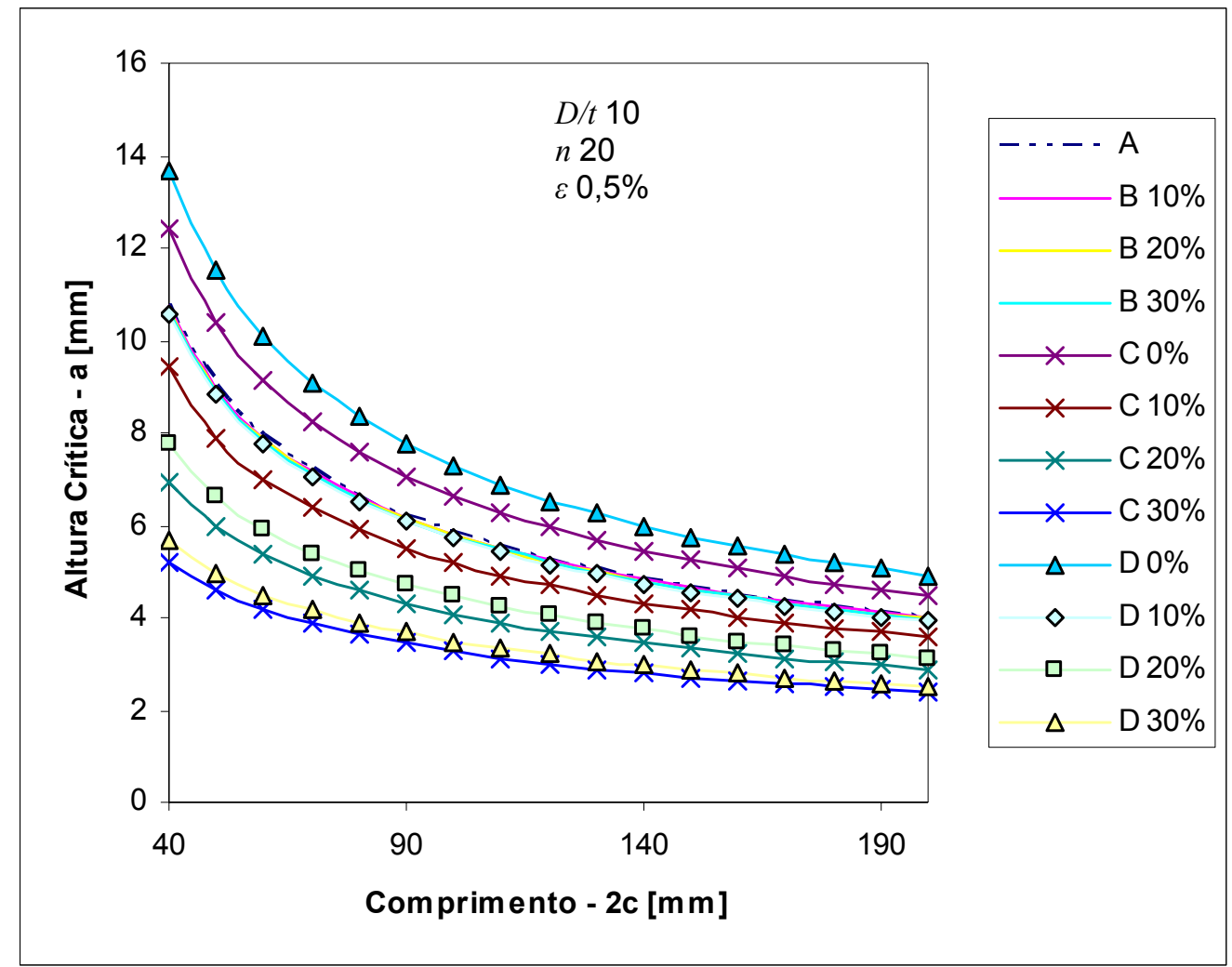

Gráfico 3 - Altura crítica versus comprimento do defeito - D/t 10 n 20 ع 0,5\%

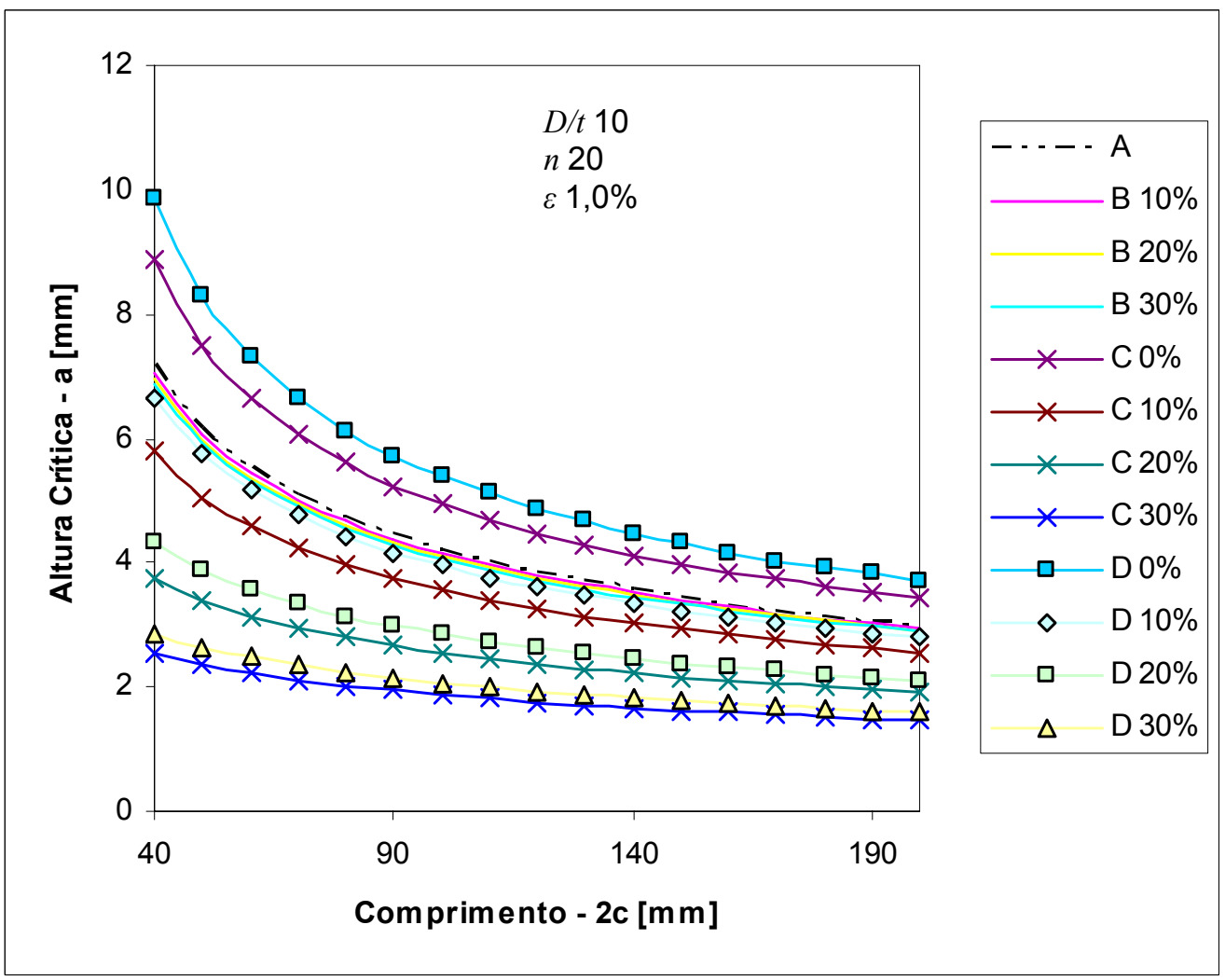

Gráfico 4 - Altura crítica versus comprimento do defeito - D/t 10 n 20 \& 1,0\% 


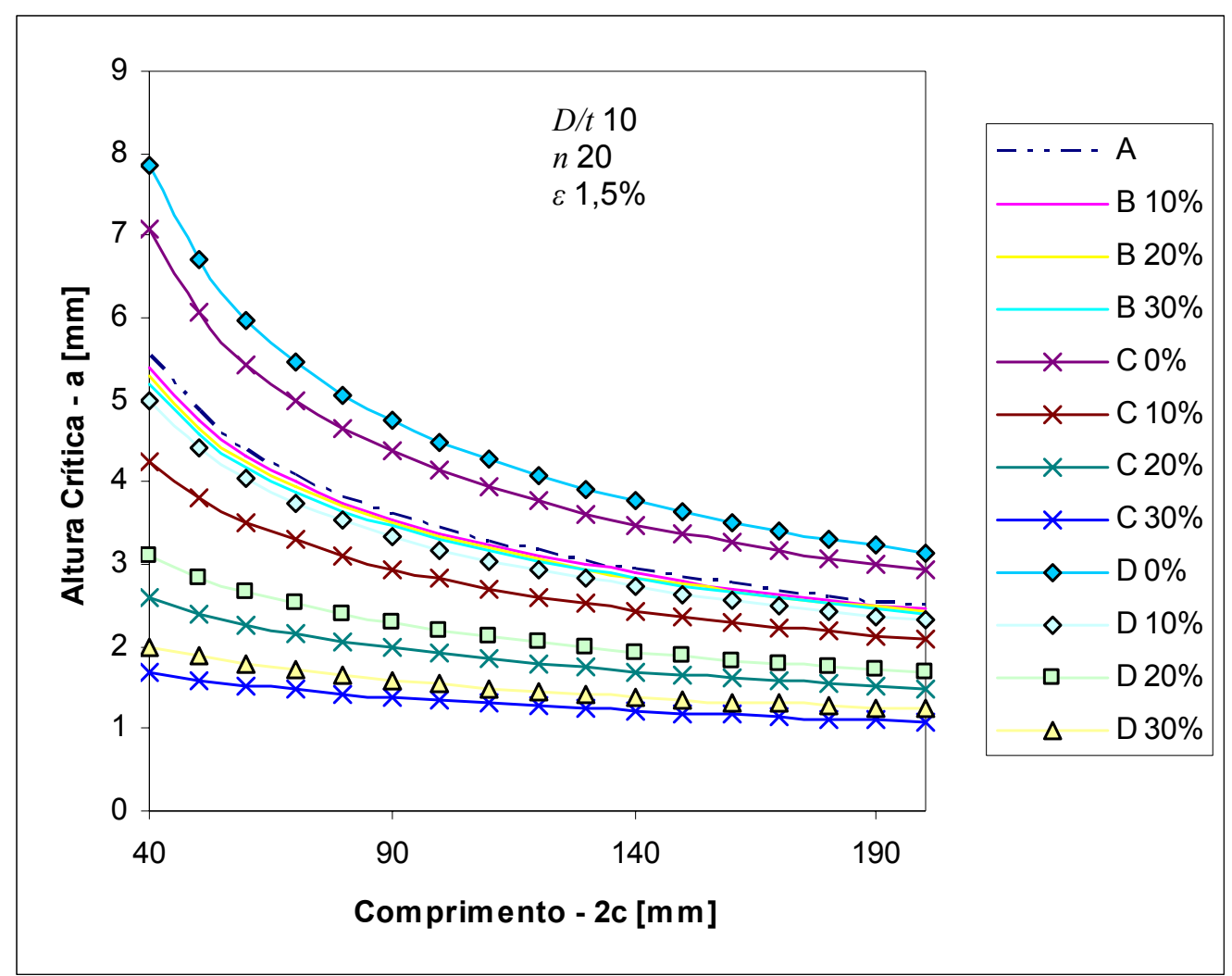

Gráfico 5 - Altura crítica versus comprimento do defeito - D/t $10 n 20 \varepsilon 1,5 \%$

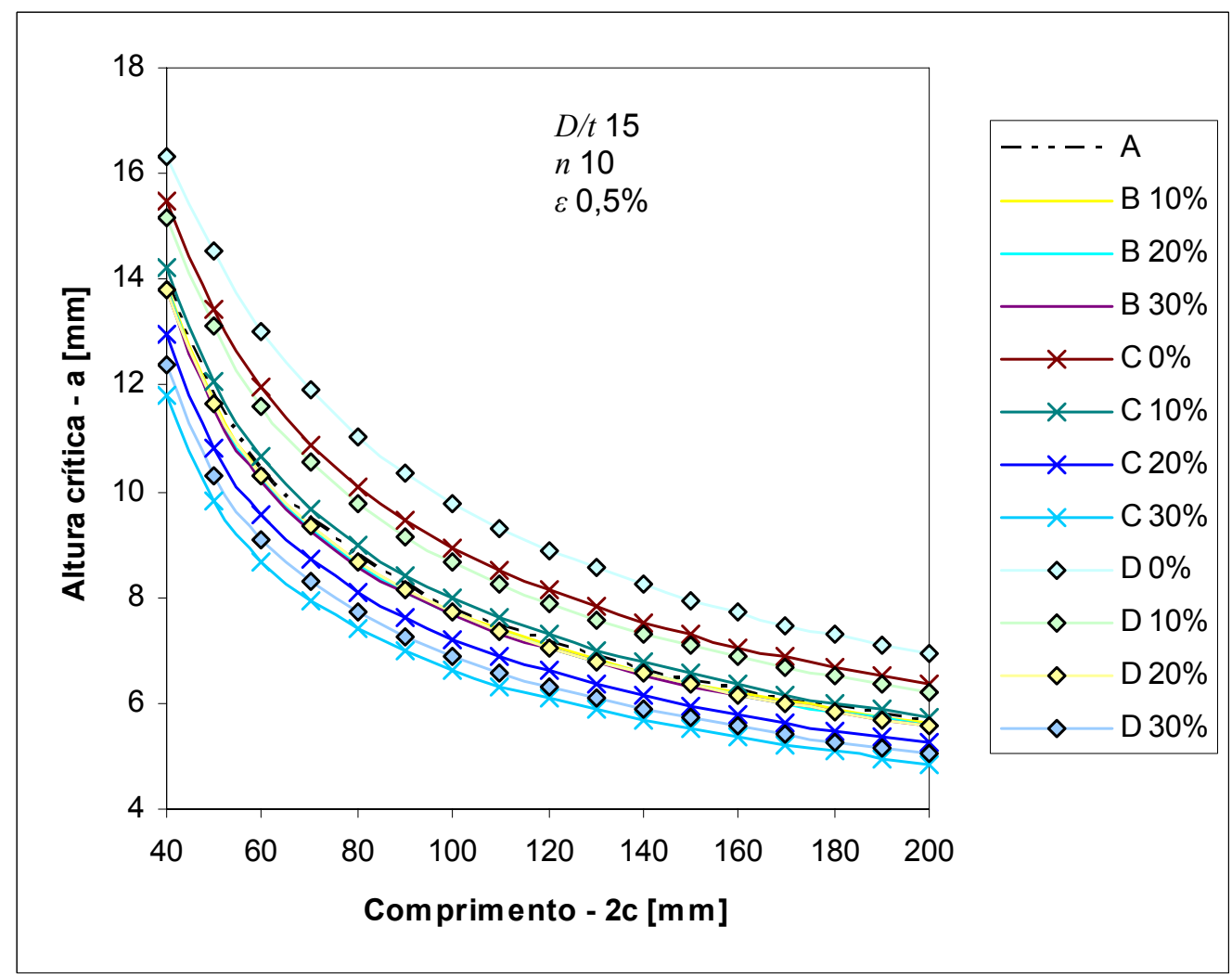

Gráfico 6 - Altura crítica versus comprimento do defeito - D/t $15 n 10 \varepsilon 0,5 \%$ 


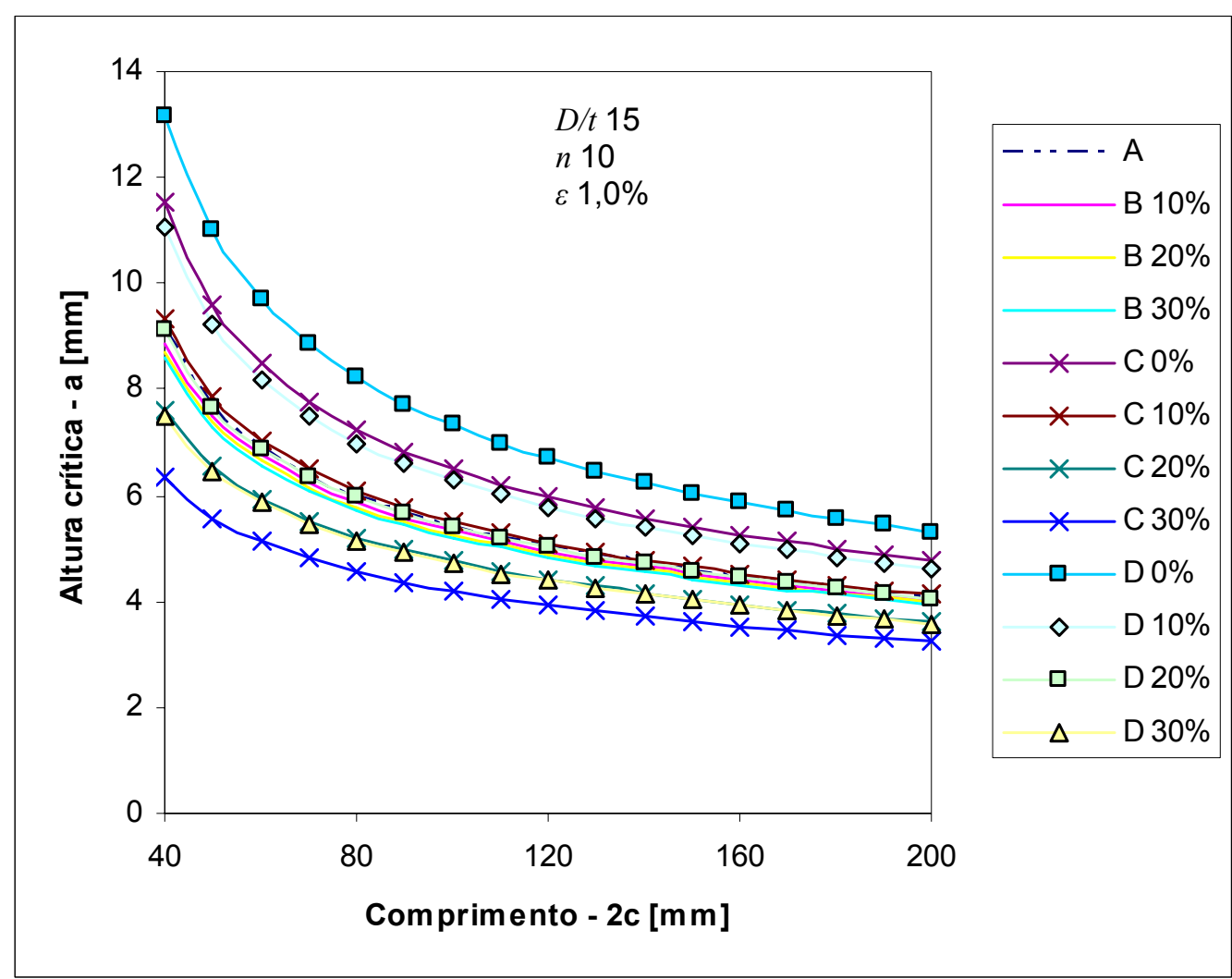

Gráfico 7 - Altura crítica versus comprimento do defeito - D/t $15 n 10$ \& 1,0\%

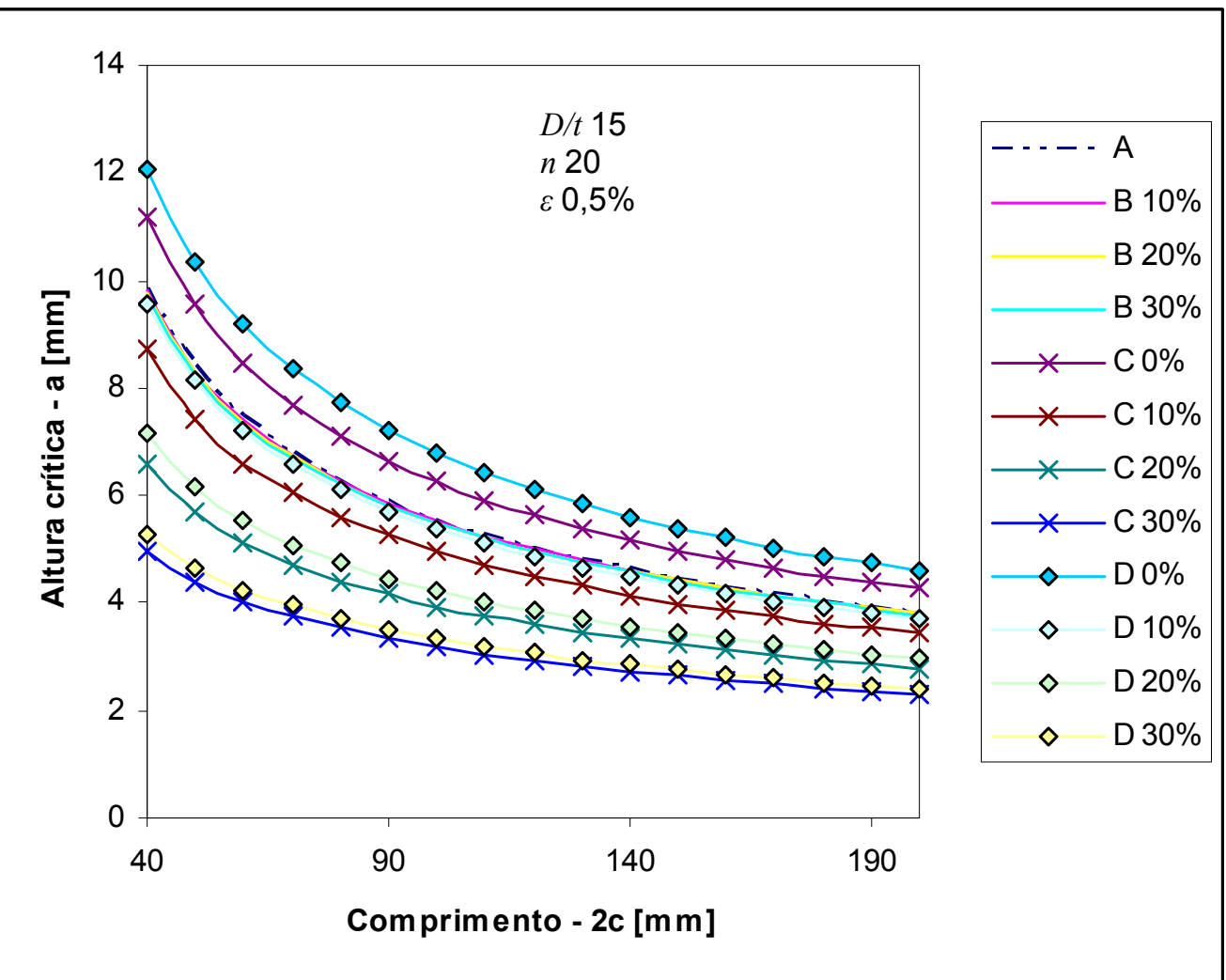

Gráfico 8 - Altura crítica versus comprimento do defeito - D/t $15 n 20 \varepsilon 0,5 \%$ 


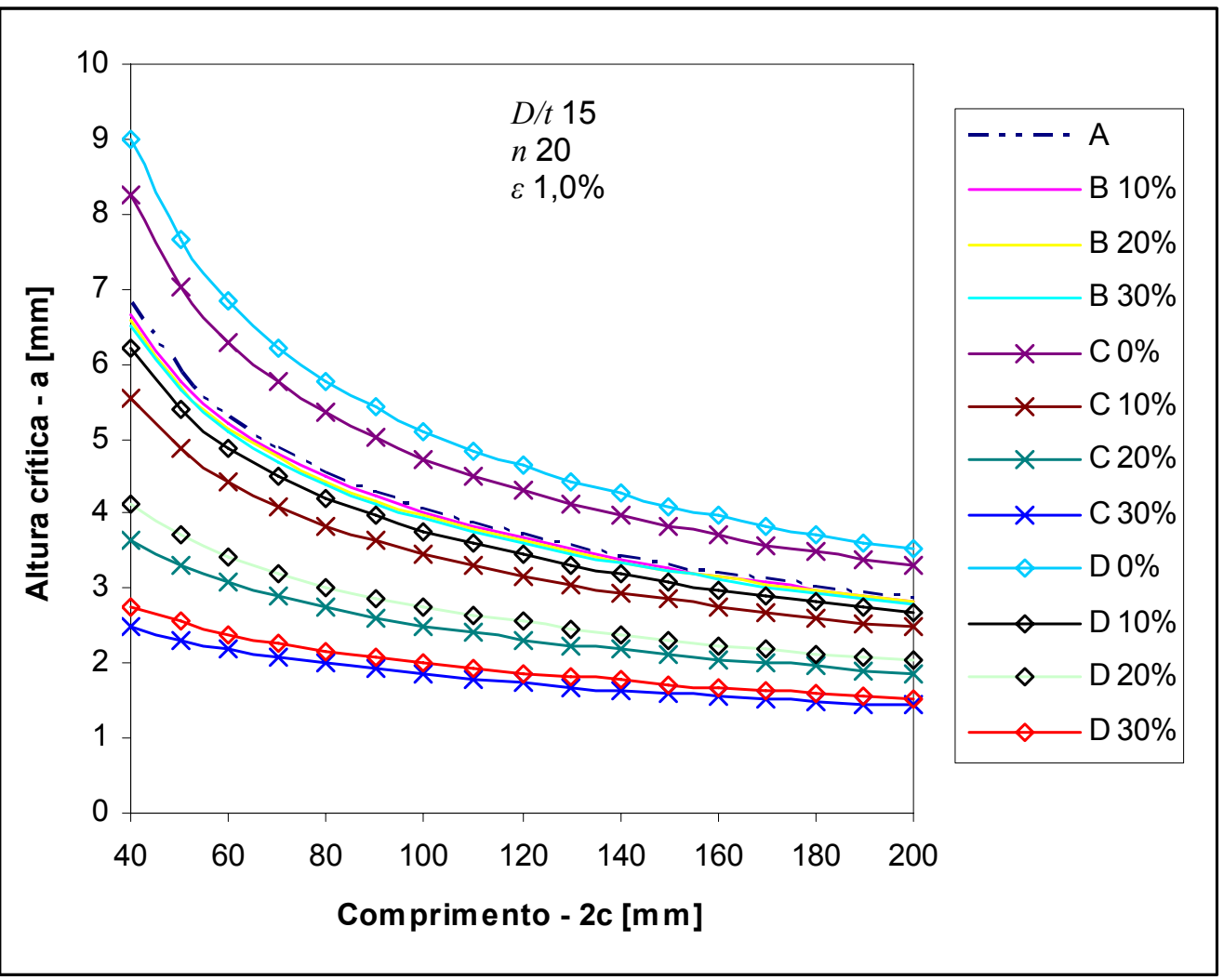

Gráfico 9 - Altura crítica versus comprimento do defeito - D/t $15 n 20 \varepsilon 1,0 \%$

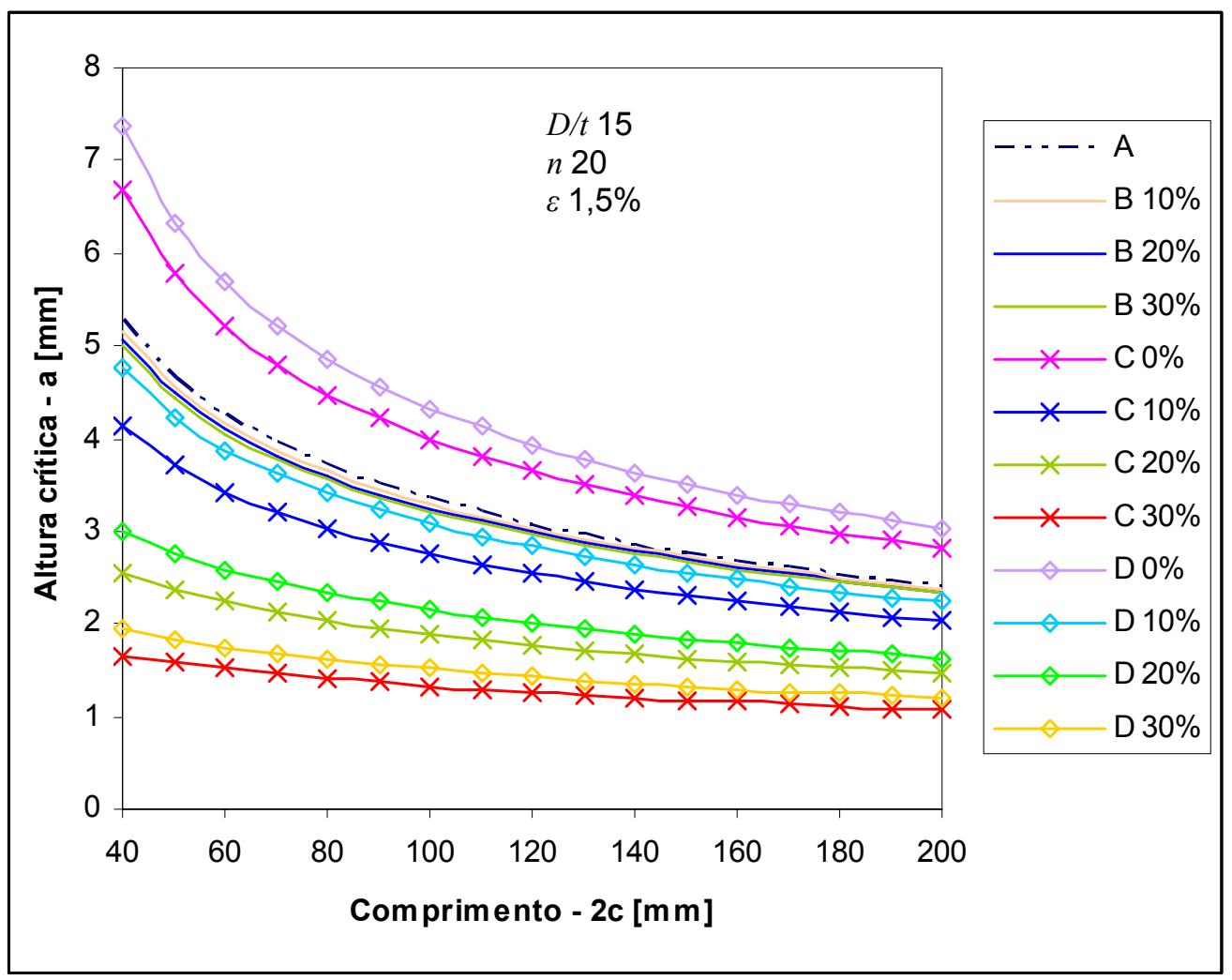

Gráfico 10 - Altura crítica versus comprimento do defeito - D/t $15 n 20 \varepsilon 1,5 \%$ 
Apesar de suas diferenças, os resultados dos casos "C" e "D" aparentam captar corretamente o efeito da pressão interna na força motriz sendo assim elegíveis para utilização em conjunto com valores de tenacidade à fratura obtidos por corpos-deprova SENT. No entanto, é conhecido que as soluções de tensão de referência da BS-7910 [1] podem levar a uma subestimativa das forças motrizes [52], e nesse caso, os resultados das análises devem ser validados por meio da comparação com resultados de força motrizes elasto-plásticas obtidos a partir da análise de elementos finitos da configuração de interesse. No mais, a comparação da forças motrizes pode revelar se o procedimento padrão da DNV-OS-F101 pode ser considerado seguro para aplicação abaixo de $0,4 \%$ de deformação longitudinal. Isto será discutido a seguir.

\subsection{VALIDAÇÃO DOS RESULTADOS}

No total, foram levantadas 28 curvas que incluem a avaliação de um defeito de $8,19 \mathrm{~mm}$ de altura por $43,68 \mathrm{~mm}$ de comprimento, diâmetro nominal de 10 polegadas e espessura de $27,3 \mathrm{~mm}(D / t=10)$. Esta configuração foi avaliada sob quatro níveis de sobrepressão interna e deformações longitudinais máximas que variam de 1,0\% a $1,5 \%$, e dois materiais diferentes $(n=10$ e $n=20)$ utilizando as metodologias eleitas anteriormente (A, C e D). Os gráficos 11 a 14 apresentam os resultados das análises de ECA obtidos pela abordagem FAD, convertidos pela equação $4.1 \mathrm{e}$ comparados com as soluções EPRI por meio de um diagrama de forças motrizes (CDFD), que permite uma visualização rápida e direta das forças motrizes.

Os gráficos 11 e 12 apresentam o resultado para um material com expoente de encruamento $n=10$. No gráfico 11 os resultados do caso "C" são comparados com as forças motrizes obtidos pela metodologia EPRI (aqui denominada de caso "E") onde a relação momento-deformação foi definida através da relação momentotensão da análise de elementos finitos (Anexo A) em conjunto com a equação 3.34 (von Mises). No gráfico 12, as forças motrizes do EPRI são comparadas com o caso " $D$ ", onde a relação momento-deformação foi definida diretamente da análise de elementos finitos a fim de manter a coerência com as premissas dos casos "C" e " $D$ ". De maneira análoga, os gráficos 13 e 14 apresentam os resultados para um material $\operatorname{com} n=20$. 


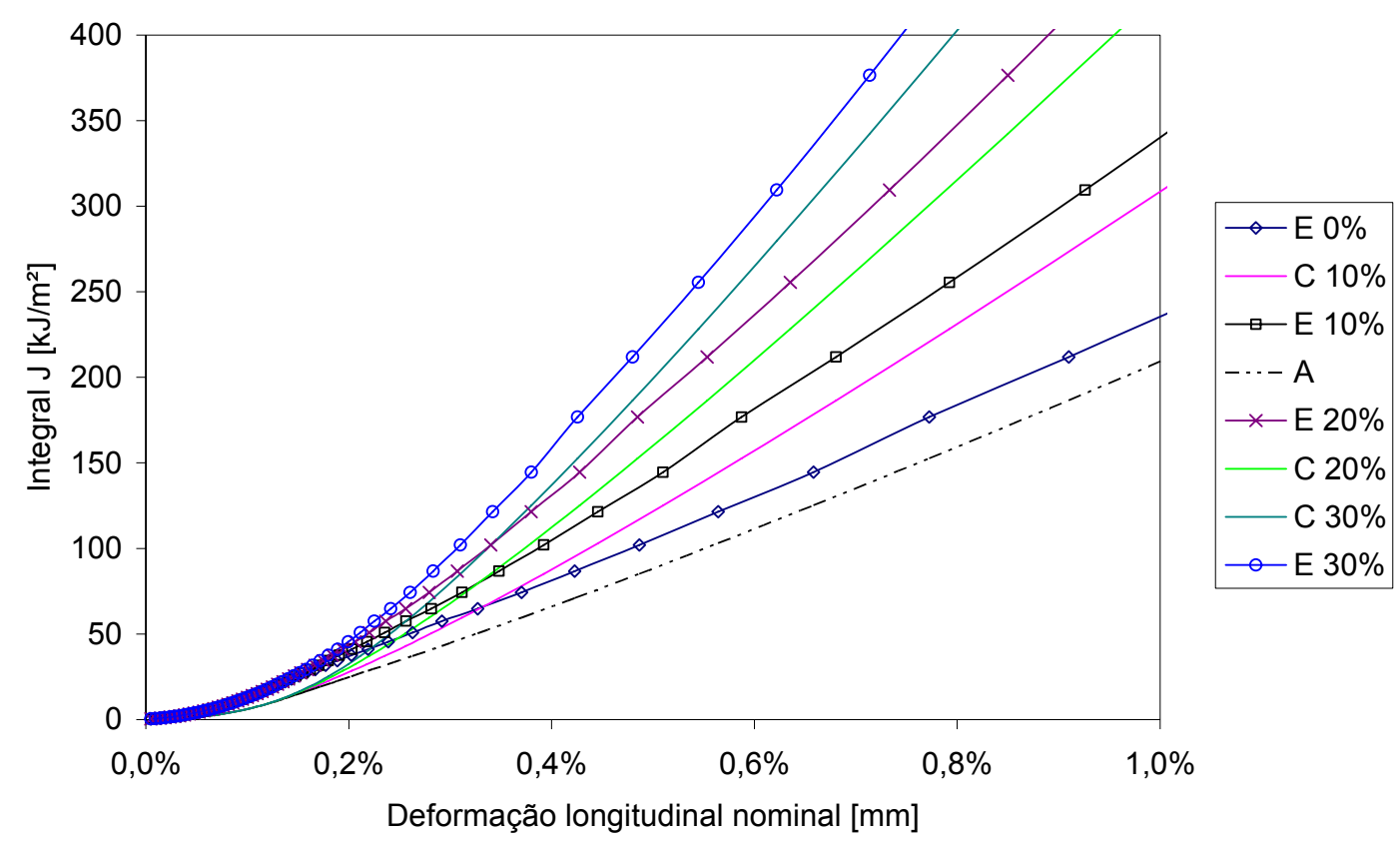

Gráfico 11 - Comparação da força motriz (CDFD) para os casos A, C e E (n=10)

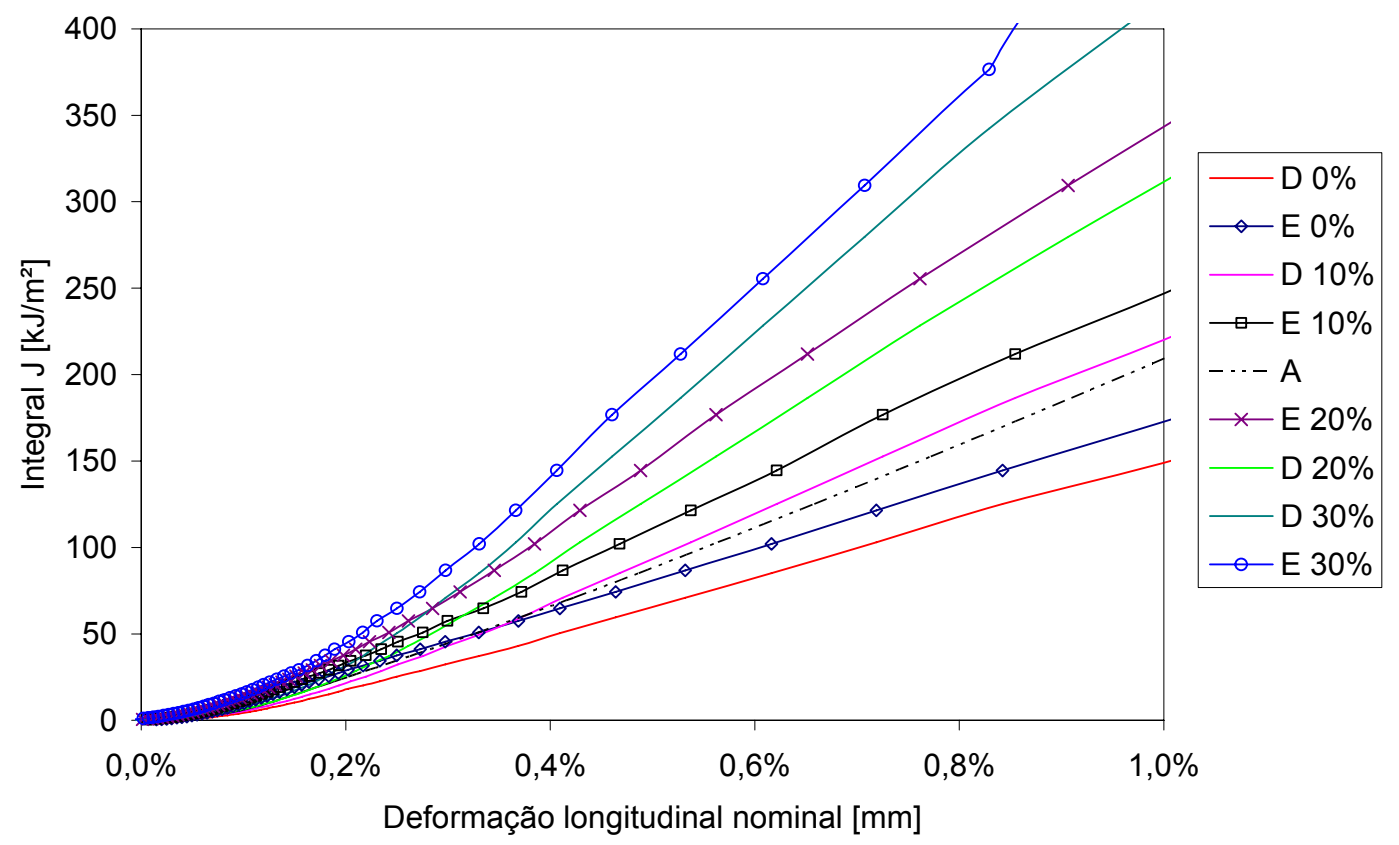

Gráfico 12 - Comparação da força motriz (CDFD) para os casos A, D e E (n=10)

Observa-se nos gráficos 11 e 12 uma consistência entre os resultados dos procedimentos alternativos e das soluções EPRI. Em geral, os resultados do EPRI são $10 \%$ maiores do que os resultados FAD. Para uma deformação de $0,4 \%$, as forças motrizes obtidas pelo procedimento padrão (Caso "A") subestimam as forças motrizes em mais de 100\% para uma sobrepressão de 30\%. O valor aceitável seria $60 \%$, já que esta é a diferença da tenacidade a fratura obtidas por SENT e SENB. 


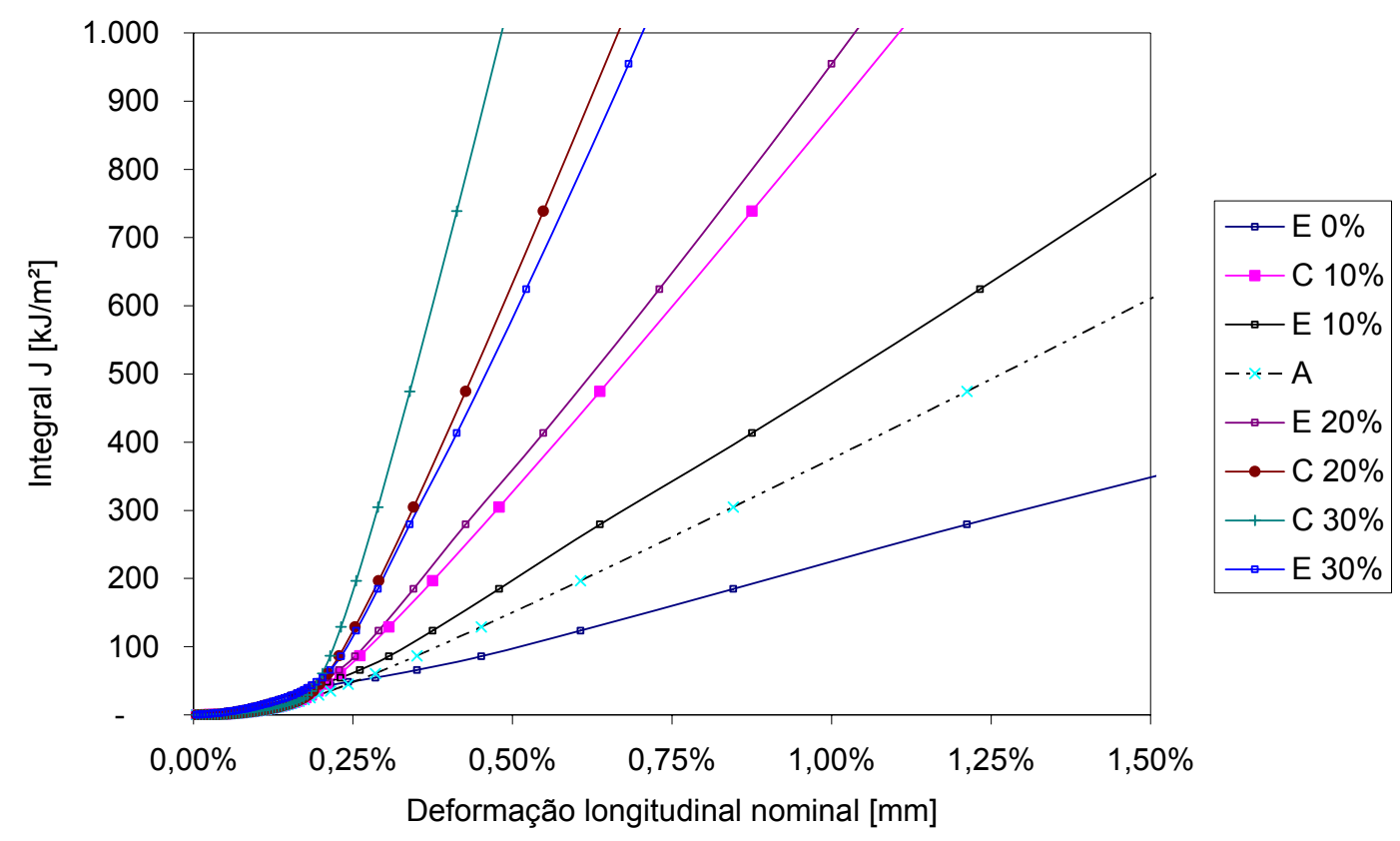

Gráfico 13 - Comparação da força motriz (CDFD) para os casos A, C e E (n=20)

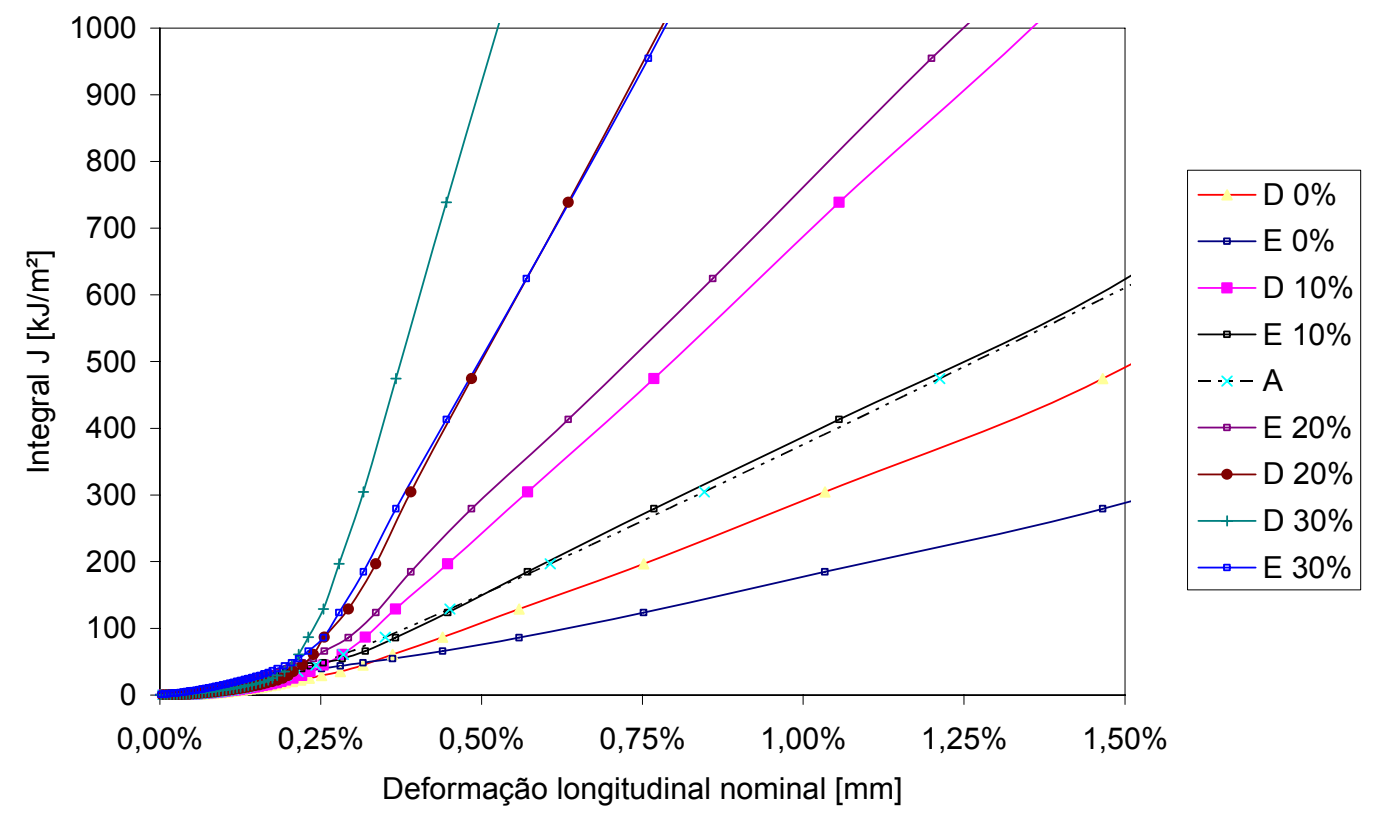

Gráfico 14 - Comparação da força motriz (CDFD) para os casos A, D e E (n=20)

Tendências diferentes são observadas nos gráficos 13 e 14. Aqui os resultados das forças motrizes obtidas pelos procedimentos $C$ e $D$ são consideravelmente maiores do que os resultados obtidos pela metodologia EPRI. No entanto, para uma deformação de $0,4 \%$, as forças motrizes obtidas pelo procedimento padrão (Caso "A") subestimam as forças motrizes em mais de $60 \%$ a partir de um nível de sobrepressão de $20 \%$. 


\section{CONCLUSÃO E SUGESTÕES PARA TRABALHOS FUTUROS}

\subsection{CONCLUSÃO}

Este trabalho buscou avaliar o efeito da pressão interna na avaliação crítica de engenharia (ECA) em dutos submersos sujeitos a flambagem lateral controlada por meio da comparação entre os resultados do procedimento padrão da norma DNV OS-F01 [5] com procedimentos alternativos que tentam incorporar este efeito nas análises. O presente estudo permitiu um melhor entendimento sobre o efeito da pressão interna na força motriz e na tenacidade à fratura de dutos submetidos a deformações longitudinais, bem como permitiu identificar as vantagens, desvantagens e limitações dos procedimentos atuais e dos procedimentos alternativos aqui avaliados a fim de propor algumas recomendações para sua efetiva utilização. As seguintes conclusões podem ser retiradas deste estudo:

1. O procedimento descrito na norma DNV-OS-F101 [5] (Caso A), onde a tenacidade à fratura do material é subestimada pela utilização de valores de tenacidade à fratura obtidos por corpos-de-prova com maior triaxialidade (SENB) a fim de compensar o aumento da força motriz, pode levar a cenários potencialmente inseguros principalmente quando a tensão circunferencial for maior ou igual a $20 \%$ da tensão de escoamento do material, mesmo para deformações abaixo do limite de $0,4 \%$. A utilização da abordagem descrita na norma DNV-OS-F101 [5] é desaconselhável para estes cenários.

2. O procedimento descrito no Safebuck [31] (Caso B), onde a razão de colapso plástico é corrigida em função da tensão circunferencial atuante por meio da equação de tensões equivalentes de von Mises (equação 3.34), não captura corretamente os efeitos da pressão interna sendo portanto desaconselhável sua utilização em conjunto com valores de tenacidade à fratura obtidos por corpos-de-prova SENT. Quando utilizando em conjunto com corpos-de-prova SENB, o procedimento possui limitações semelhantes àquelas observadas no procedimento da DNV-OS-F101 [5]. 
3. Os procedimentos baseados no Safebuck [31] (Casos C e D), onde as propriedades uniaxiais do material foram mantidas, apresentam os melhores resultados e aparentam capturar corretamente o efeito da pressão interna na força motriz sendo assim elegíveis para utilização em conjunto com valores de tenacidade à fratura obtidos por corpos-de-prova SENT. No entanto, é conhecido que as soluções de tensão de referência da BS-7910 [1] podem levar a uma substimativa das forças motrizes, e nesse caso, os resultados das análises devem ser validados por meio da comparação com resultados de força motrizes elasto-plásticas obtidos a partir da análise de elementos finitos da configuração de interesse.

4. Compêndios de soluções de forças motrizes elasto-plásticas (e.g metodologia EPRI) são extremamente práticos e úteis uma vez que permitem a rápida caracterização das forças motrizes elasto-plásticas de um defeito. Contudo, atenção especial deve ser dada para casos com carregamentos combinados, pois estes são expressos em função dos carregamentos aplicados, e.g. momento de flexão, pressão, força axial, etc... Em componentes sujeitos a carregamentos complexos, a classificação das solicitações pode se tornar uma tarefa árdua.

5. É recomendada a utilização dos valores de tenacidade à fratura de iniciação, i.e. $J_{0,2}$ e $J_{0,2 b l}$, para avaliação de defeitos de final de vida sujeitos a carregamentos longitudinais extremos. Os motivos apresentados no item 4.1.3 envolvem incertezas a cerca da capacidade de deformação trativa de dutos sujeitos a esforços combinados e a falta da definição de um fator de segurança parcial para a análise. Neste estudo, os valores de $J_{0,2}$ foram utilizados, no entanto os valores de $J_{0,2 b l}$ são igualmente aceitáveis, desde que sejam válidos conforme critério da BS-7448 [39]. 


\subsection{SUGESTÕES PARA TRABALHOS FUTUROS}

Os seguintes tópicos são sugeridos para a continuidade do trabalho:

- Determinação dos parâmetros $h_{1}$ para dutos trincados submetidos à carregamentos combinados que incluam tração axial, flexão e pressão interna, ou alternativamente, compêndios de soluções para forças motrizes baseados em deformações aplicadas.

- Comparação dos resultados apresentados com resultados de forças motrizes obtidos em modelo de elementos finitos que incluam a propagação da trinca por rasgamento dúctil, i.e. modelos micromecânicos.

- Estudo das questões metodológicas referentes às limitações da metodologia EPRI e da tensão de referência para casos de carregamentos combinados extremos a fim de justificar as diferenças na estimativa das forças motrizes observadas no item 5.2.

- Avaliação do efeito das bandas de Lüders sobre as forças motrizes de trinca em comparação com os resultados do modelo de Ramberg-Osgood para descrição da curva tensão deformação do material, uma vez que para deformações até $2 \%$, o material geralmente exibe um comportamento elástico perfeitamente plástico o que equivaleria a um $n$ muito elevado.

- Desenvolvimento de procedimentos probabilísticos ou a calibração de fatores de segurança a fim de remover parte do conservadorismo nos dados de entrada das análises, uma vez que esse conceito de projeto já é utilizado para outros modos de falha avaliados pela DNV OS-F101 [5]. 


\section{REFERÊNCIA BIBLIOGRÁFICA}

1. BRITISH STANDARD INSTITUTION, Guidance on Methods for Assessing the Acceptability of Flaws in Metallic Structures, BS 7910:2005 Incorporating amendments No. 1, 2007.

2. AMERICAN PETROLEUM INSTITUTE, AMERICAN SOCIETY OF MECHANICAL ENGINEERS, Fitness for Service, API 579-1/ASME FFS-1, 2007.

3. BRITISH ENERGY, Assessment of Integrity of Structures Containing Defects, British Energy Generation Report R/H/R6, Revision 4, 2001

4. SINTAP, Structural Integrity Assessment Procedure for European Industry, Final Procedure, 1999.

5. DET NORSK VERITAS, Submarine Pipeline Systems, Norma de Projeto, DNV-OS-F101, 2007.

6. DNV, SINTEF, TWI, JIP Fracture Control for Installation Methods Introducing Cyclic Plastic Strains: Project Guideline for Engineering Critical Assessments For Pipelines Installation Methods Introducing Cyclic Plastic Strains, Relatório Técnico, 2003, No. 2003-3135

7. DET NORSK VERITAS, Fracture Control for Pipeline Installation Methods Introducing Cyclic Plastic Strain, Prática Recomendada, DNV RP-F108, 2006

8. ØTSBY, E., HELLESVIK, A.O., Large-Scale experimental investigation of the effect of biaxial loading on the deformation capacity of pipes with defects, International Journal of Pressure Vessels and Piping, 85, 2008, pp. 814-824.

9. CHIODO,M.S.G., Procedimento de Avaliação da Integral J e CTOD de Dutos com Trincas Circunferenciais Submetidos à Flexão e Aplicações à Instalação de Risers pelo Método do Carretel, Dissertação de Mestrado, São Paulo, 2009. 
10. ANDERSON, T. L., Fracture Mechanics: Fundamentals and Applications, 3a. edição, CRC Press, Boca Raton, 2005, 640 p.

11. SAXENA, A., Nonlinear Fracture Mechanics, 1a. edição, CRC Press, Boca Raton, 1998, $484 \mathrm{p}$.

12. WILLIAMS, M.L., On the stress distribution at the base of a stationary crack, Journal of Applied Mechanics, Vol. 24, 1957, pp. 109-114.

13. RICE, J.R., A path independent integral and the approximate analysis of strain concentration by notches and cracks, Journal of Applied Mechanics, Vol. 35, 1968, pp. 379-386.

14. HUTCHINSON, J.W., Singular behavior at the end of a tensile crack tip in a hardening material, Journal of the Mechanics and Physics of Solids, Vol. 16, 1968, pp. 13-31.

15. RICE, J.R. and ROSENGREN, G.F., Plane strain deformation near a crack tip in power-law hardening material, Journal of the Mechanics and Physics of Solids, Vol. 16, 1968, pp. 1-12.

16. DOWLING, N. E., Mechanical Behavior of Materials, 2nd Edition, Prentice Hall, NJ, 1999.

17. BEGLEY, J.A., LANDES, J.D., The $\mathbf{J}$ Integral as a Fracture Criterion, Fracture Toughness, Proceedings of the 1971 National Symposium on Fracture Mechanics - Part II, ASTM STP 514, 1972, pp 1-20.

18.ZERBST, U., AINSWORTH, R.A., SCHWALBE, K.-H., Basic Principles of flaw assessment methods, International Journal of Pressure Vessel and Piping 99, 2000, pp. 855-867.

19. SHIH, C. F. AND HUTCHINSON, J.W., Fully Plastic Solutions and Large Scale Yielding Estimates for Plane Stress Crack Problems, Transactions of ASME Journal of Engineering Materials and Technology - Series H, Vol. 98, 1976, pp. 289-295 
20. KUMAR, V., GERMAN M. D. AND SHIH, C. F., An Engineering Approach to Elastic-Plastic Fracture Analysis, EPRI Report NP-1931, Electric Power Research Institute, Palo Alto, CA, 1981.

21. ZAHOOR, A., Ductile Fracture Handbook -Volume 2, EPRI ReportNP-6301-D, Electric Power Research Institute, Palo Alto, CA, 1989.

22.CHIODO, M.S.G., RUGGIERI, C., J and CTOD estimation for circumferential surface cracks in pipes under bending, Engineering Fracture Mechanics 77, 2010, pp. 415-436.

23.PARISE, L.F.S., RUGGIERI, C., Crack Driving Forces in Circumferentially Deformation Under Combined Bending and Internal Pressure, Rio Pipeline Conference \& Exposition, 2011, IBP1115_11.

24. WIESNER, C.S., MADDOX, S.J., XU, W., WEBSTER, G.A., BURDEKIN, F.M., ANDREWS, R.M., HARRISON, J.D., Engineering Critical Analyses to BS7910 - the UK Guide on Methods for Assessing the Acceptability of Flaws in Metallic Structures, International Journal of Pressure Vessel and Piping 99, 2000, pp. 883-893.

25. AINSWORTH, R.A., The assessment of defects in structures of strain hardening material, Engineering Fracture Mechanics 19, 1984, pp 633-642.

26. SMITH, S., Development of the BS-7910 Failure Assessment Diagram for Strain Based Design With Application to Pipelines, Proceedings of the ASME 2012 31th International Conference on Ocean, Offshore and Artic Engineering, 2012, OMAE2012-83527.

27.DET NORSK VERITAS, Global Buckling of Submarine Pipelines: Structural Design Due to High Temperature / High Pressure, Prática Recomendada, DNV RP-F110, 2007.

28. BAl, Y. Pipelines and Risers, Elsevier Ocean Engineering Book Series Vol 3, 1a. edição, Elsevier, Oxford, 2001, 526 p. 
29. YANG, Z., et al., Lateral Buckling Analysis and ECA for Pipeline with Complex Temperature Profile, Proceedings of the ASME 2012 31th International Conference on Ocean, Offshore and Artic Engineering, 2012, OMAE2012-83853.

30.SOLANO, R.F., ANTUNES,A.S., HANSEN, A.S., BEDROSSIAN, A., ROBERTS, G., Comparison of Design and Operational Behavior of an Offshore Pipeline with Controlled Lateral Buckling, Proceedings of the ASME 2012 31th International Conference on Ocean, Offshore and Artic Engineering, 2012, OMAE2012-83646.

31. ATKINS BOREAS, JIP SafeBuck II - Safe Design of Pipelines with Lateral Buckling: Design Guideline, Newcastle, 2008.

32. COLLBERG, L., CARR, M., LEVOLD, E., Safebuck Design Guideline and DNV RP F110, Offshore Technology Conference, Houston, EUA, 2011. OTC 21575.

33.BRUTON, D.A.S., CARR, M., Overview of the Safebuck JIP, Offshore Technology Conference, Houston, EUA, 2011, OTC 21671.

34. MACDONALD, K.A., LANGE, H.I., Engineering Critical Assessment of Thin-Walled Offshore Pipelines, Proceedings of IPC 2008 7th International Pipeline Conference, Calgary, Canada, 2008, IPC2008-64188.

35. COShAM, A., MACDONALD, K.A., Fracture Control in Pipelines Under High Plastic Strain - A Critique of DNV-RP-F108, Proceedings of IPC 2008 7th International Pipeline Conference, Calgary, Canada, 2008, IPC200864348.

36. KASTNER, W., E. ROHRICH, W. SCHMITT, and R. STEINBUCH, Critical crack sizes in ductile piping, International Journal of Pressure Vessels and Piping, 9 (3) 197-219. ISSN 0308-0161, 1981, apud BS-7910.

37.DET NORSK VERITAS, Fatigue Design of Offshore Steel Structures, Prática Racomendada, DNV RP-C203, 2010. 
38. RAJU, I.S. and J.C. NEWMAN, Stress intensity factors for a wide range of semi-elliptical surface cracks in finite thickness plates, Engineering Fracture Mechanics, 11 (4) 817-829, 1979, apud BS-7910.

39. BRITISH STANDARD INSTITUTION, Fracture mechanics toughness tests, BS 7448:Parts1-2-4, 2001.

40.NYHUS, B. ET AL., Efficient Fracture assessment of pipelines: A constraint corrected SENT specimen approach, Engineering Fracture Mechanics 68, 2001, pp. 527-547

41.JOYCE, J.A., LINK, R.E., Effects of Constraint on Upper-Shelf Fracture Toughness. ASTM STP 1256 - Fracture Mechanics, 26 ${ }^{\text {th }}$ Volume, W.G. Reuter, et al. Eds., America Society for Testing and Materials, Philadelphia, 1995, pp. 142-177.

42. AMERICAN SOCIETY OF MECHANICAL ENGINEERS, Pipeline Transportation Systems for Liquid Hydrocarbons and Other Liquids, Norma de Projeto, ASME B31.4, 2009.

43. NYHUS, B., ØTSBY, E., et al. Fracture Control - Offshore Pipelines: Experimental Studies on the Effect of Crack Depth and Asymmetric Geometries on the Ductile Tearing Resistance, Proceedings of the 30th International Conference on Ocean, Offshore and Artic Engineering (OMAE 2005), ASME, 2005.

44. ØTSBY, E., Fracture Control - Offshore Pipelines: New Strain-Based Fracture Mechanics Equations Including The Effects of Biaxial Loading, Mismatch and Misalignment, Proceedings of the 30th International Conference on Ocean, Offshore and Artic Engineering (OMAE 2005), ASME, 2005, OMAE2005-67518.

45. RUGGIERI C, PANONTIN TL, DODDS RH. Numerical modeling of ductile crack growth in 3-D using computational cell elements. International Journal of Fracture 1996;82:67-95.

46. TYSON, W.R., SHEN, G., Effect of Biaxial Stress on Crack Driving Force, Proceedings of 2006 ASME Pressure Vessels and Piping Division Conference, PVP, 2006, PVP2006-ICPVT-11-93849. 
47.TYSON, W.R., SHEN, G., ROY, G., Effect of Biaxial Stress on ECA of Pipelines under Strain-Based Design, Proceedings of the Seventeenth (2007) International Offshore and Polar Engineering Conference, ISOPE, 2007.

48. BRAVO, R.E., CRAVERO, S., ERNST, H.A., Combined Loading Effects on the Fracture Mechanics Behavior of Linepipes, Rio Pipeline Conference \& Exposition, 2009, IBP1342_09.

49.NOUPANAH, N., TAHERI, F., Ductile crack growth and constraint in pipelines subject to combined loadings, Engineering Fracture Mechanics 78, 2011, pp. 2010-2028.

50.DYBWAD, J., ØTSBY, E., TÖRNQVIST, R., THAULOW, C., Simulations of Ductile Tearing at Large Strains of Biaxially Loaded Pipes, Proceedings of the 28th International Conference on Ocean, Offshore and Artic Engineering (OMAE 2009), ASME, 2009.

51. OLSØ, E., HEIER, E., NYHUS, B., ØTSBY, E., ECA for operation - Is Today's Practice of Relying on SENB Instead of SENT Testing While Not Taking Internal Pressure Into Account Conservative?, Proceedings of the ASME 2011 30th International Conference on Ocean, Offshore and Artic Engineering, 2011.

52.BJERKE, S.L., SCULTORI, M., WASTBERG, S., DNV's Strain-based Fracture Assessment Approach for Pipeline Girth Welds, Proceedings of the Twenty-first (2011) International Offshore and Polar Engineering Conference, 2011. 


\section{ANEXO A - ANÁLISE DE ELEMENTOS FINITOS}

Para caracterizar a resposta momento-curvatura do duto foram utilizados elementos finitos não-lineares para simular o fenômeno da flambagem lateral utilizando o conceito de ancoragem virtual apresentado anteriormente. $\mathrm{O}$ modelo incorpora:

- Não linearidades geométricas (grandes deslocamentos e grandes rotações);

- Não linearidades do material (modelo de plasticidade)

- Não linearidades de contato (contato tubo-solo)

O leito marinho deve ser considerado regular sem a presença de dormentes ou outros iniciadores que necessitem de avaliação da fadiga de alto ciclo devido à presença de vibrações induzidas por vórtices nos vão livres;

\section{MODELO}

Todas as análises foram realizadas utilizando o programa de elementos finitos Abaqus/Standard. O critério de escoamento adotado foi o de von Mises e a plasticidade do material foi computada no modelo utilizando o modelo de encruamento de Ramberg Osgood. No entanto, essa opção no Abaqus não comporta carregamentos cíclicos sendo necessário utilizar o modelo de plasticidade isotrópica e entrar com os dados de tensão-deformação plástica em forma de uma tabela. A parcela de deformação plástica (uniaxial) foi computada pela equação:

$$
\varepsilon_{p}=\alpha \varepsilon_{0}\left(\frac{\sigma}{\sigma_{0}}\right)^{n}
$$

A malha adotada no duto utiliza elementos de viga tipo PIPE31H e o tamanho máximo do elemento foi limitado a $0,25 \mathrm{~m}$ a fim de capturar com fidelidade a curvatura da alça de flambagem. $O$ solo foi modelado com um elemento discreto rígido e o contato tubo-solo foi definido por coeficientes de fricção anisotrópicos conforme apresentado na Tabela A.1.

Tabela A.1 - Parâmetros do contato tubo-solo utilizado

\begin{tabular}{l|ll}
\hline & Axial & Lateral \\
\hline Friç̧ão $-f$ & 0,47 & 0,9 \\
\hline
\end{tabular}




\section{CONDIÇÕES DE CONTORNO E CARREGAMENTOS}

Para gerar deformações superiores $1,5 \%$, optou-se por fixar espaçamento do duto em 3 quilômetros e acomodá-lo em um solo regular com a extremidades engastadas e uma irregularidade senoidal no centro. A temperatura do duto foi aumentada linearmente de $3^{\circ} \mathrm{C}$ até $200^{\circ} \mathrm{C}$. As pressões internas foram definidas em função do nível das tensões circunferenciais em relação ao patamar de escoamento do material $(X)$ foi definido entre 0 a $30 \%$. A seqüência de aplicação das condições de contorno e carregamento é apresentada na tabela abaixo:

Tabela A.2 - Seqüência de aplicação das condições de contorno e carregamentos no modelo

\begin{tabular}{|l|}
\hline Passo 1: Definição do contato tubo-solo \\
\hline Passo 2: Acomodação do duto no solo sob tensão constante \\
\hline Passo 3: Criação de irregularidade no centro do espaçamento \\
\hline Passo 4: Aplicação de pressão externa \\
\hline Passo 5: Enchimento do duto (pressão de coluna de fluído) \\
\hline Passo 6: Pressurização do duto \\
\hline Passo 7: Aplicação do gradiente de temperatura \\
\hline Passo 8: Estabilização \\
\hline
\end{tabular}

\section{Análise de sensibilidade}

A fim de avaliar a influência dos parâmetros de entrada no comportamento elasto-plástico na condição pós-flambagem, foram realizadas cerca de 50 análises de sensibilidade. Abaixo segue resumo dos casos analisados:

Tabela A.3 - Parametros avaliados nas análises de sensibilidade

\begin{tabular}{ll} 
Parâmetro & Descrição \\
\hline Refinamento da malha & Tamanho máximo do elemento de 0,25 e 1m \\
Modelo Constitutivo & Ramberg Osgood e Perfeitamente Plástico \\
Propriedades do material & Constantes e Variando com a temperatura \\
Limites do material & Inferior (415 MPa), Superior (515 MPA). \\
Razão $D / t$ & 10 e 15 \\
$\sigma_{0}$ & $415 \mathrm{MPa}($ X60) e 450 MPa (X65) \\
$n$ & 10 e 20 \\
$\alpha$ & 1 e 1,35 \\
$X$ (sobre-pressão) & $0,10,20$ e $30 \%$. \\
Lâmina D'água (LDA) & 1000,1300 e 1600 \\
Tensão de Lançamento & 50,100 e $150 \mathrm{kN}$
\end{tabular}




\section{CONSIDERAÇÕES SOBRE OS RESULTADOS DAS ANÁLISES}

No total foram realizados 56 casos de flambagem global por elementos finitos variando os parâmetros da análise. As seguintes conclusões podem ser retiradas da análise dos resultados:

- A relação tensão equivalente - deformação equivalente é única para o material e corresponde ao comportamento uniaxial de tensão-deformação como era de se esperar uma vez que o modelo de elementos finitos utiliza o critério de escoamento de Von-Mises para computar a plasticidade. A deformação equivalente é descrita como: $\varepsilon_{e}=\varepsilon_{p e}+\frac{\sigma_{e}}{E}$

- As tensões/deformações principais são iguais as tensões/deformações longitudinais e circunferenciais uma vez que o cisalhamento é nulo. Portanto, a tensão equivalente pode ser descrita como:

$\sigma_{e}=\sqrt{\sigma_{a}{ }^{2}+\sigma_{c}{ }^{2}-\sigma_{a} \cdot \sigma_{c}}$

- As tensões circunferenciais são constantes e aderem perfeitamente as equações 3.21 a 3.23 apresentadas no capítulo 3.3 .

- A relação entre curvatura-deformação é constante, ou seja, $\varepsilon=\kappa z$. $O$ fator $z$ depende da posição da linha neutra do tubo, sendo função do raio e tensão axial aplicada.

- A relação momento curvatura é pouco influenciada pela pressão interna.

- A relação tensão-deformação longitudinal é fortemente influenciada pela pressão interna.

- A lâmina d'água ( $L D A)$ e a tensão de lançamento (TBOT) influenciam diretamente na força axial efetiva do duto. Isso influencia apenas a temperatura de início da instabilidade elástica causada que ocorre na flambagem lateral do duto. A condição pós flambagem não é influenciada.

Referência: Dassault Systèmes Simulia Corp, ABAQUS version 6.10 documentation, Providence, 2010. 